\title{
UNUSUAL FEATURES IN THE MICROSTRUCTURE OF FERRITE
}

\author{
By Henry S. Rawdon and Torkel Berglund
}

\begin{abstract}
Ferrite sometimes shows in its microstructure evidence of the fact that the metal may exist in various allotropic forms. Two of these features, apparently related to the $\delta$ and $\gamma$ forms of iron, can usually be associated with tiny inclusions distributed in such a manner as to record the grain structure which existed in the high-temperature allotropic conditions. In the $\alpha$ (ordinary) condition there often appears within the grains a "veining" which gives the metal a pseudofine-grained appearance. Ferrite stressed or forged at a temperature close to the $\alpha-\gamma$ transformation shows veining exceptionally well. Additions of $\mathrm{Al}$ or $\mathrm{Mn}$ to iron had no pronounced effect on $\alpha$ veining whereas ferrite containing $\mathrm{Si}$ in amount sufficient to suppress the transformation showed no veining. The ordinary mechanical properties of iron are affected little, if any, by $\alpha$ veining, the $\delta$ network appears to be associated with the hot-shortness of iron. The real nature of $\alpha$ veining is still in question.
\end{abstract}

\section{CONTENTS}

I. Introduction

II. General nature of the unusual structural features

1. $\delta$ network

652

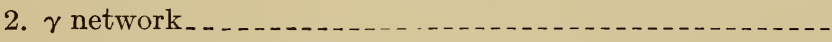

652

3. Veining in the $\alpha$ grains

III. Materials studied

IV. Factors affecting the structure of ferrite

1. Casting: Size and shape of ingot

2. Heat treatment

(a) Annealing

(b) Heating followed by quenching

3. Mechanical deformation, forging of open-hearth iron ......

V. Observations on the effect of forging irons of different compositions_

1. Cast material

2. Forged material

VI. Tension tests of open-hearth iron at elevated temperatures_._._._. 689

VII. Miscellaneous factors affecting veining

1. Long-continued heating in hydrogen

2. Inclusions

VIII. Effect of $\alpha$ veining on mechanical properties_._._._._._. 702

IX. Discussion

X. Summary 


\section{INTRODUCTION}

Iron is usually considered as having a relatively simple type of microstructure and as being characteristic of pure metals in general. The structure of ferrite (iron) is probably better known to most metallurgists than that of any other metal or alloy. Sometimes, however, commercial iron, such as open-hearth iron, wrought iron, and remelted electrolytic iron, shows rather unusual structural characteristics, to the nature and possible significance of which very little attention seems to have been paid. The most common one of these unusual features, as ordinarily observed, appears in a polished and etched section of the metal as a distinct network pattern in addition to the usual grain-boundary pattern of the ferrite, and has been briefly referred to at times in the literature.

Andrews's description ${ }^{1}$ appears to have been the first one appearing in the literature. He observed that certain specimens of wrought iron, after etching with an aqueous nitric-acid solution (1 per cent), showed what he termed "duplex crystallization." Many of the grains of iron or "primary crystals" had the appearance of being subdivided into a large number of "secondary crystals."

The structural pattern observed on the surface of a polished specimen of iron after it has been heated in vacuo, in hydrogen or some other inert gas, often resembles in many respects the structural features described later in this paper. Rosenhain and Humfrey ${ }^{2}$ obtained evidence of the change in the crystalline state of iron which occurs during the A3 transformation from the change in surface appearance produced by heating a polished sample in vacuo to a temperature above the transformation. The deformation or "buckling" of the surface resulting from the pronounced volume change occurring in the A3 transformation accounted for the surface pattern which was produced. Somewhat later, Humfrey ${ }^{3}$ obtained some results with iron heated in vacuo within the so-called $\beta$ temperature range; that is, somewhat below the A3 change, that suggest, in the published micrograph, an internal subdivision of the grains resembling the feature described later in this paper and referred to as "veining." Kroll ${ }^{4}$ interpreted the rather confused network pattern which he obtained on the polished surface of an iron specimen by heating in hydrogen to a temperature above that of the A3 transformation as consisting of three distinct networks corresponding, respectively, to the $\alpha, \beta$, and $\gamma$ forms of iron.

\footnotetext{
1 Thomas Andrews, “Micro-metallography of iron," Pt. I, Proc. Royal Soc. (London), 58, p. 59; 1895.

2 W. Rosenhain and J. C. Humfrey, "The crystalline structure of iron at high temperatures," Proc. Royal Soc. (London), 83, p. 200; 1909.

3 J. C. Humfrey, "The intercrystalline fracture of iron and steel," Iron and Steel Inst., Carnegie Schol. Mem. IV. p. 80; 1912.

A. Kroll, "The crystallization of the iron-carbon system," J. Iron and Steel Inst., 81, p. 304; 1910.
} 
Robin ${ }^{5}$ in describing the microstructure of ferrite as ordinarily observed-that is, after etching a polished surface-mentioned the structural feature "veinage," a network existing within the ordinary $\alpha$ grains, and concluded that this feature should not be regarded as indicating a recrystallization of the iroa. Mention was made by this bureau ${ }^{6}$ several years ago of this same feature in remelted electrolytic iron as well as in unmelted electrolytic iron which had been heated several times as high as $1,050^{\circ} \mathrm{C}$. Storey's discussion of this microstructure of remelted electrolytic iron ${ }^{7}$ contains the best description of this feature of the structure of ferrite that has come to the authors' notice. The subdivision of the ordinary $\alpha$ grains of remelted electrolytic iron into "inner grains" or "subgrains," found when the metal was etched sufficiently, he considered to be the direct result of the $\alpha-\gamma$ transformation. He states:

If we consider that, owing to the large gamma grains, a large number of nongamma nuclei were formed in each gamma grain and that each nucleus was similarly oriented, owing to similarly oriented gamma crystals, we can readily see that the ferrite grains would be composed of a large number of groups of similarly oriented crystals.

In brief, he considered that a ferrite grain which showed the interior veining was, in reality, a conglomerate of smaller grains all similarly oriented.

Among the more recent writers who have made reference to unusual features in the structure of ferrite are Pulsifer, ${ }^{8}$ who has given typical micrographs of open-hearth iron showing such features, and Tritton and Hanson, ${ }^{9}$ who have designated a feature they observed in the structure of open-hearth iron as a "duplex structure" or "inner crystal boundaries" and reported that this structural feature was revealed satisfactorily only by a special method of double etching. Sauerwald, Schultze, and Jackwirth, ${ }^{10}$ who followed the method of Rosenhain, reported a "heat-etched" pattern on polished specimens of copper heated in vacuo, as well as on electrolytic iron and lowcarbon steel heated above the A3 transformation in the same manner, which they interpreted as evidence of recrystallization of the flowed surface layer which was produced during the polishing.

Sir Robert Hadfield ${ }^{11}$ has reported an interesting observation on the structure of a specimen of iron from the Delhi pillar in which reference is made to an unusual structural feature which is identical

${ }^{5}$ Felix Robin, Traité de Metallographie, p. 169; 1912.

${ }^{6}$ G. K. Burgess and J. J. Crowe, Critical Ranges A2 and A3 of Pure Iron, B. S. Sci. Paper, No. 213; 1914.

7 O. W. Storey, “A microscopic study of electrolytic iron," Trans. Am. Electrochem. Soc., 25, p. 489; 1914.

${ }^{8}$ H. B. Pulsifer, Structural metallography; 1921.

${ }^{9}$ F. S. Tritton and D. Hanson, "Ferrous alloys research, Part II, Iron and oxygen," J. Iron and Steel Inst., 110, p. 90; 1924.

${ }^{10}$ F. Sauerwald, W. Schultze, and G. Jackwirth, Zür Kritik der Metallographischen Heissätzung, Zeit für anorg. und allgemeine Chemie, 140, pp. 384-390; 1924.

$11 \mathrm{~J}$. N. Friend and W. E. Thorneycroft, "Ancient iron from Richborough and Folkstone, discussion," J. Iron and Steel Inst., 112, No. II, p. 233; 1925. 
with that referred to as "veining" in this report. The suggestion was made by Hadfield that possibly this structure may be the effect of aging. He states:

A smaller-grain structure, independent of the larger one, is more or less faintly traceable (as seen in a micrograph at a magnification of 50 ). There are also a large number of small lines, which at high magnification are shown to have a regular formation and appear related to the smaller-grain structure, and may be due to secular effects - that is, aging. On reheating a portion of the specimen to $900^{\circ} \mathrm{C}$. the whole of this fragmentary grain structure is made to disappear, leaving only large clear-etching ferrite grains.

The earlier phases of this investigation were begun before the appearance of the last three references cited above. The greater part of the work, however, was carried out by the junior author during his stay at the Bureau of Standards (1926-27) as a Fellow of the Swedish-American Foundation, Stockholm, cooperating with the American-Scandinavian Foundation, New York, N. Y.

\section{GENERAL NATURE OF THE UNUSUAL STRUCTURAL FEATURES}

The unusual features which have been observed in the structure of ferrite are of three types, two of which are alike in that the structures appear to have originated when the iron was in one of the high temperature allotropic forms; that is, either the $\delta$ or $\gamma$ condition; whereas the third type is associated with the low-temperature or $\alpha$ condition of the iron. As a matter of convenience, therefore, in discussing these features they will be referred to as $\delta, \gamma$, and $\alpha$, respectively. There is no evidence available to show that these features may not be more or less related as to their fundamental cause. For purposes of description, however, it is simpler to regard them as distinct, more or less unrelated, features. As will be seen from the micrographs which follow, these unusual structural features appear as an addition to the ordinary grain-boundary structural pattern of ferrite. Etching is necessary in order to reveal them, and they are often best seen when the microscope is at a-slightly different focus from the position at which the ordinary grain-boundary pattern is most clearly seen. The term "phantom" which has been used ${ }^{12}$ in reference to one of them is quite descriptive of their general character and appearance.

\section{1. $\delta$ NETWORK}

The feature designated here as the " $\delta$ network" has been observed only in cast material, in material which has been only very slightly worked or has been heated to an exceedingly high temperature. As will be shown later, this network is to be attributed to very small inclusions in the iron which, as the metal solidifies into the $\delta$ condition, 
are localized on the surfaces of the grains as they form. When the low-temperature allotropic condition is assumed and a new grain system results, the $\delta$ network is unaffected and appears in a section of the material under the microscope as a network pattern independent of and superimposed upon the true grain-boundary pattern. Figure 1 illustrates this feature.

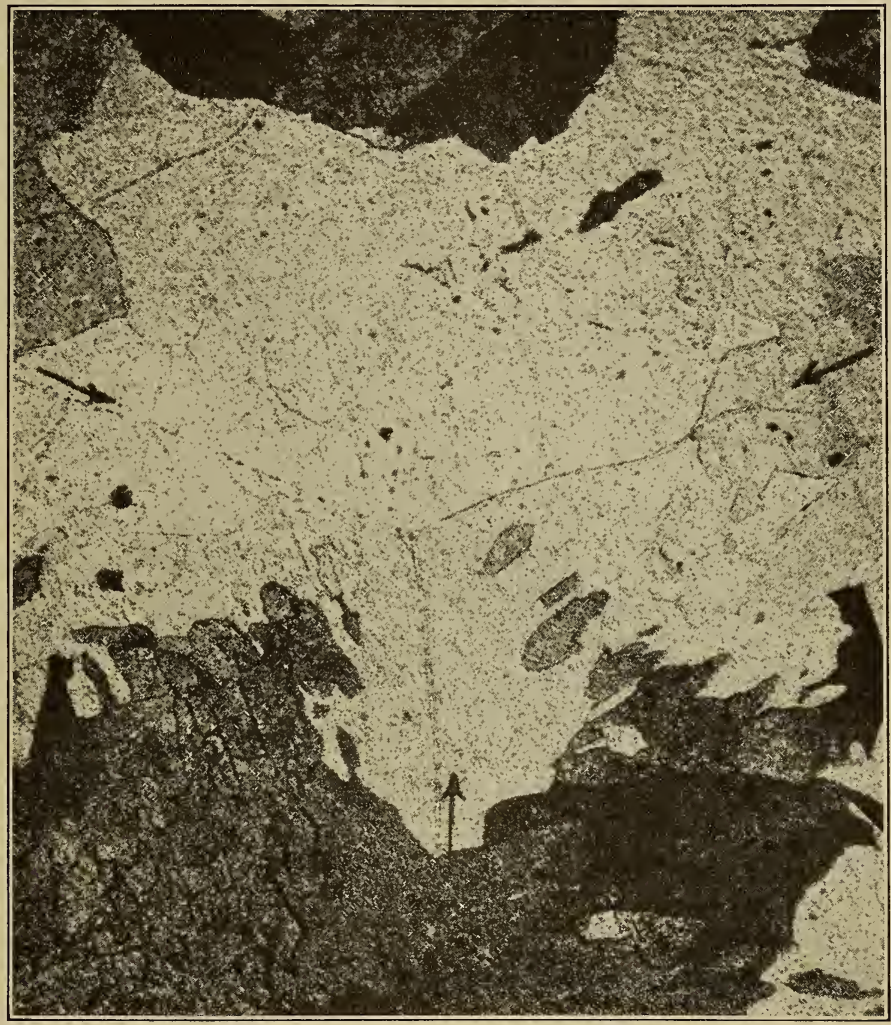

FIG. 1.-Open-hearth iron in the cast condition; etched with ammonium persulphate solution. $\times 50$

Note the network indicated by the arrows. This has been termed the $\delta$ network and is a record of the structural condition existing when the iron was at very high temperature.

\section{2. $\gamma$ NETWORK}

The $\gamma$ pattern is illustrated in Figure 2. This feature, like the $\delta$ network, appears in the polished and etched specimen as a distinct network superimposed upon and apparently unrelated to the network formed by the $\alpha$ grain boundaries. Its general appearance, especially the occurrence of twin crystals, is suggestive of the structure of $\gamma$ iron. It has not been observed in cast material and in attempts which were made to produce these various structural features in ferrite by heat treatment no evidence of the $\gamma$ network was obtained unless the specimen had been heated to a temperature considerably above the Ac3 transformation. 

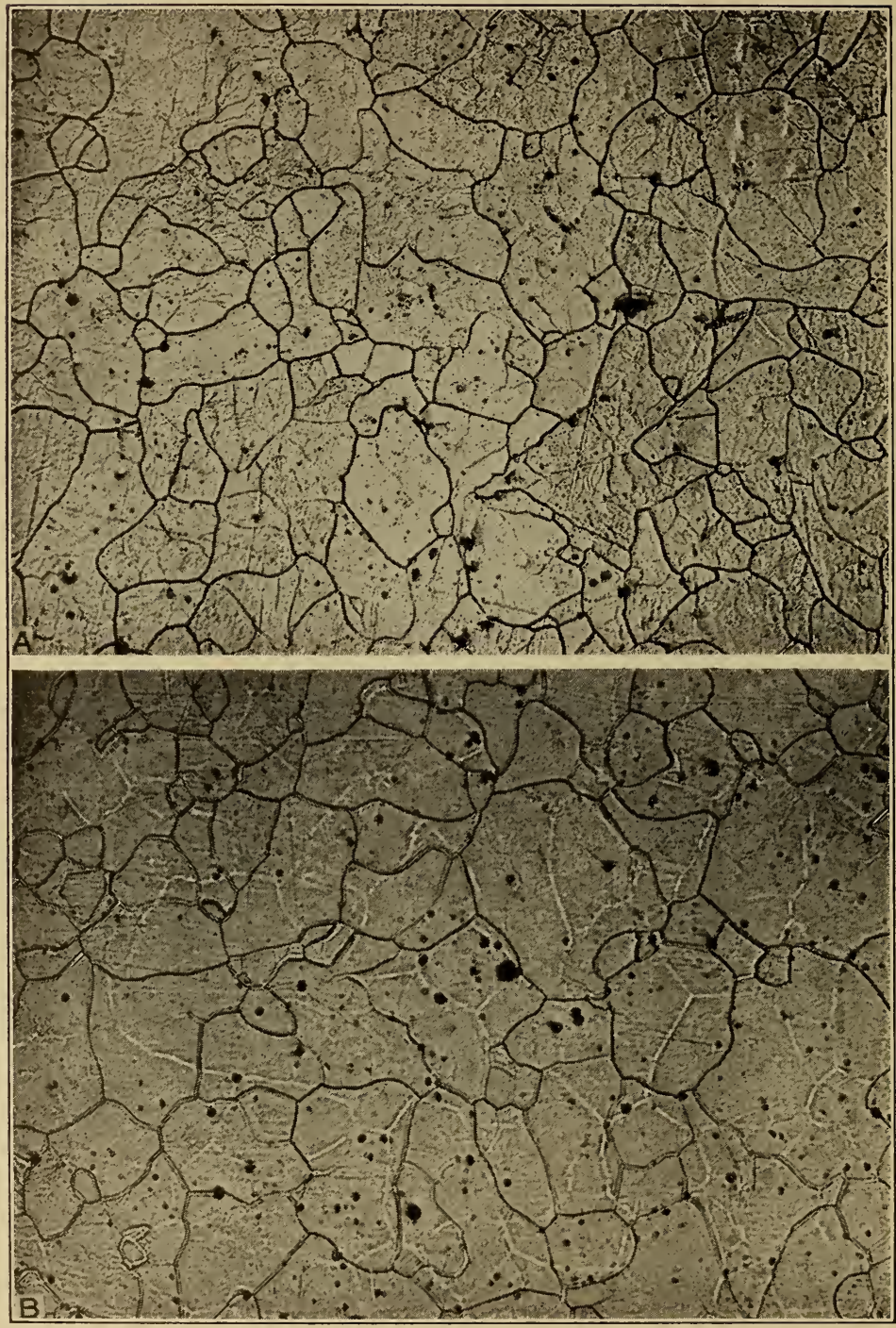

Fig. 2.-Unusual features in the microstructure of open-hearth iron in the hot-worked condition; etched with an alcoholic solution of picric acid. $\times 100$

(a) In addition to the grain boundary pattern formed by the grains of ferrite, many of the grains show an interior network. This feature has been termed " $\alpha$ veining" in this report.

(b) Note the "phantom" network superimposed upon, but apparently unrelated to, the ordinary grain boundary network pattern. This feature has been termed " $\gamma$ network" in this report.

The $\gamma$ network appeared when the iron ( $a$ ) after being forged at a high temperature to onehalf its initial thickness was heated to $1,100^{\circ} \mathrm{C}$. 

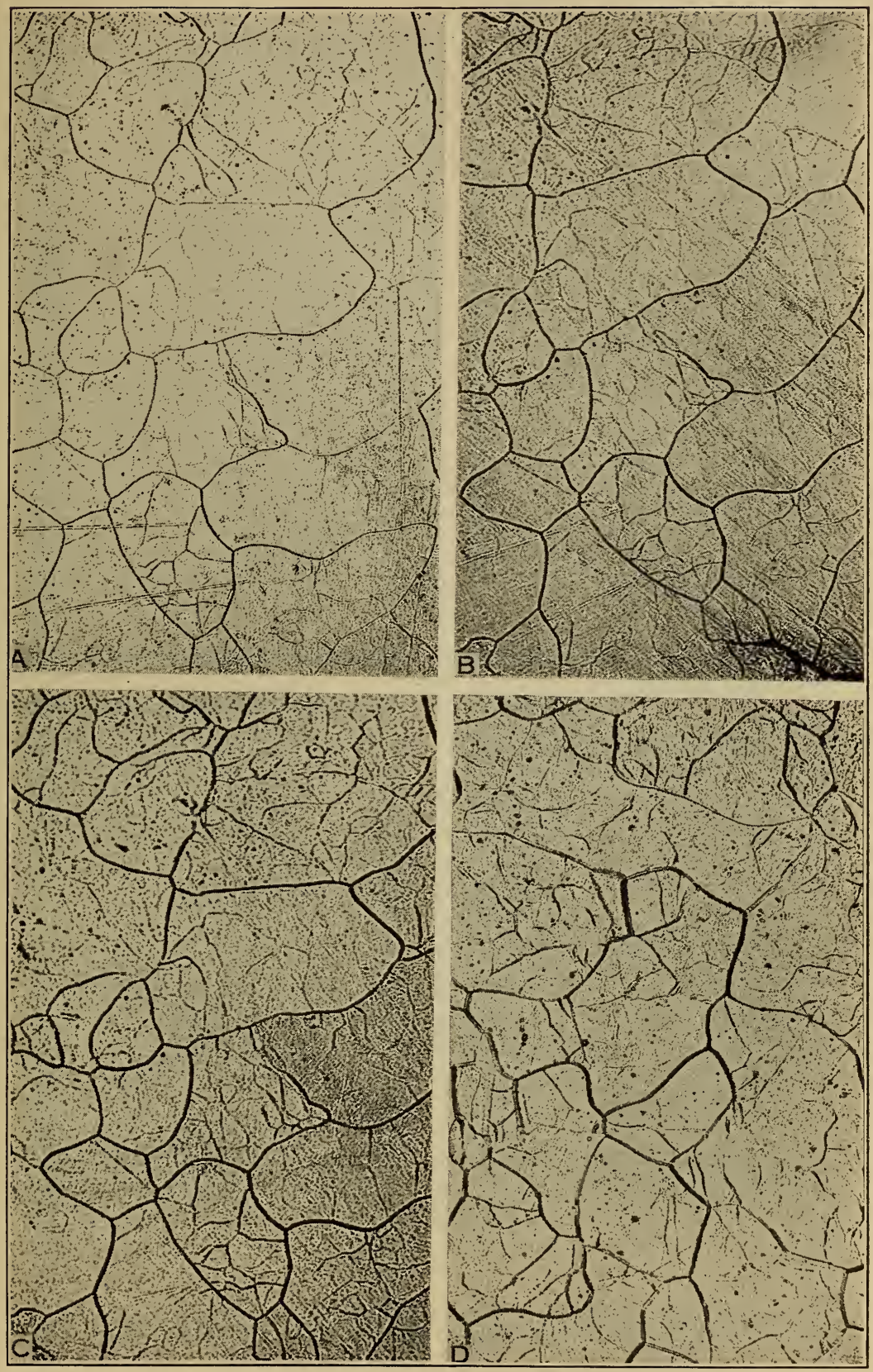

FIG. 3.-Remelted electrolytic iron showing veining within the grains, etched for different lengths of time. $\times 100$

Etching period in picric acid: (a) 1 minute; (b) 2 minutes; (c) 3 minutes; $(d) 18$ minutes. $73815^{\circ}-28-2$ 


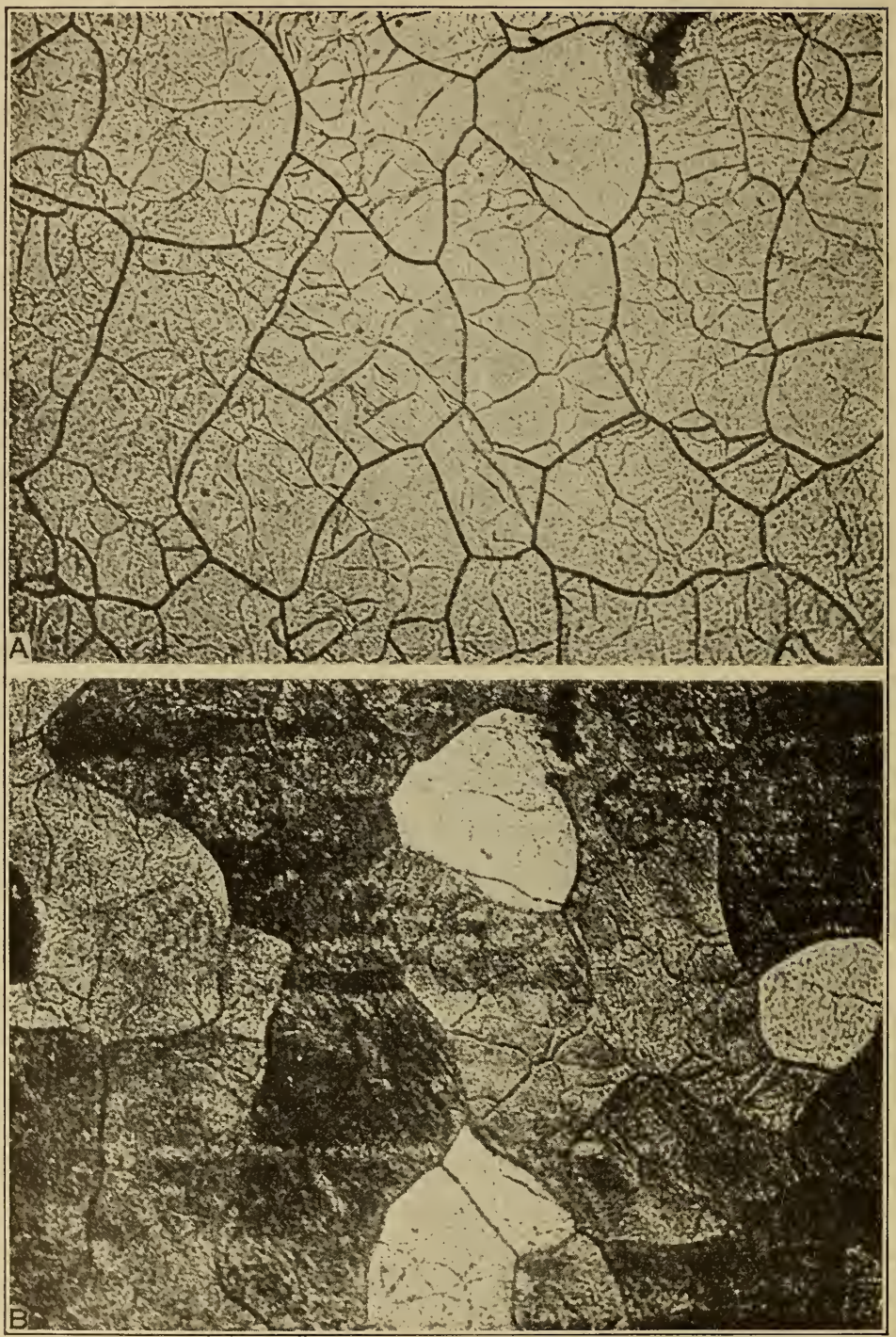

FIG. 4.-Relation of grain structure to $\alpha$ veining in remelted electrolytic iron. $\times 100$

(a) Etched with picric acid.

(b) Same spot given an additional etching with ammonium persulphate solution. This etchant produces grain contrast and definitely shows that veining is not simply a recrystallization of the larger grains.

In all of the following figures picric acid was used as the etchant, unless mention is made, of some other etching method. 


\section{VEINING IN THE $\alpha$ GRAINS}

This structural feature is by far the most common of the "unusual" features herein described. Unlike the other two types, the $\alpha$ veining pattern is definitely associated with the individual ferrite grains as they exist in the metal at ordinary temperature and has been found both in cast and worked material. The veining, when well developed, appears as branching tree-like ramifications within the individual ferrite grains, the origin, in the majority of cases, being at the grain boundary. The "veins" arising at different points on the boundary intersect and join so that a grain often has the appearance of having been subdivided into a number of smaller ones, hence the conclusion which has been expressed by some observers that this feature is simply a secondary recrystallization. $\alpha$ veining was easily revealed in all the materials in which it was found by the usual acid-etching reagents used for iron, though it was often necessary to prolong the etching period considerably beyond that required for revealing the $\alpha$ grain boundaries. Figure 3 shows the appearance of the $\alpha$ veining in remelted electrolytic iron after different etching periods. Figure 4 shows a sample of electrolytic iron etched first so as to reveal the $\alpha$ veining and then so as to color the individual ferrite grains. It is very evident that $\alpha$ veining is not simply a recrystallization effect. The veining is an intracrystalline feature and the small subdivisions resulting from the ramifications of the network are not separate grains as has been suggested, but apparently relatively undisturbed portions of a much larger grain.

That "veining" is a manifestation of some condition existing throughout the body of the grain and not merely a surface characteristic developed by etching is shown by Figure 5. A spot on the etched surface of a polished specimen of electrolytic iron was located by means of reference punch marks, photographed and then ground, polished, reetched, and rephotographed. The same veining pattern was obtained in both cases, although considerable metal was removed from the surface by the repolishing as is shown by the difference in the number and size of the inclusions in the two cases.

Not all the grains in any specimen in which veining occurs show the network equally well developed. In some cases the veining varies decidedly in the grains in different parts of a section of the specimen as is shown in Figure 6, which shows a 1-inch round bar of openhearth iron. The micrographs show that in the central part of the bar the grains, as a, rule, were almost free from veining, whereas in other portions veining was a very prominent feature in the structure.

The amount of veining present appears also to be related to the mechanical working the iron has received. In a 2 -inch round of open-hearth iron, as well as in the 1-inch round just mentioned, veining was well developed. In a rod of the same material, one- 
fourth inch diameter, no veining was found although it could readily be developed in this material by suitable treatment. (See Sec. VI.)

Apparently veining is not unique for ferrite. The same feature, or at least one of very similar appearance, has been observed in some other metals under certain conditions. Figure 7 shows the structure of cast nickel in which the appearance of veining was particularly well developed.

\section{MATERIALS STUDIED}

The special structural features just described have been observed in remelted electrolytic iron, open-hearth iron, and to some extent, in wrought iron. The first two materials were used in the examinations, the results of which are reported in this paper. The occurrence of these special structural features in wrought iron is not at all frequent, and when they are found the condition is a local one, as only certain streaks show them.

The following is the composition of the open-hearth iron used for most of the work, although use was made of some specimens of this material from other heats, the composition of which may be taken as differing in no essential respect from that given below:

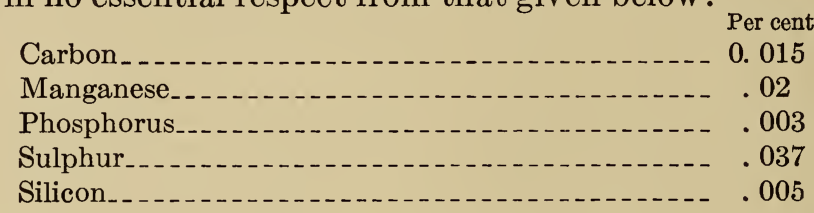

The copper content of this material is usually 0.03 to 0.04 per cent and the oxygen content is an appreciable one. In some of the openhearth iron used the oxygen varied from 0.030 per cent in the outer part to 0.072 per cent in the center of a bar 2 inches in diameter. The average nitrogen content of the same bar was 0.0055 per cent.

The following composition is representative of the remelted electrolytic iron used for some of the observations:

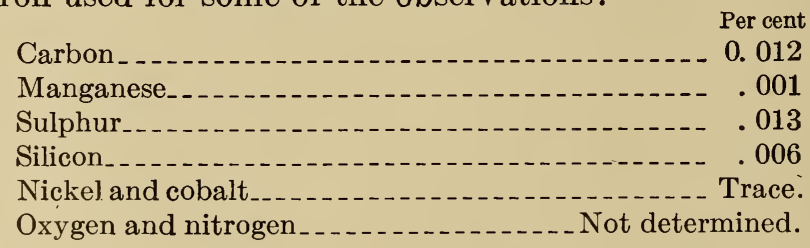

As is explained later (Sec. V), several "melts" of iron to which some addition, such as aluminum, manganese, or silicon, had been made were also used.

\section{FACTORS AFFECTING THE STRUCTURE OF FERRITE}

Tests were made to determine to what extent the unusual features observed in the structure of ferrite could be modified or eliminated by special treatment given to the material. These tests were princi- 
pally for showing the effect upon the $\alpha$ veining, since this feature is by far the most common of the unusual structural variations; some information on the other types of structure was obtained, however.

\section{CASTING: SIZE AND SHAPE OF INGOT}

Veining within the ferrite grains has been repeatedly noted in cast material. In order to show whether the occurrence of this structural feature in such material is related to the form or relative size of the ingot in which the iron is cast, small ingots of three different shapes as shown in Figure 8 were made in pure magnesia crucibles. Openhearth iron was turned in a lathe to approximately the size and shape desired, inserted into the mold, and then melted in vacuo in the Arsem electric resistance furnace. It will be seen that the form of the ingot varied from a relatively wide shallow "cake" to a very narrow tall cylinder. In the latter shape the ingot mold might be expected to exert more "restraint" on the iron during the volume changes which are known to accompany the allotropic transformation of jron than in the former shape.

The structure of the case material of the three differently shaped ingots is shown in Figures 9 and 10 . In heating ingot $\mathrm{B}$, on account of the slightly uneven temperature distribution, the lower part of the iron cylinder accidentally was not melted. The difference in the structure between this portion and that which did melt is striking and worthy of note. It is shown in Figure 9.

It will be seen from the micrographs of the iron cast in the three different forms that the structure of the three was essentially the same. In all, traces of the $\alpha$ veining were present. In the portion of ingot $\mathrm{B}$ which was heated to a temperature only slightly below the melting point, however, veining was a very prominent feature of the structure and the conclusion that the conditions which obtain during the solidification of the cast metal are of much less importance in giving rise to $\alpha$ veining than is the heating of the metal to a high temperature when closely confined on all sides would appear to be warranted. Evidence of the $\delta$ network was shown clearly by the tall cylindrical ingots, though not so plainly by the wide flat one. The nature of the $\delta$ network was more clearly indicated, however, by tests described later.

\section{HEAT TREATMENT}

(a) Annealing.-The general conclusion drawn from the examination of a considerable number of annealed specimens which initially showed $\alpha$ veining was that annealing does not eliminate this feature from the structure of the ferrite. In order to show definitely the effect of annealing, however, examinations were made of polished specimens annealed in hydrogen, the same spot, the location of which 


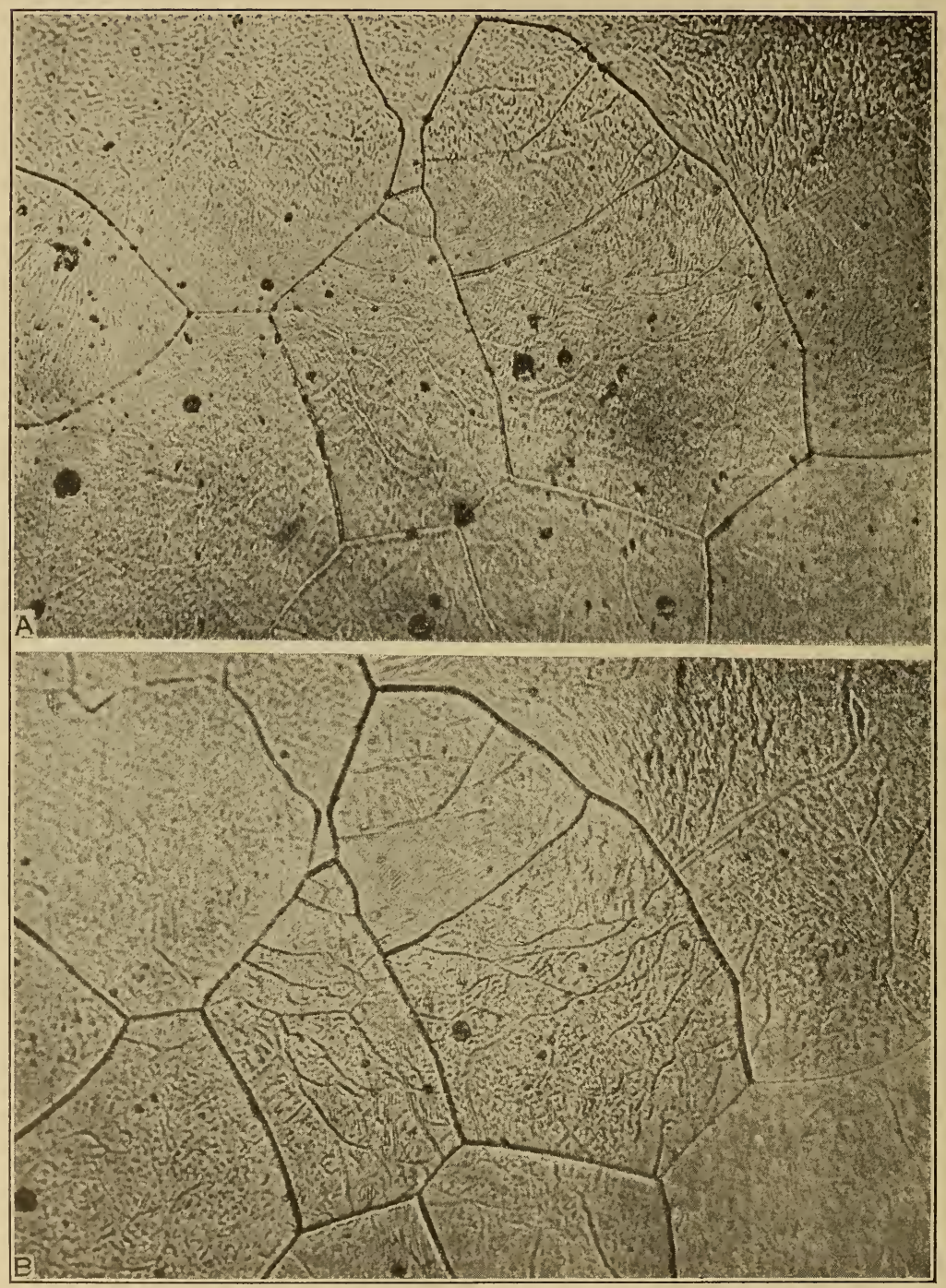

FIG. 5.-Open-hearth iron showing veining. $\times 500$

After taking micrograph (a) the specimen was lightly ground, repolished, and etched. (b) shows the same spot as $(a)$. Note that the same veining pattern appears in $(b)$ as in $(a)$. The veining is not simply a surface etching effect. The amount of metal removed can be estimated from the size of the oxide inclusions which were ground away. 


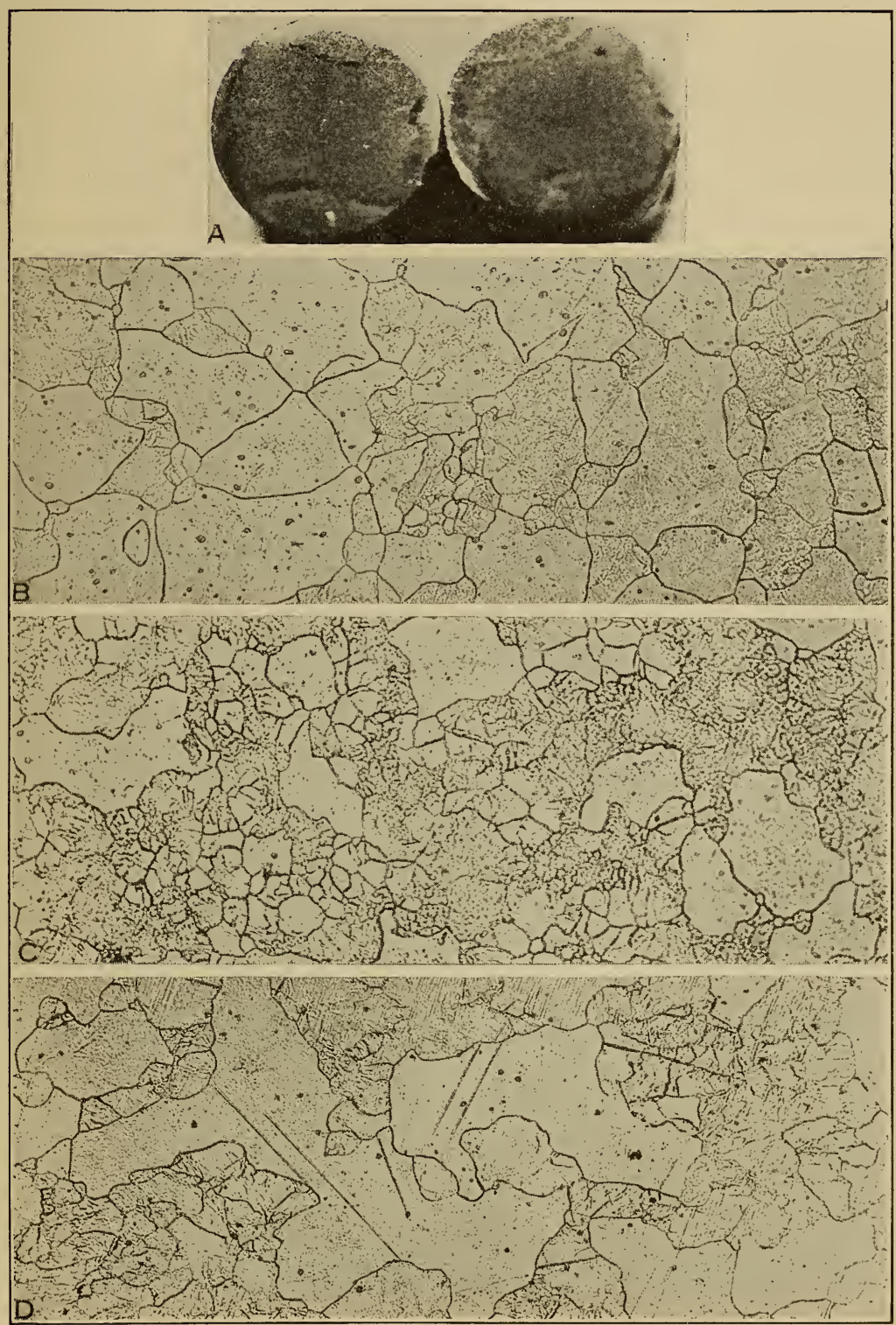

FIG. 6.-Variations in the amount of veining shown by a 1-inch "round" of open-hearth iron. $\times 100$

(a) Cross sections of the 1-inch "round," etched. $\times 1$.

(b) Structure of the central portion of the "round."

(c) Structure corresponding to the four-sided figure in (a) produced during the rolling.

(d) Structure near the surface of the "round." 


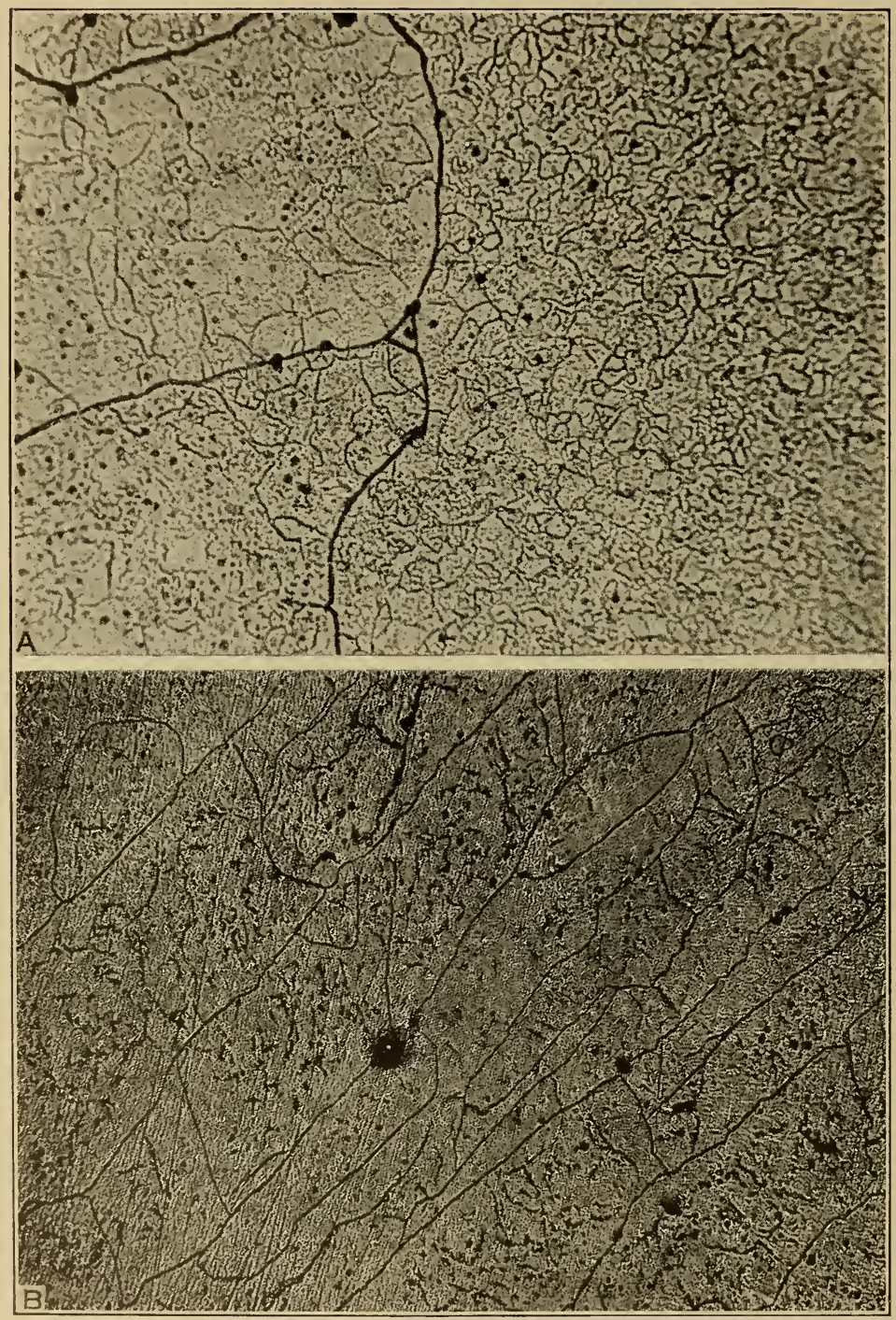

FIG. 7.-Cast nickel showing veining within the grains, etched with nitric acid. $\times 100$

(a) Commercial cast nickel used as an anode in electroplating.

(b) Remelted electrolytic nickel. 
was established by reference punch marks on the surface, being used throughout each series of observations. The arrangement by which the specimens could be heated in a hydrogen atmosphere and, if desired, be quenched directly from the hydrogen atmosphere into water is shown in Figure 11. The specimens were placed in the cold furnace, which was then closed, filled with hydrogen, and heated to $750^{\circ} \mathrm{C}$. The specimens were held two hours at this temperature, the hydrogen atmosphere being maintained throughout, and then allowed to cool in the furnace in the hydrogen atmosphere. The results obtained in a series of observations on a specimen annealed in this manner are shown in Figure 12. It will be seen from these micrographs, which show the initial structure, the "heat-etched" surface of the annealed specimen, and the structure of the annealed material revealed by etching a repolished surface after annealing, that, while annealing does not in general eliminate $\alpha$ veining from the structural pattern of the material, the conclusion that it has no effect whatever is not upheld. The appearance of some grains was distinctly different after annealing than it was before, the $\alpha$

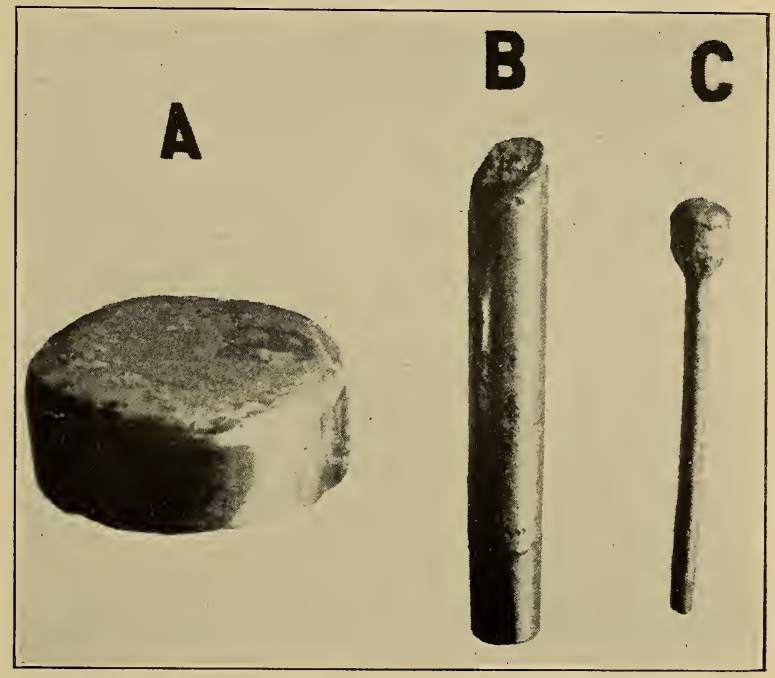

FIg. 8.-Forms of ingots used for open-hearth iron to show the effect of casting conditions on structure. $\times \frac{8}{10}$

veining in such grains being very much less distinct and in some cases seemed to have disappeared entirely.

The appearance of the heat-etched surface of the annealed ferrite when examined by "conical illumination" (fig. 13) throws some light on the nature of $\alpha$ veining. Comparison of the $\alpha$ veining pattern with the polishing scratch on the same surface shows, by the similarity in illumination, that heat etching revealed the veining as a network of shallow furrows or ditches over the surface of the specimen.

Ferrite which has been heated to a temperature considerably above the transformation temperature frequently shows evidence of the feature which has been termed " $\gamma$ network." Although this feature was observed in the structure of some specimens in their initial condition, in those specimens whose thermal history was known, 


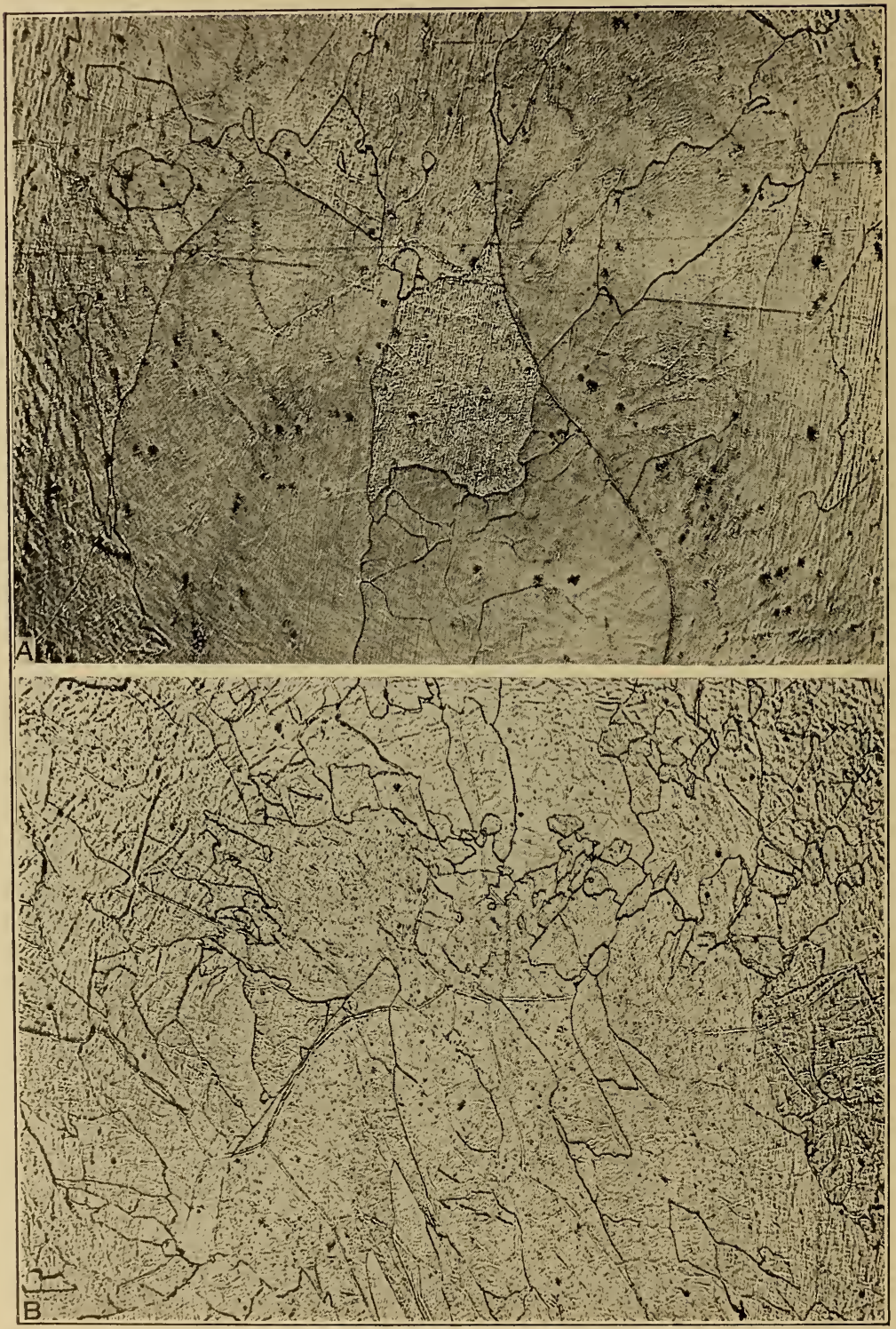

FIG. 9.-Structure of cast open-hearth iron, ingots $A$ and $C$, Figure 8. $\times 100$

No important structural differences are shown. Traces of veining are to be seen in each.

(a) Ingot $\mathrm{A}$.

(b) Ingot C. 


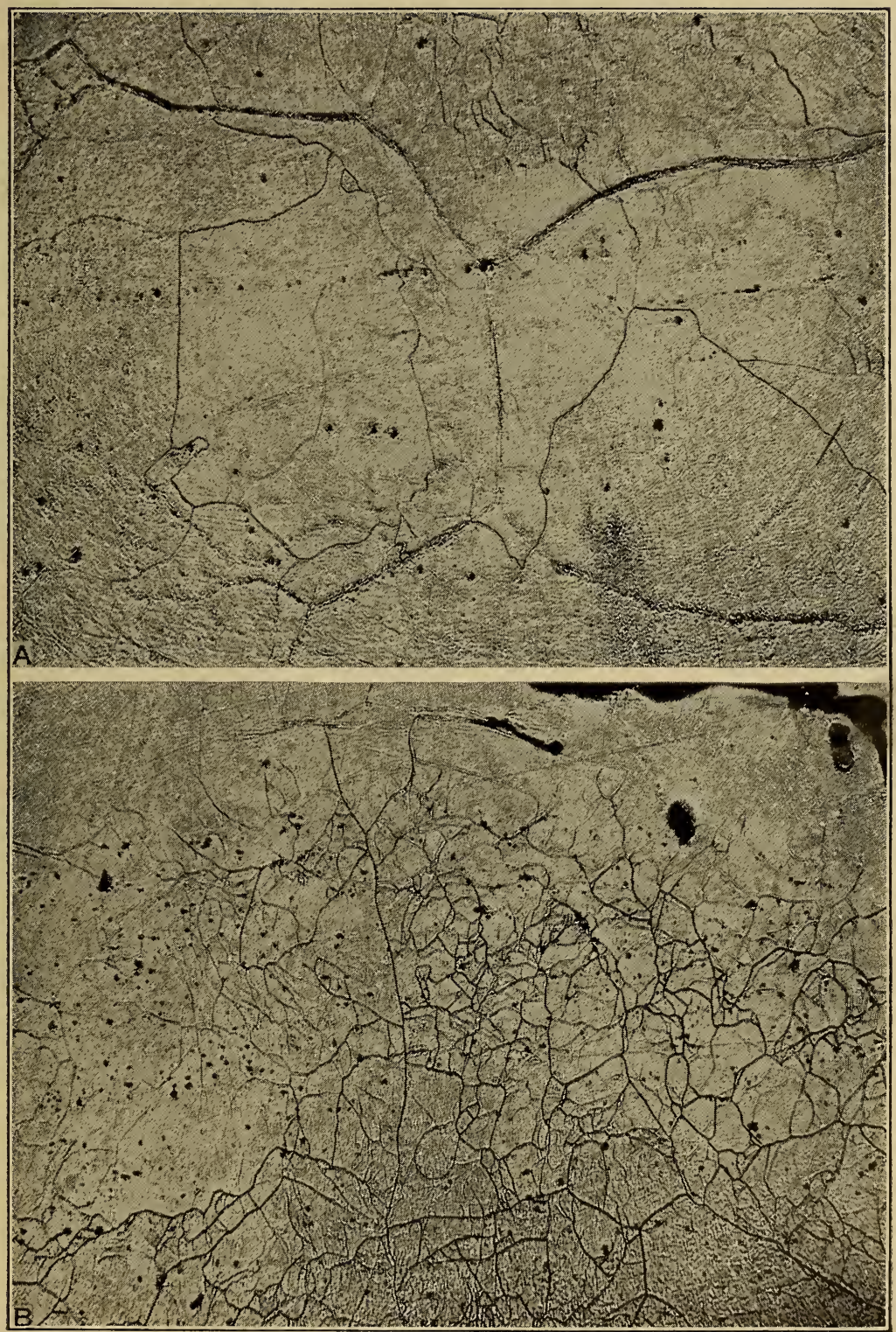

Fig. 10.-Structure of cast open-hearth iron, ingot B, figure $8 . \times 100$

(a) Upper part of the ingot.

(b) Lower part of the ingot which, though heated close to the melting point, was not melted.

Note the pronounced $a$ veining in $(b)$; in $(a)$, the $\delta$ network forms a prominent structural feature. 
however, it was found only in those which had been heated to a temperature above that of the $\alpha-\gamma$ transformation. Sometimes deformation of the iron at a high temperature, as shown in a subsequent section, seemed to aid in producing the $\gamma$ network in the structure of the ferrite as observed at ordinary temperature. Figure

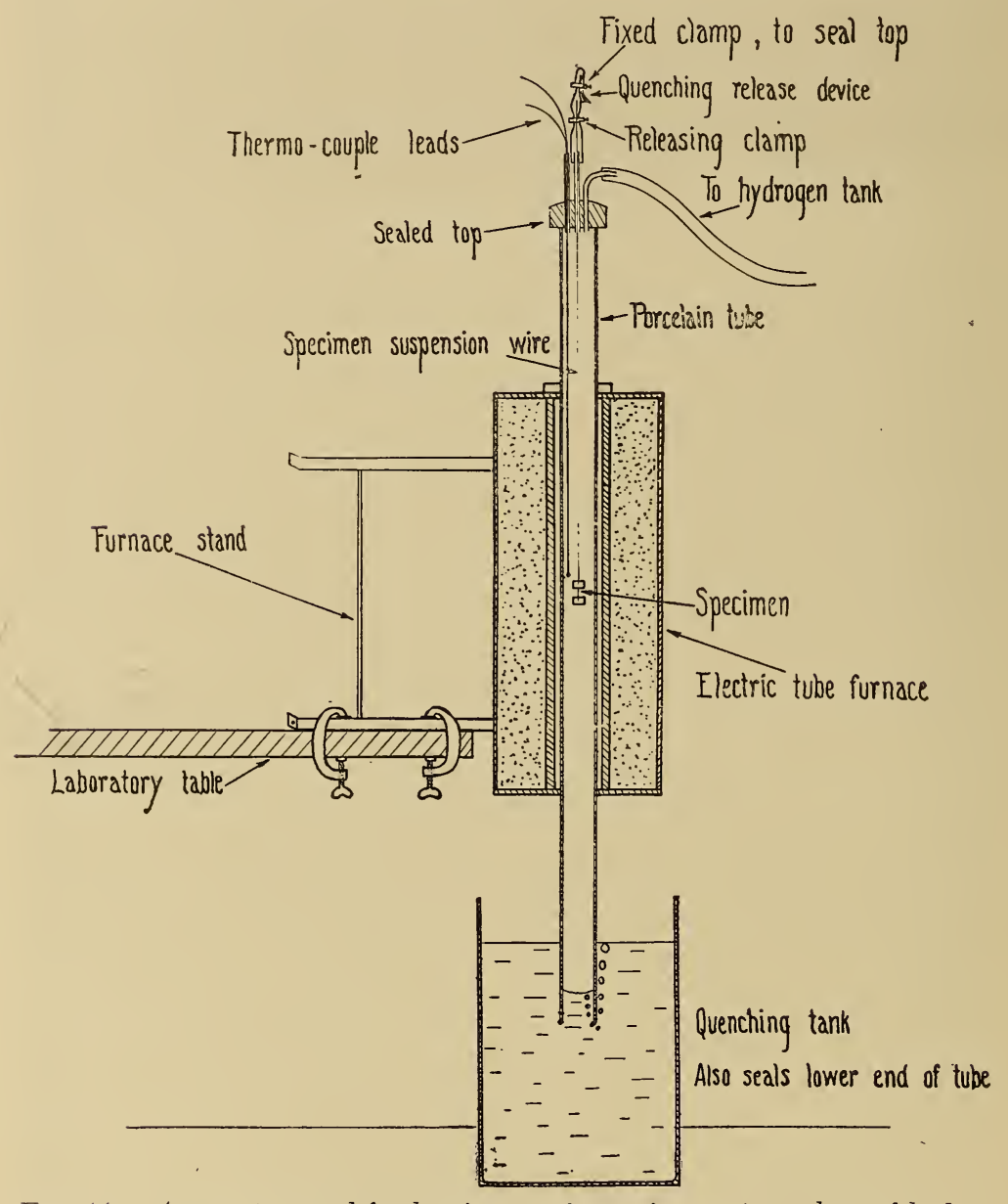

FIG. 11.-A pparatus used for heating specimens in an atmosphere of hydrogen and quenching therefrom directly into water

14 shows the occurrence of this feature in the structure of iron as related to the treatment which the metal has been given.

(b) Heating Followed by Quenching.-A series of experiments were carried out to determine whether the structural features observed in ferrite were related in any way to a rapid cooling of the metal from a high temperature. The temperatures used were chosen with reference to the allotropic or $\alpha-\gamma$ transformation which occurs in iron at $900^{\circ}$ C., approximately. Ferrite quenched in cold water 

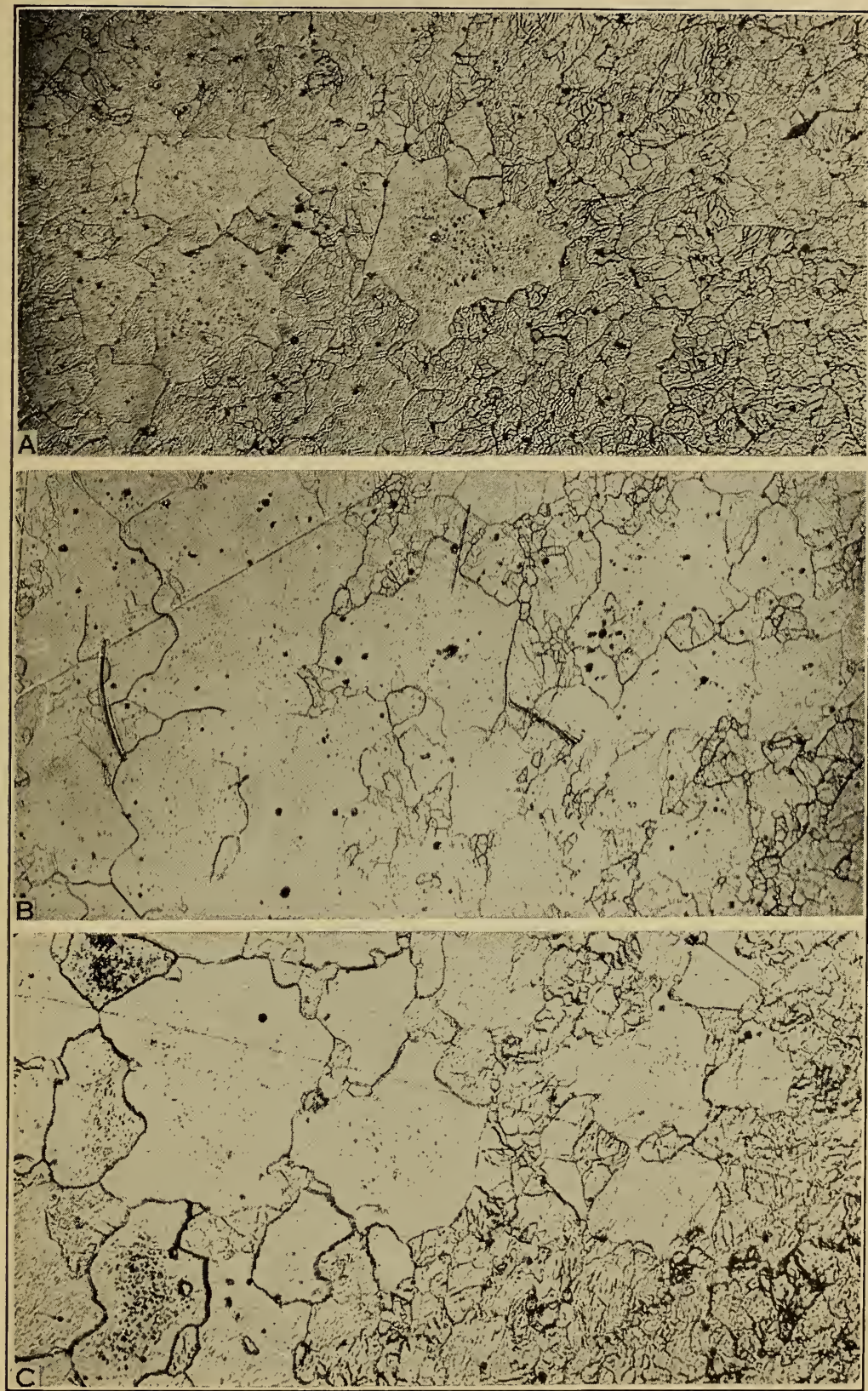

Frg. 12.-Effect of annealing in hydrogen upon the veining in the grains of open-hearth iron. $\times 100$

(a) Initial condition.

(b) Same spot on specimen (a) which, after polishing, was heated in hydrogen two hours at $750^{\circ} \mathrm{C}$. The specimen became "heat etched" during the heating; the few scratches should be disregarded.

(c) Same spot as (b), repolished and etched. 
from a temperature close to the transformation temperature shows numerous deformation lines in its structure which result from the pronounced expansion changes which occur during the transformation as Figure 15 shows. These markings are of a different character from the features previously described and when present serve to obscure the others. These quenching or deformation lines are readily removed by annealing.

A series of tests in which iron was quenched from different temperatures below that of the transformation gave results which at first

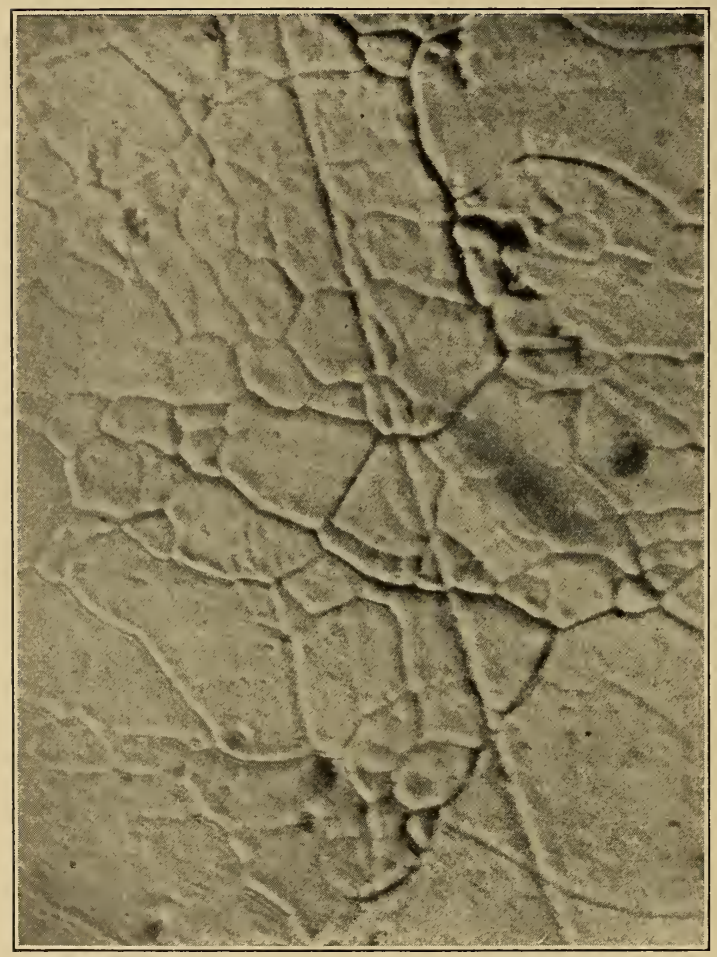

FIG. 13.-A ppearance of the "heat-etched" surface of open-hearth iron, showing veining, $\times 1,000$; epiphragmatic or conical illumination

The material was treated as in Figure 12. Comparison of the veining with the polishing scratch shows that the veining, as revealed by the heat etching, consists of a network of shallow "ditches." were interpreted as indicating that $\alpha$ veining was eliminated from the structure of $\alpha$ iron by quenching in cold water from a temperature of $750^{\circ}$ C. or somewhat above. Figure 16 shows the results obtained. It will be seen that iron which initially showed marked evidence of $\alpha$ veining, when quenched from $750^{\circ}$ C. had a structure, as revealed by etching in the ordinary manner, consisting of grains which showed no evidence of anything unusual in their appearance. Later tests, however, suggested that the structure had not been changed, but that the effect of the quenching had been to render it necessary to etch the iron much longer in order to reveal the $\alpha$

veining pattern. Figure 17 shows the results obtained when the etching period was carefully timed. It will be seen that iron which had been quenched from $750^{\circ} \mathrm{C}$., when etched for the same period which served to reveal the $\alpha$ veining very clearly in the unquenched iron, showed no evidence of this pattern in the structure. When the etching period was lengthened, however, to approximately three times the initial period, the $\alpha$ veining was revealed. In other cases 

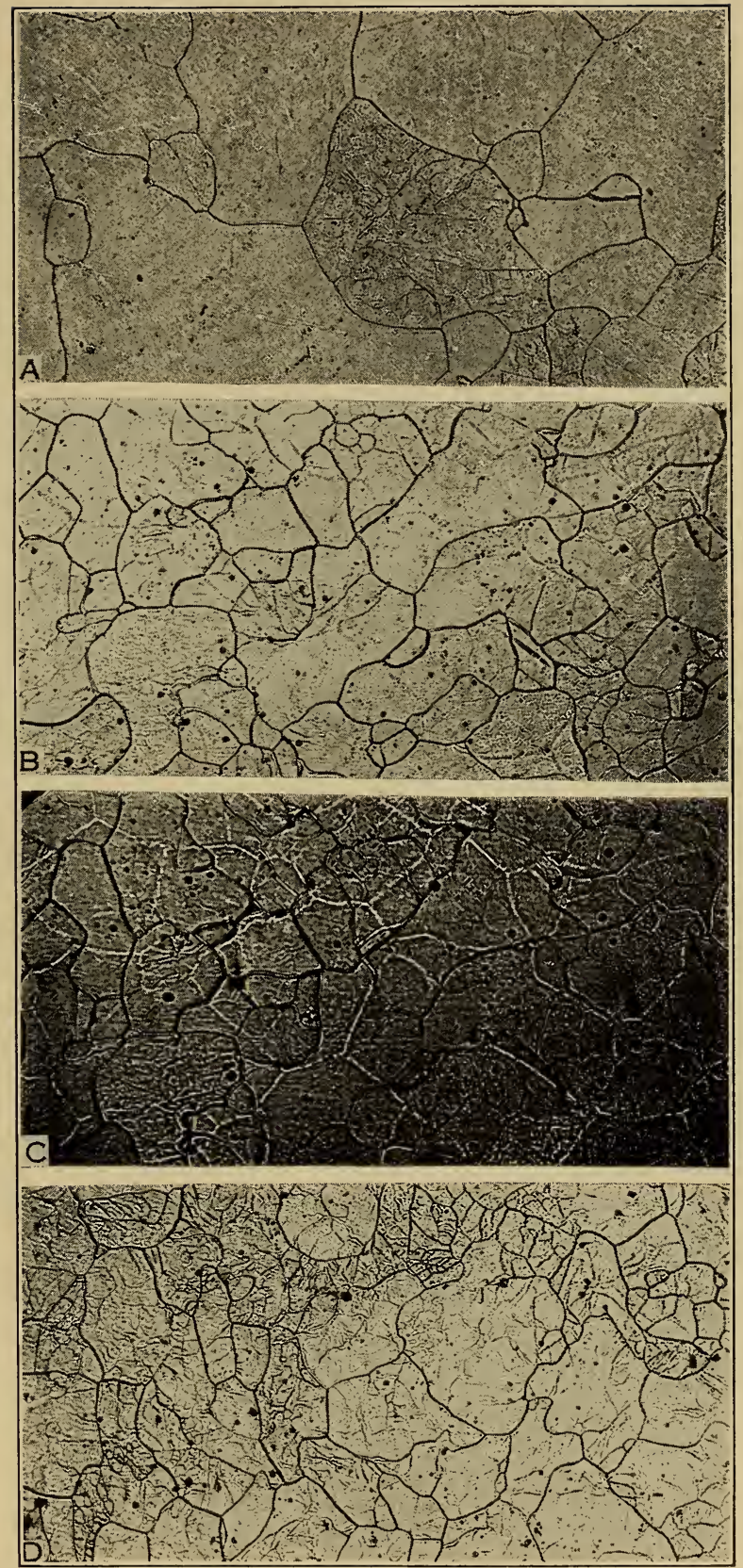

FIG. 14.-Occurrence of the $\gamma$ network in open-hearth iron after heat treatment. $\times 100$

(a) The iron was air cooled after being heated to $940^{\circ} \mathrm{C}$. The $\gamma$ network was extremely faint.

(b) Same material, air cooled after being heated to $1,100^{\circ} \mathrm{C}$.

(c) Same as (b), observed with a slightly different focusing of the microscope. Note how pronounced the $\gamma$ network is.

(d) Same material as $(c)$, reheated to $820^{\circ} \mathrm{C}$. and air cooled. The veining is pronounced but the network has disappeared. 
it was necessary to increase the etching period still more in order to reveal clearly the true structure of the ferrite after quenching.

By heating the iron in hydrogen and quenching it directly into water from this atmosphere, it was possible to observe the effect of

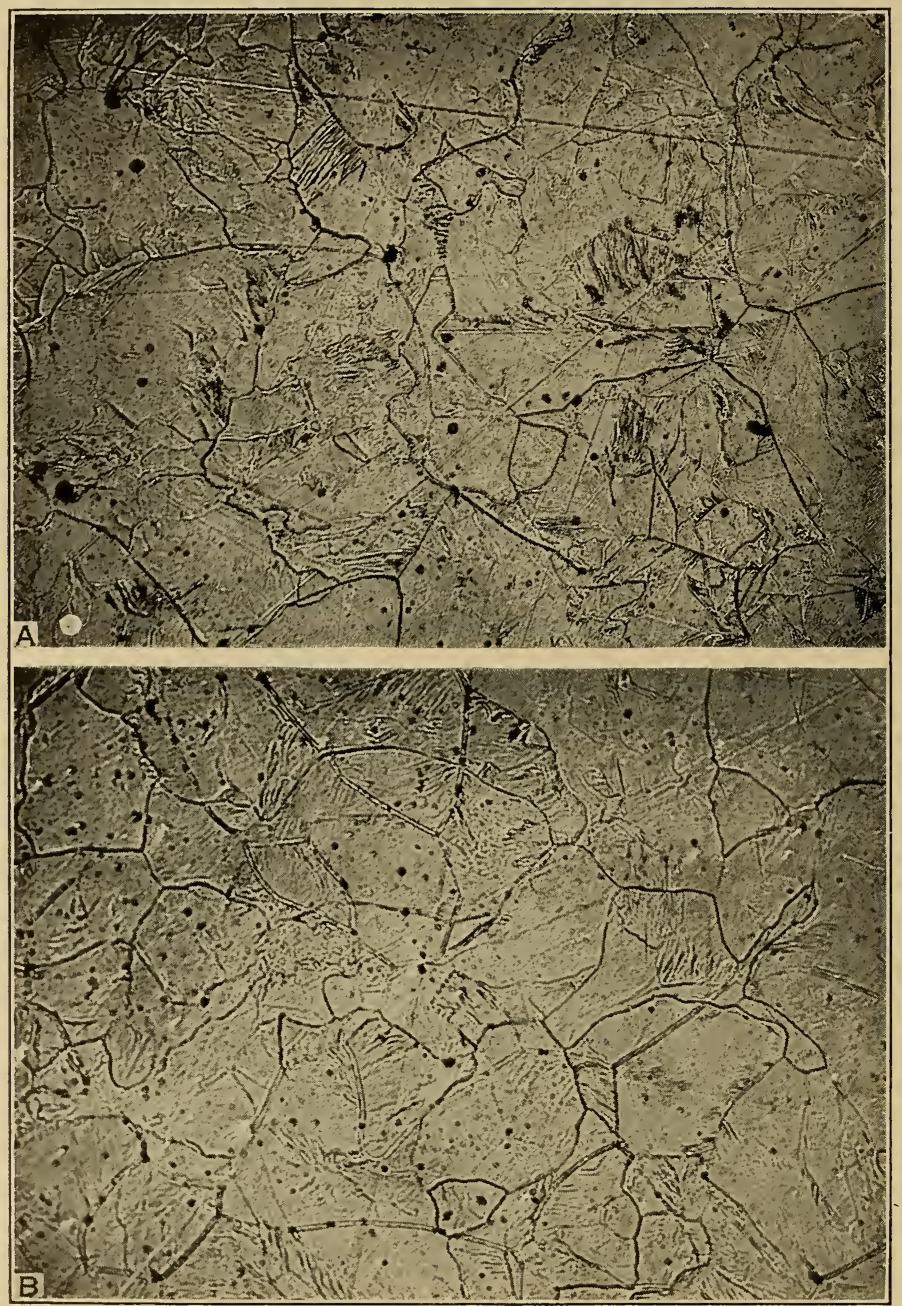

FIG. 15.-Effect upon the microstructure of open-hearth iron of quenching in water from a temperature close to the a- $\gamma$ transformation. $\times 100$

(a) Quenched from $925^{\circ} \mathrm{C}$.

(b) Quenched from $880^{\circ} \mathrm{C}$.

The "deformation lines" resulting from the volume change accompanying the $a-\gamma$ change obscure most of the other structural features; some traces of the $\gamma$ network may be seen, however.

quenching upon individual grains, the structure of which had been already determined in the material before it was quenched. Figure 18 shows the structure of material treated in this manner. These 

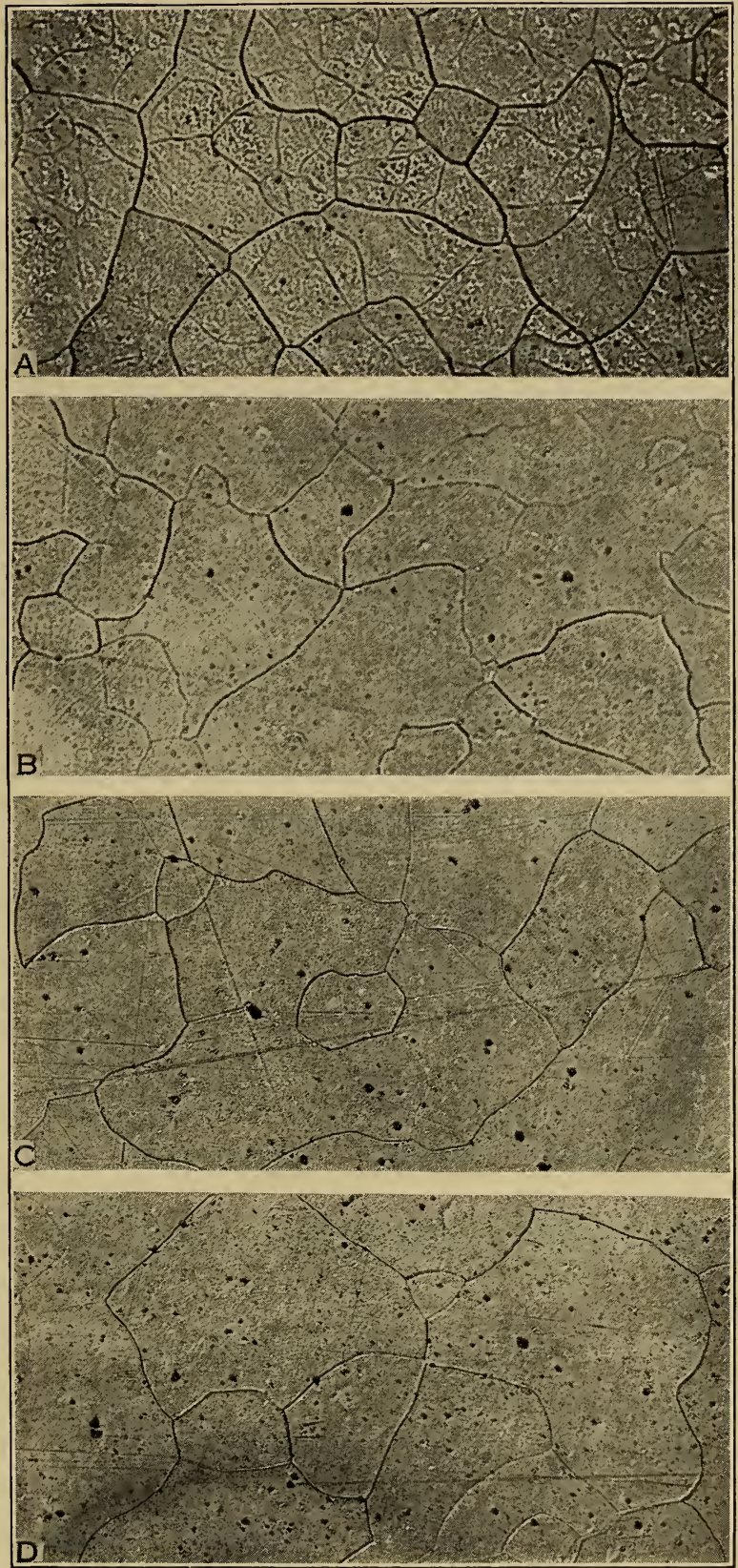

FIG. 16.-Effect of quenching from $750^{\circ}$ C. upon the a veining in open-hearth iron. $\times 100$

The material which initially showed veining after being heated to $950^{\circ}$ C. and air cooled was treated as follows:

(a) Quenched in water after being heated one-half hour at $700^{\circ} \mathrm{C}$. The veining still persists.

(b) Quenched as above from $750^{\circ} \mathrm{C}$

(c) Quenched as above from $780^{\circ} \mathrm{C}$.

(d) Quenched as above from $820^{\circ} \mathrm{C}$

Treatments $(b),(c)$, and $(d)$ appear to have caused the veining to disappear. A longer etching period, however (compare fig. 17), would have revealed the veining: 


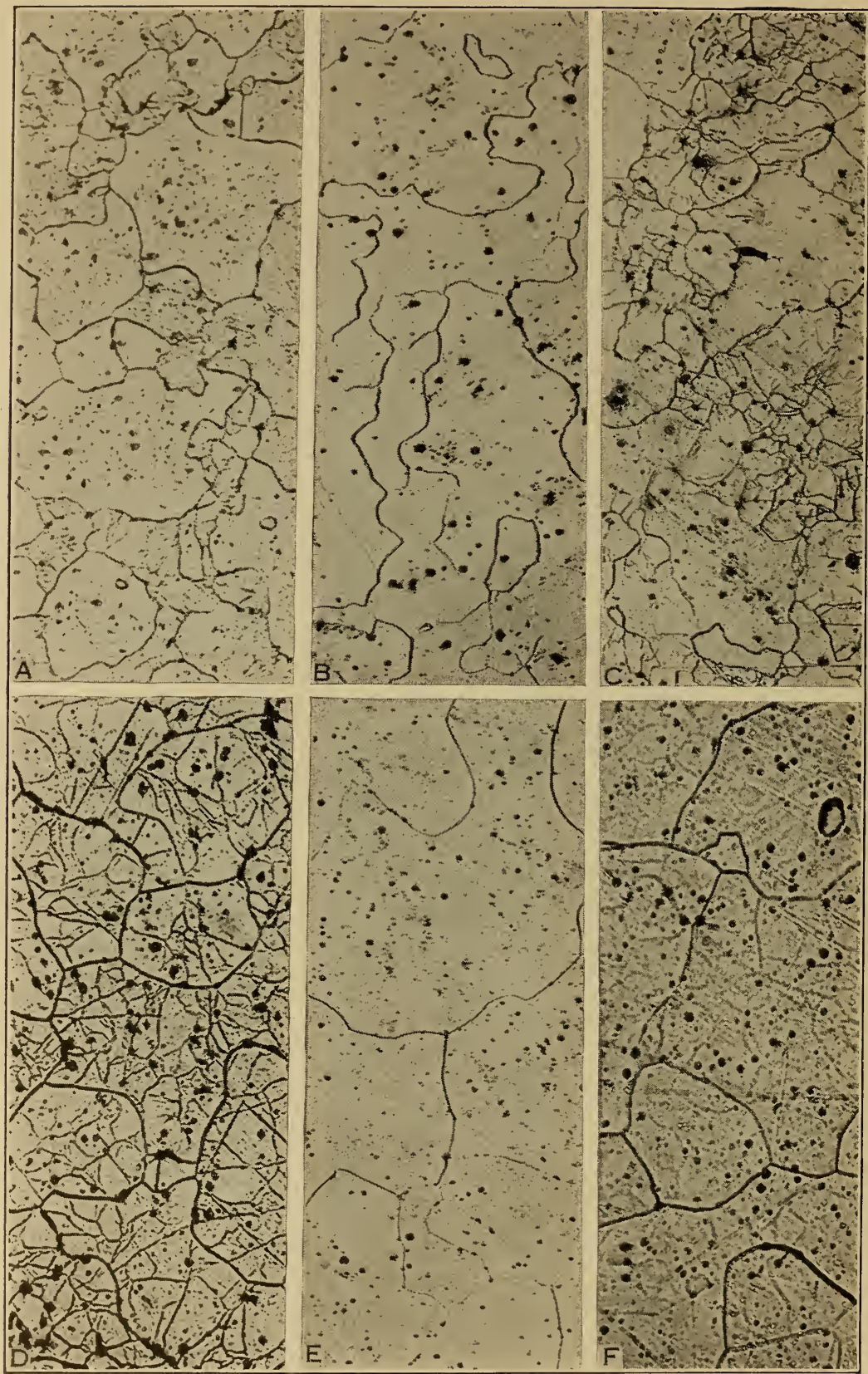

FIG. 17.-Effect of quenching from $750^{\circ}$ C. upon the a veining in open-hearth iron. $\times 100$

Compare Figure 16. The specimens were etched in a picric-acid solution for the periods given below. The results show that the veining was not removed by the quenching.

(a) Initial condition of a 1-inch "round" of hot-rolled open-hearth iron etched for 8 minutes.

(b) Same material, quenched from $750^{\circ} \mathrm{C}$., etched for 8 minutes.

(c) Same as $(b)$, etched for 25 minutes.

(d) Initial condition of a 2-inch "round" of hot-rolled open-hearth iron etched for 8 minutes.

(c) Same as $(d)$, quenched from $750^{\circ} \mathrm{C}$., etched for 8 minutes.

(f) Same as $(d)$, etched 25 minutes. 


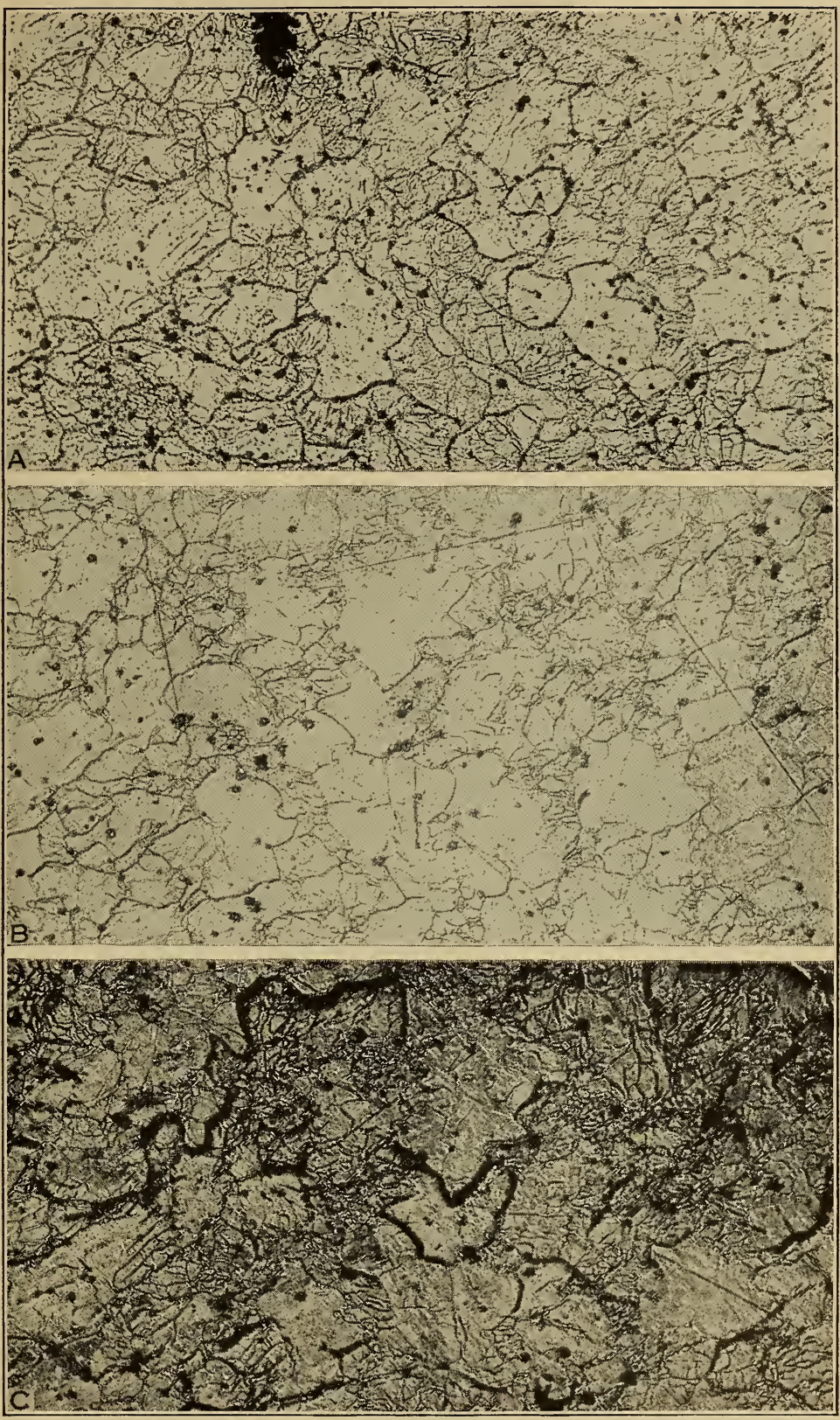

FIG. 18.-Effect of quenching from $750^{\circ}$ C. upon the a veining in openhearth iron. $\times 100$

The iron was heated two hours in hydrogen, and quenched in water directly from the hydrogen atmosphere.

(a) Initial condition of the material, marked spot.

(b) Same spot after quenching, regrinding slightly, repolishing, and etching for $15 \mathrm{~min}$ utes.

(c) Same as (b), the etching period being prolonged to about one hour. 
micrographs serve to demonstrate again the fact that, in order to reveal clearly the true structure of ferrite which has been heat treated by quenching from a temperature somewhat below the transformation temperature, it is necessary to etch the metal several times as long as is required in order to reveal the structure of the unquenched ferrite. $\alpha$ veining, whatever its true nature may be, is evidently a very persistent feature in the structure of ferrite and, once formed, is not readily eliminated.

\section{MECHANICAL DEFORMATION, FORGING OF OPEN-HEARTH IRON}

Some preliminary tests had indicated that open-hearth iron in which the $\alpha$ veining pattern was not pronounced could be made to show this feature somewhat more prominently by "hot working" the iron. In order to show this effect more clearly and definitely, samples of open-hearth iron were forged by means of a trip hammer, one set at a temperature considerably above and one set below the temperature range in which open-hearth iron is well known to be "hot-short." The "hot-short" temperature range for open-hearth iron is approximately 800 to $1,000^{\circ}$ C. $\left(1,470\right.$ to $1,830^{\circ}$ F.). The temperature of any small specimen can not be determined with any degree of certainty during forging. In the tests in which the material was forged at the higher temperature, the temperature of the iron when taken from the furnace, as determined by means of an optical pyrometer, was considerably above $1,000^{\circ}$. The temperature of the specimen as it was being forged was observed in the same manner. The temperature at which forging was stopped was not below $900^{\circ} \mathrm{C}$. All of the deformation of the grains was completed before the $\alpha-\gamma$ transformation of the iron started. A comparison bar was taken from the furnace when its temperature was somewhat below $800^{\circ}$ C.- that is, below the $\alpha-\gamma$ transformationand forged, the finishing temperature being somewhat above $600^{\circ} \mathrm{C}$. As shown by the micrographs of Figure 19, the extent to which $\alpha$ veining occurs in the microstructure of ferrite is closely related to the temperature at which the iron has been hot worked. The openhearth iron which initially had very little veining in its structure, after being forged at the higher temperature, above $900^{\circ} \mathrm{C}$., showed no change in structure with respect to this feature of veining, although its grain size was somewhat smaller and traces of the $\gamma$ network were present. Similar material forged at the lower temperature, below $800^{\circ} \mathrm{C}$., however, differed very markedly in its structure from the initial condition, veining being a very prominent feature of the microstructure of iron hot worked under such conditions.

The results of the forging tests suggest strongly that $\alpha$ veining in ferrite originates as a result of the deformation of the grains and, hence, is somewhat related to the phenomenon of "slip." The result, however, is distinctly different from that produced by ordi- 

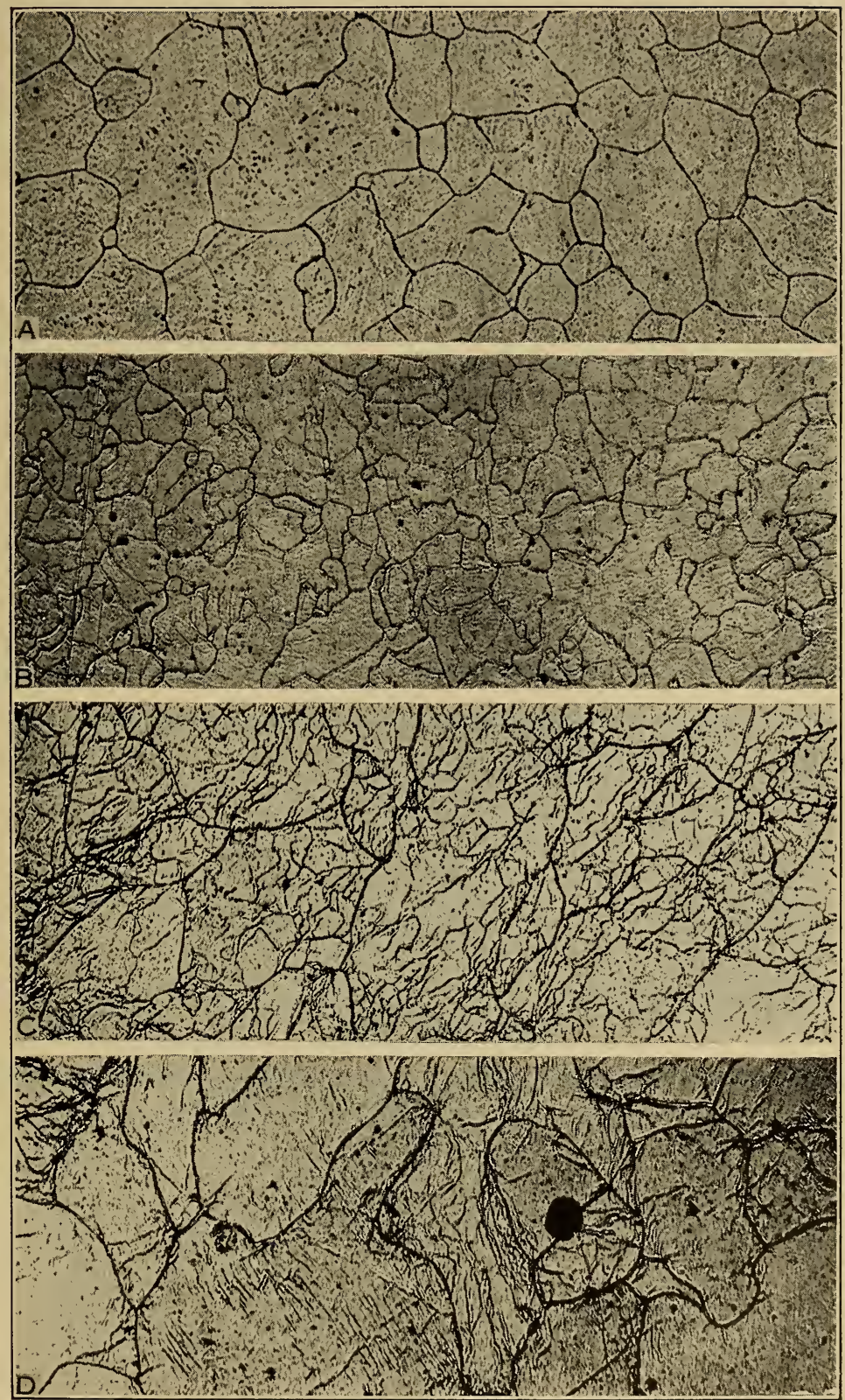

FIG. 19.-Effect of hot-working (forging) upon the development of veining in the grains of open-hearth iron. $\times 100$

(a) Initial condition of the iron, very little veining.

(b) Same material as (a) after forging at a temperature above $900^{\circ} \mathrm{C}$.

(c) and (d) Same material as (a) forged at a temperature considerably below $900^{\circ} \mathrm{C}$., the finishing temperature being somewhat above $600^{\circ} \mathrm{C}$. 
nary cold working and can readily be distinguished from it. The micrographs of Figure 19 show that in some grains the veining shows some regularity and appears as more or less parallel markings which are more suggestive of slip than is the veining network as it ordinarily occurs.

\section{OBSERVATIONS ON THE EFFECT OF FORGING IRONS OF DIFFERENT COMPOSITIONS}

Small ingots were prepared of electrolytic iron and of open-hearth iron, to some of which was added a small amount of one of the elements often associated with iron commercially-aluminum, manganese, and silicon. Aluminum, used in the manufacture of open-hearth iron, is known to play frequently an important rôle in affecting the properties of iron..$^{13}$ Manganese was used because of its well-known effect upon the sulphur present in iron, although the amount of this element (manganese in commercial open-hearth iron) is unappreciable as compared with the amount in steels. Silicon was added in a sufficient amount to obtain a material free from the $\alpha-\gamma$ transformation. Manganese was added in the form of "carbon-free" manganese made by the thermit method, silicon as the element, while for the aluminum additions an aluminum-iron alloy with an aluminum content of approximately 60 per cent was prepared. Most of the ingots contained about $800 \mathrm{~g}$ of metal. A few, including those with the aluminum addition, were smaller, 200 to $300 \mathrm{~g}$. In all cases the metal was allowed to solidify in the crucible and to cool within the furnace.

The different materials prepared for this part of the investigation are listed in Table 1. For convenience in referring to the different materials in the description which follows, the ingot numbers given in this table are used.

TABLE 1.-Materials prepared for forging at different temperatures

[Each ingot was prepared by melting in vacuo in the Arsem electric resistance furnace in a magnesia crucible and allowed to cool in the crucible in the furnace]

\begin{tabular}{|c|c|c|c|}
\hline Ingot No. & Material & Preparation & Remarks \\
\hline $\begin{array}{l}966-- \\
977-- \\
979--\end{array}$ & Electrolytic iron. & $\left\{\begin{array}{l}\text { Heated in hydrogen in order to } \\
\text { remove the surface oxide before } \\
\text { melting; crucibles of pure mag- } \\
\text { nesia were used for melting. }\end{array}\right.$ & \multirow{3}{*}{$\begin{array}{l}\text { The structure indicated a relatively } \\
\text { high oxide content in this ingot, }\end{array}$} \\
\hline 980 & ..._do & nesia were used lor meitng. & \\
\hline $\begin{array}{l}967 . \\
978 . \\
973 .\end{array}$ & Open-hearth iron. & $\left\{\begin{array}{c}\text { Crucibles of commercial magnesia } \\
\text { used in melting. }\end{array}\right.$ & \\
\hline 972 . & Electrolytic iron.- & An addition of an iron-aluminum & \multirow{5}{*}{$\begin{array}{l}0.86 \text { per cent } \mathrm{Al} \text { by chemical analy- } \\
\text { sis. } \\
\text { Less than } 0.05 \text { per cent Al by } \\
\text { chemical analysis. } \\
0.54 \text { per cent } \mathrm{Mn} \text { by chemical } \\
\text { analysis. } \\
0.53 \text { per cent } \mathrm{Mn} \text { by chemical } \\
\text { analysis. } \\
4.35 \text { per cent Si by chemical analy- } \\
\text { sis. }\end{array}$} \\
\hline $976 \ldots$ & Open-hearth iron & An addition similar to above, & \\
\hline $983 \ldots$ & Electrolytic iron.- & An addition of 0.7 per cent man- & \\
\hline 984 & Open-hearth iron.- & & \\
\hline $981 \ldots$ & Electrolytic iron & $\begin{array}{l}\text { Approximately } 5 \text { per cent } \mathrm{Si} \text { was } \\
\text { added. }\end{array}$ & \\
\hline
\end{tabular}

${ }^{13}$ S. Epstein and H. S. Rawdon, "Progress in the study of normal and abnormal steel," Trans. Am. Soc. Steel Treat., 12, p. 337; 1927. 
The addition of aluminum was made by inserting the required amount of an iron-aluminum alloy in a hole drilled into the metal to be melted, then closing the hole with an iron plug and sealing the plug in place.

Observations were made of the structure of the various materials in the initial, or cast, condition and after forging $(a)$ at a temperature very considerably above the transformation range, $(b)$ close to the transformation range, and (c) considerably below it. The temperature was approximately determined in each case by means of an optical pyrometer, the aim being to choose and control the temperature of forging with respect to the allotropic transformation in iron rather than to determine accurately the temperature during any particular phase of the forging operation.

A summary of the examinations made of the structure of the various irons after the different treatments received is given in Table 2 and typical micrographs are also given in Figures 20 to 34, inclusive.

TABLE 2.-Observations on the structure of irons of special composition MATERIAL IN CAST OR INGOT CONDITION

\begin{tabular}{|c|c|c|c|c|c|}
\hline \multirow{2}{*}{$\begin{array}{c}\text { Specimen } \\
\text { No. }\end{array}$} & \multirow{2}{*}{ Nature of material } & \multicolumn{3}{|c|}{ Structural features } & \multirow{2}{*}{$\begin{array}{l}\text { Micrograph } \\
\text { (fig. No.) }\end{array}$} \\
\hline & & $\begin{array}{l}\delta \text {-net- } \\
\text { work }\end{array}$ & $\begin{array}{l}\gamma \text {-net- } \\
\text { work }\end{array}$ & $\alpha$-veining & \\
\hline $\begin{array}{l}966 \\
977 \\
980 \\
967 \\
978 \\
973 \\
972 \\
976 \\
984 \\
981\end{array}$ & $\begin{array}{l}\text { Electrolytic iron, remelted } \\
\text { Same with high-oxide content } \\
\text { Open-hearth ingot iron } \\
\text { Electrolytic iron }+1 \text { per cent } \mathrm{Al} \\
\text { Open-hearth iron }+0.5 \text { per cent } \mathrm{Al} \\
\text { Electrolytic iron }+0.7 \text { per cent } \mathrm{Mn} \\
\text { Open-hearth iron }+0.7 \text { per cent } \mathrm{Mn} \\
\text { Electrolytic iron }+5 \text { per cent } \mathrm{Si}\end{array}$ & 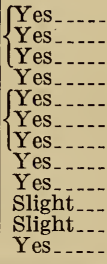 & 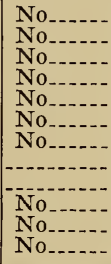 & 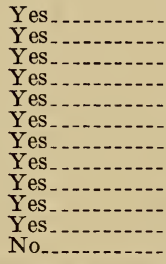 & $\begin{array}{l}20, \text { a. } \\
21 \text {, a. } \\
21, \text { c. } \\
21, \text { b. } \\
22 \text {; } 25 \text {, d. } \\
24 \text {, a. } \\
24 \text {, c. } \\
23 \text {. }\end{array}$ \\
\hline
\end{tabular}

AFTER FORGING AT HIGH TEMPERATURE (1,000 C. AND ABOVE)

\begin{tabular}{|c|c|c|c|c|c|}
\hline $\begin{array}{l}966 \\
977 \\
979 \\
980 \\
9678 \\
978 \\
972 \\
976 \\
983 \\
984 \\
981\end{array}$ & $\begin{array}{l}\text { Electrolytic iron, remelted } \\
\text { Same, with high-oxide content } \\
\text { Open-hearth iron, remelted } \\
\text { Electrolytic iron, } 1 \text { per cent } \mathrm{Al} \\
\text { Open-hearth iron } 0.5 \text { per cent } \mathrm{Al} \\
\text { Elcctroly tic iron with } 0.7 \text { per cent } \mathrm{Mn}^{-} \\
\text {Open-hearth iron with } 0.7 \text { per cent } \mathrm{Mn} \\
\text { Electrolytic iron with } 5 \text { per cent } \mathrm{Si} \text { - }\end{array}$ & 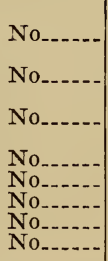 & 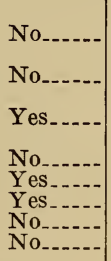 & 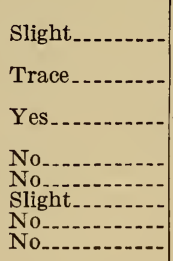 & 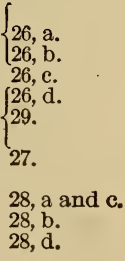 \\
\hline
\end{tabular}


TABLE 2.-Observations on the structure of irons of special composition-Contd. FORGED IN TRANSFORMATION RANGE (950 TO $800^{\circ}$ C.)

\begin{tabular}{|c|c|c|c|c|c|}
\hline \multirow{2}{*}{$\begin{array}{l}\text { Specimen } \\
\text { No. }\end{array}$} & \multirow{2}{*}{ Nature of material } & \multicolumn{3}{|c|}{ Structural features } & \multirow{2}{*}{$\begin{array}{l}\text { Micrograph } \\
\text { (fig. No.) }\end{array}$} \\
\hline & & $\begin{array}{l}\delta \text {-net- } \\
\text { work }\end{array}$ & $\begin{array}{l}\gamma \text {-net- } \\
\text { work }\end{array}$ & $\alpha$-veining & \\
\hline $\begin{array}{l}966 \\
977 \\
979 \\
980 \\
967 \\
978 \\
973 \\
972 \\
976 \\
983 \\
984 \\
981\end{array}$ & $\begin{array}{l}\text { Electrolytic iron, remelted } \\
\text { Electrolytic iron with high oxide } \\
\text { Open-hearth iron } \\
\text { Electrolytic iron with } 0.9 \text { per cent } \mathrm{Al} \\
\text { Open-hearth iron with } 0.05 \text { per cent } \mathrm{Al} \\
\text { Electrolytic iron with } 0.5 \text { per cent } \mathrm{Mn} \\
\text { Open-hearth iron with } 0.5 \text { per cent } \mathrm{Mn} \\
\text { Electrolytic iron with } 4 \text { per cent } \mathrm{Si} . . . .\end{array}$ & 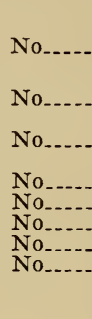 & 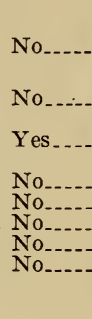 & $\left\{\begin{array}{l}\text { Yes; often hav- } \\
\text { ing appear- } \\
\text { an c e of } \\
\text { "slip." }\end{array}\right.$ & $\begin{array}{l}\left\{\begin{array}{l}3 \\
30, \mathrm{~b} \text { and } \mathrm{c} .\end{array}\right. \\
\left\{\begin{array}{l}30, \mathrm{~d} . \\
33 .\end{array}\right. \\
31, \mathrm{a} \text { and } \mathrm{b} . \\
\text { 32, a and b. } \\
\text { 32, c and d. } \\
\text { 31, c. }\end{array}$ \\
\hline
\end{tabular}

FORGED AT A TEMPERATURE BELOW THE TRANSFORMATION, FINISHED AT APPROXIMATELY $600^{\circ} \mathrm{C}$.

\begin{tabular}{|c|c|c|c|c|c|}
\hline $966 \ldots$ & Electrolytic iron, remelted. & No...... & No...... & $\begin{array}{l}\text { Cold-w ork } \\
\text { slip lines } \\
\text { with some } \\
\alpha \text { veining, } \\
\text { cracked at } \\
\text { center. } \\
\text { Cold-w ork } \\
\text { slip lines; } \\
\text { cracked at } \\
\text { center. }\end{array}$ & 34. \\
\hline
\end{tabular}

\section{CAST MATERIAL}

The observations showed definitely that the structural feature of ferrite which has been termed " $\delta$ network" (figs. 20 to 25 ) is associated only with the cast condition of the metal. It was found in none of the worked material. The addition of aluminum to ferrite apparently accentuates this feature to a considerably greater extent than does the addition of manganese or silicon (fig. 22). The microscopic examination of the $\delta$ network at rather high magnification showed that, at least in those cases in which this feature is pronounced, the network is the result of minute inclusions localized in such a manner as to give rise to the network pattern upon etching. In a very few cases, however, the impurities which are apparently responsible for the existence of the network are so minute that they are not revealed in the microstructure (fig. 25).

The most probable explanation of this network pattern is that impurities suspended in the molten metal, perhaps in an emulsified condition, are, upon solidification of the metal, pushed forward by the grains as they form and, upon complete solidification of the metal, exist in large measure as a "film" of particles enveloping the grains and having in cross section the appearance of a network. This pat- 


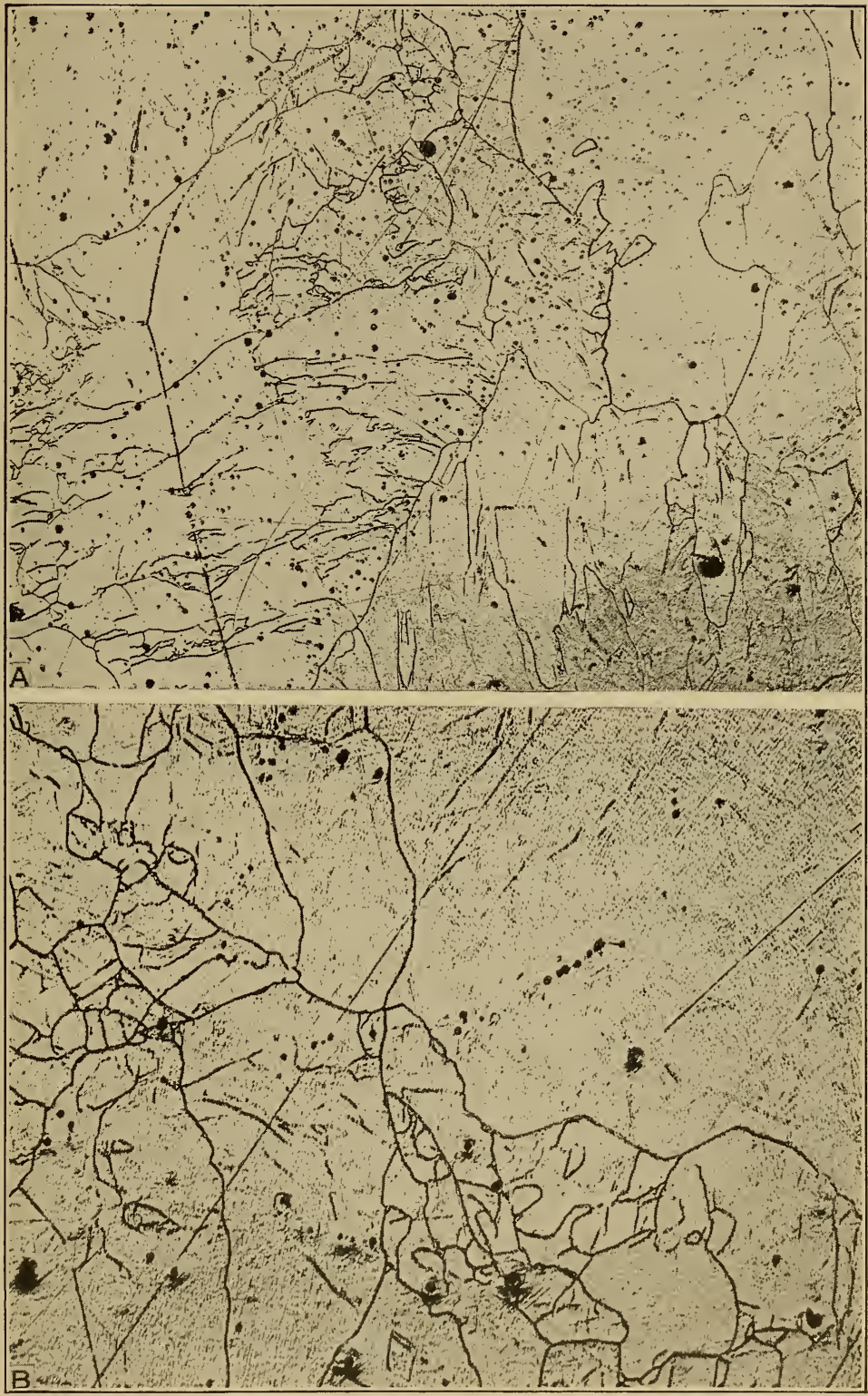

FIG. 20.-Structure of electrolytic iron in the "cast" condition

(a) Some veining within the grains may be seen as well as the $\delta$-grain boundaries (ingot 977). $\times 20$.

(b) Most of the grains show some veining. $\times 100$

These two ingots are representative of the electrolytic iron to which additions of aluminum, manganese, or silicon were made for the material used in the forging tests described later.

$73815^{\circ}-28-5$ 


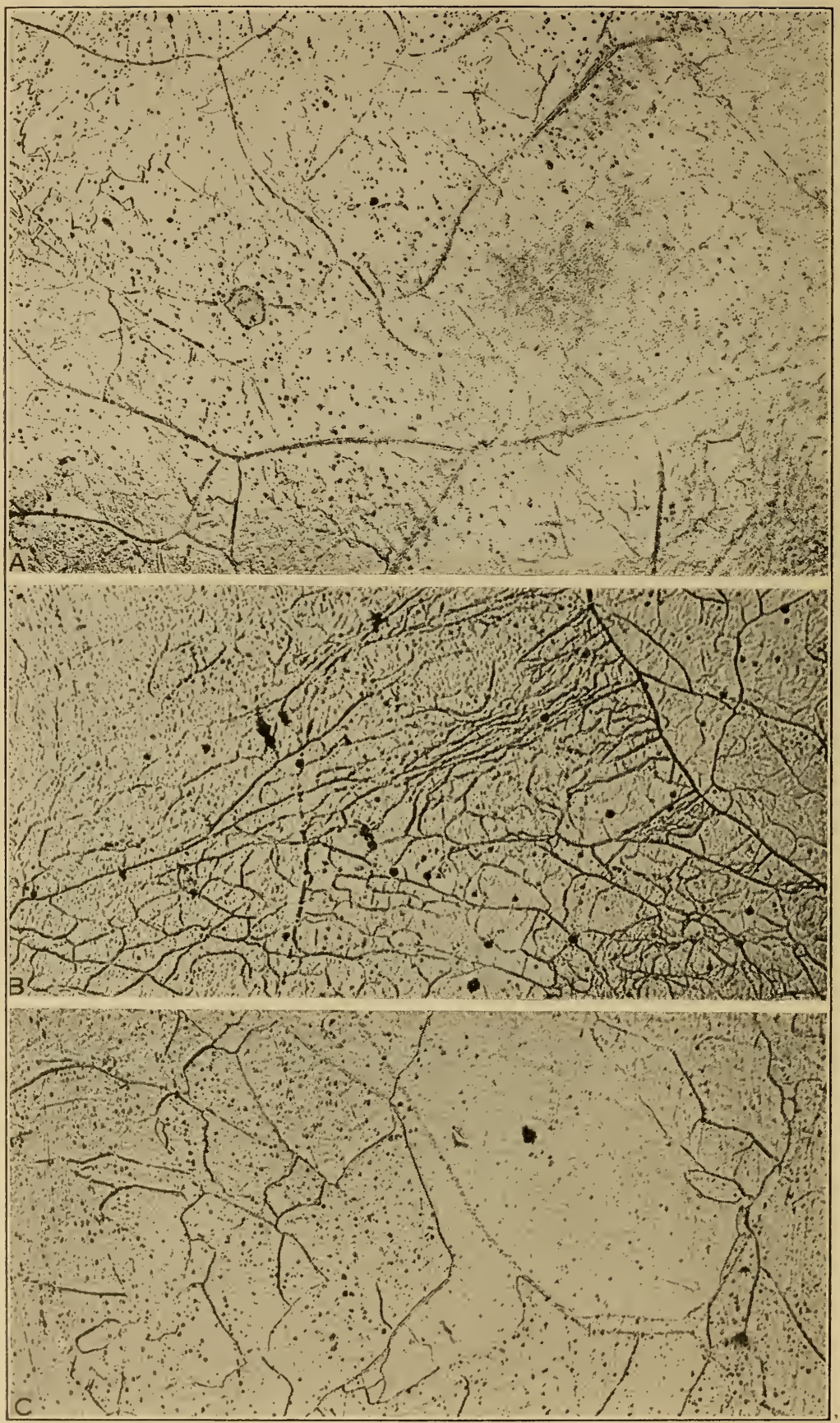

FIG. 21.-Structure of open-hearth iron in the cast condition

(a) The $\delta$-grain boundaries are very pronounced in this material (ingot 967 ). $\times 20$.

(b) The veining is very pronounced in this material (ingot 973). $\times 100$.

(c) The $\delta$-grain pattern is very evident, together with some $\alpha$ veining (ingot 978 ). $\times 100$.

These three ingots are representative of the open-hearth iron to which additions of aluminum, manganese, or silicon were made for the material used in the forging tests described later. 
tern bears no evident relation to the ordinary structural or grainboundary pattern of the iron, since this results from the transformation which occurs at a temperature which is very much below that at which the $\delta$ grains form.

$\alpha$ veining as it occurs in ferrite in the cast condition is of two general types. In one (fig. $21, \mathrm{~b}$ ) it consists of a coarse subdivision of the grain by "veins" all of which are approximately parallel and are somewhat suggestive of "slip" within the grains. In the other, the veining is much more irregular and branching in its appearance (fig. 20, b).

None of the irons showed any evidence of $\gamma$ network when in the cast state. The $\alpha$ veining, on the other hand, was a rather common feature of the structure, although not nearly so prominent as it was in some of the same materials after being forged.

Ferrite containing ahuminum or manganese showed $\alpha$ veining in practically the same degree as in the plain electrolytic and openhearth iron. No veining was detected, however, in the ferrite containing silicon.

\section{FORGED MATERIAL}

Forging of the iron results in the elimination of the $\delta$ network from the structure of the metal, as might be expected when one considers what this network really is. On the other hand, several of the specimens, after being forged, showed evidence of the $\gamma$ network; and in some cases it was possible to show that this feature, like the $\delta$ network of the cast metal, is associated with the presence of inclusions (fig. 29.) Although it seems very probable that the same inclusions, or at least part of them, which initially help to form the $\delta$ network of the cast metal, assist in the formation of the $\gamma$ network when the material has been forged, a definite conclusion to this effect is not warranted by the evidence available. Hightemperature forging, with a finishing temperature of 950 to $1,000^{\circ} \mathrm{C}$., resulted in all cases in grain refinement; $\alpha$ veining was entirely eliminated from several of the materials and existed only to a relatively small extent in the others. Evidently forging at high temperature is not conducive to the formation of veining, such veining as was found (figs. 26, 27, and 28) may, perhaps, be the residual of that initially present in the cast metal.

When forged at a lower temperature, however, 950 to $800^{\circ}$ C.that is, close to the A3 change-all of the nonalloyed ferrites showed evidence of pronounced veining (fig. 30) as did also the ferrite treated with aluminum (fig. 31). In many cases the veining was so pronounced as compared with that of the cast metal and its character so different that there can be no reasonable doubt that the forging was responsible for the formation of the veining. 


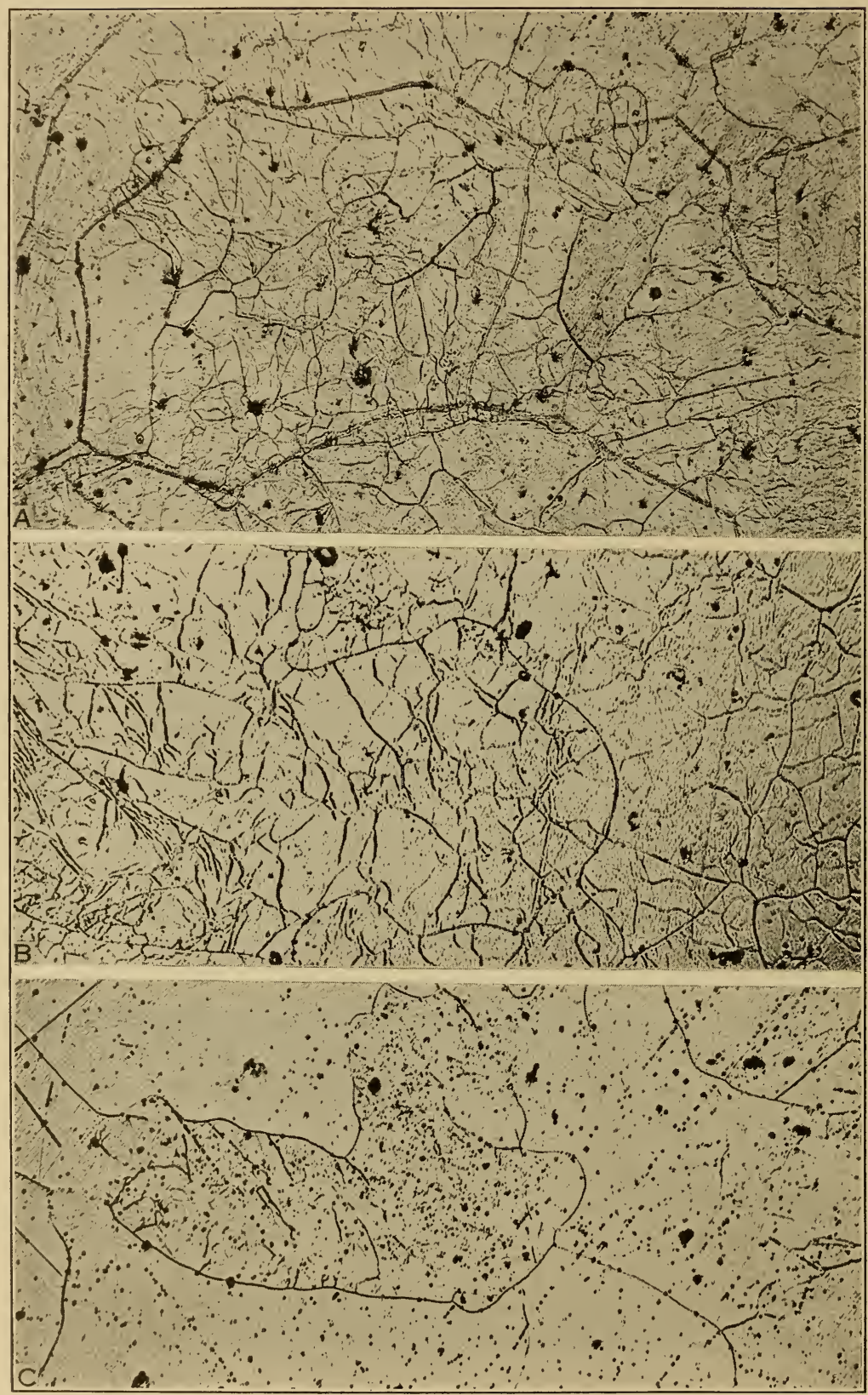

FIG. 22.-Structure of electrolytic iron in the cast condition containing 1 per cent aluminum (ingot 972)

(a) The addition of aluminum to the iron has rendered the $\delta$-grain boundaries very pronounced; the veining is also very plain. $\times 50$.

(b) A portion of the ingot showing pronounced veining. $\times 100$.

(c) Another spot of the section in which veining was almost absent. $\times 100$. 
The iron containing manganese (fig. 32) showed very slight veining, and in the iron containing silicon (fig. $31, \mathrm{c}$ ) the amount of veining was so extremely slight as to be negligible. Although the forging of the different materials was carried out at the same temperature (approximately), the conditions were not strictly comparable in all other respects. In order to forge the open-hearth iron in the trans-

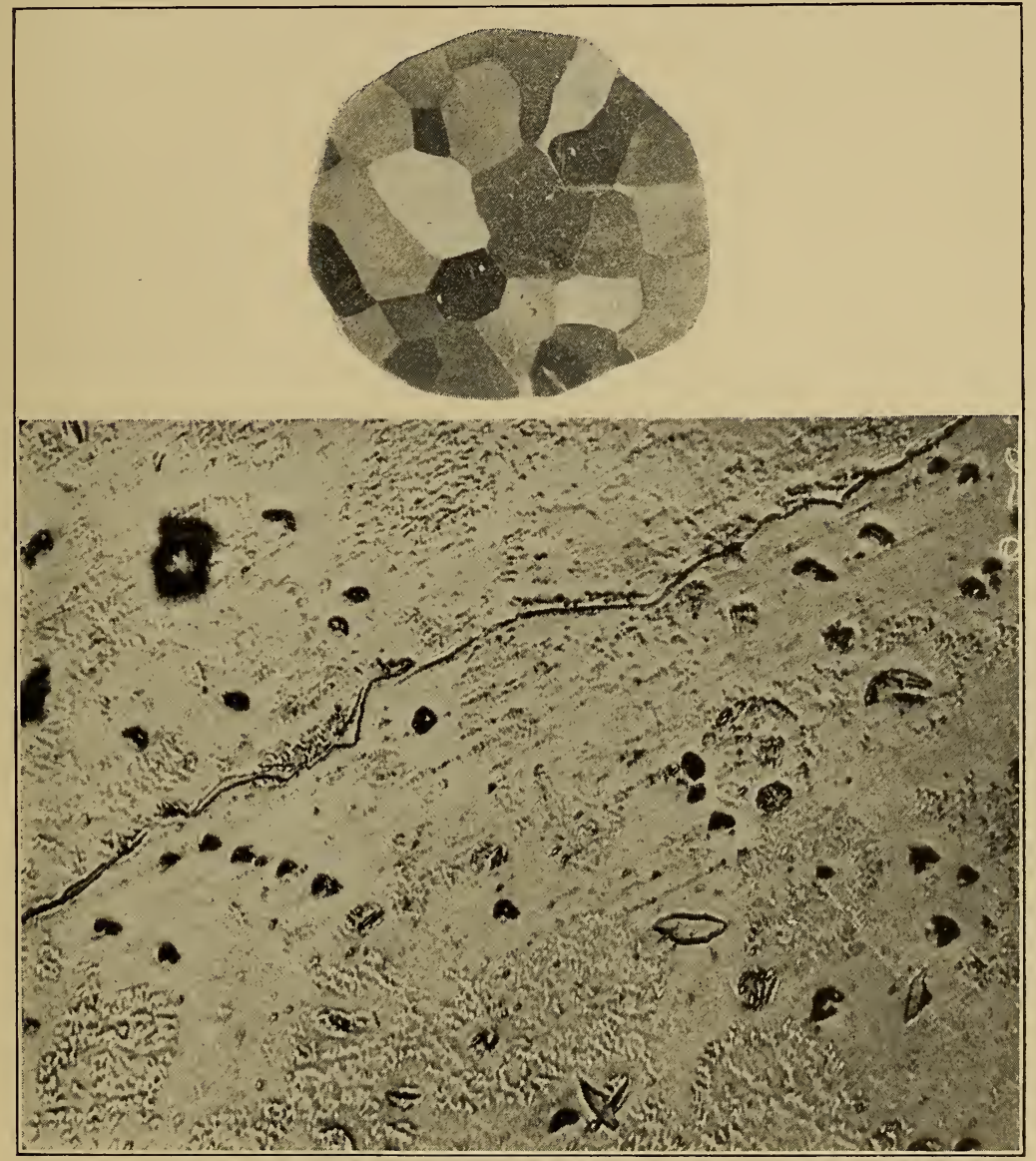

FIG. 23.- Structure of electrolytic iron in the cast condition containing silicon (ingot 981)

(a) Cross section of the ingot etched with ammonium persulphate. $\times 1$.

(b) Same as $(a) \times 500$. No veining was found in this material.

formation range it was necessary to use very light blows, whereas some of the other materials, particularly the silicon-iron, "worked" very easily. The work done upon the individual grains necessarily varied in the different materials, and some of the differences in structure shown by materials forged under apparently the same conditions may be attributed to this cause. In some specimens (figs. 30 and 31 ) the veining produced by forging was very suggestive 


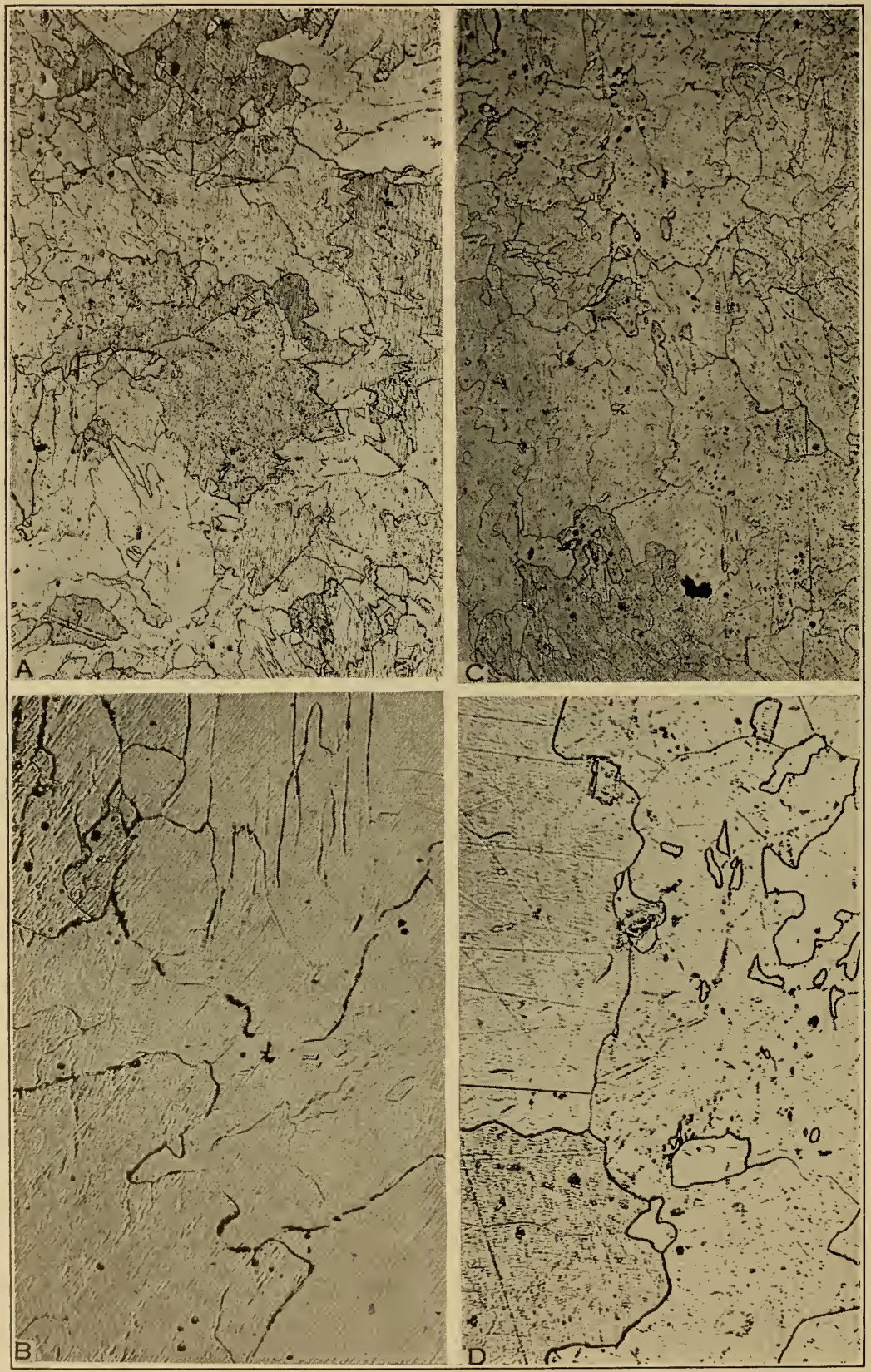

FIG. 24.-Structure of electrolytic and open-hearth iron in the cast condition containing manganese

(a) Electrolytic iron containing manganese; veining occurs in many of the grains (ingot 983). $\times 20$.

(b) Same as $(a) . \times 100$

(c) Open-hearth iron containing manganese (ingot 584$), \quad \times 20$.

(d) Same as (c). $\times 100$. 


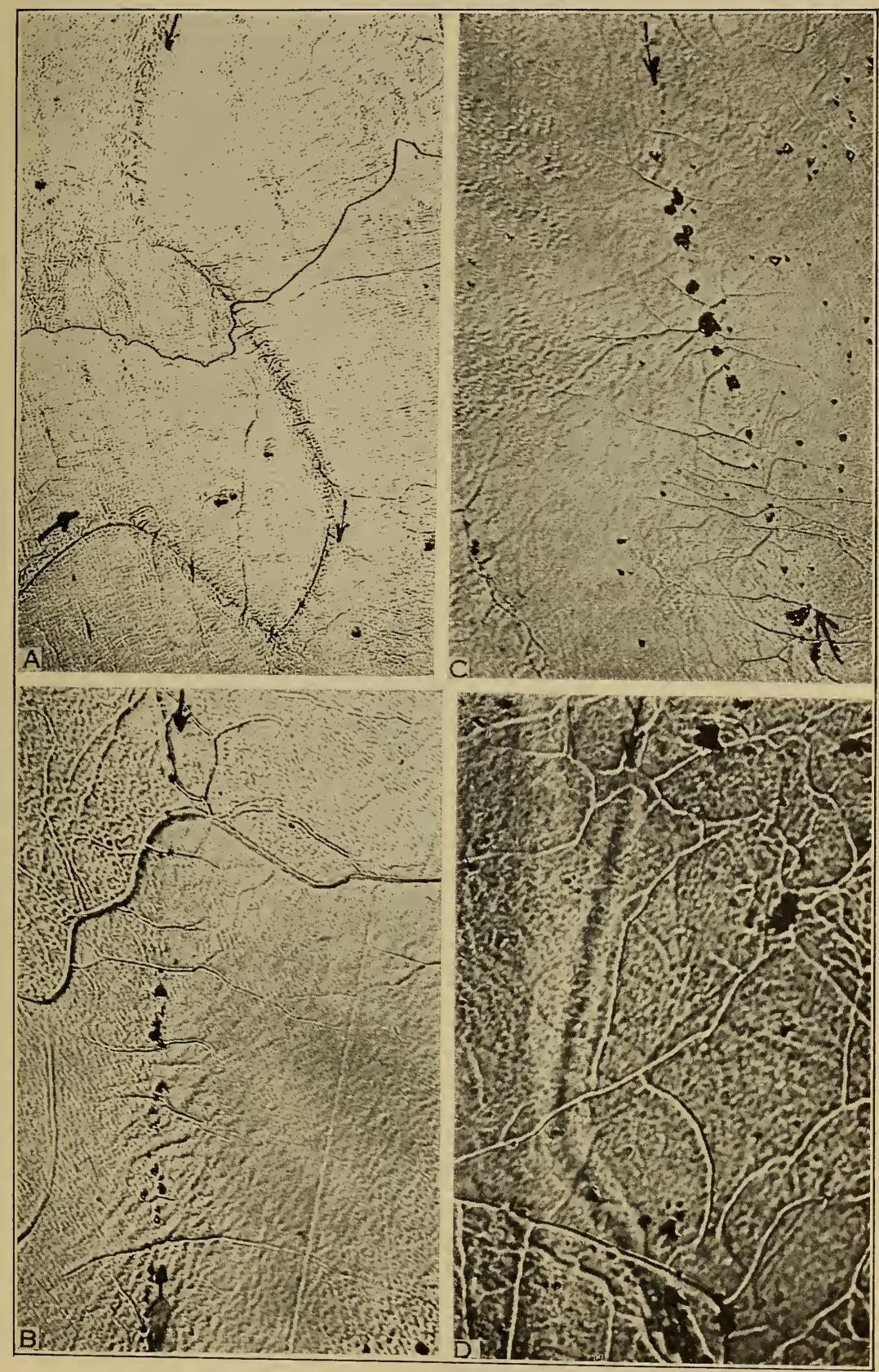

FIG. 25.-Nature of the $\delta$ network in ferrite

(a) Open-hearth iron in the cast condition showing the $\delta$ network. $\times 100$

$(b)$ and $(c)$ portions of $(a) . \times 500$. Small inclusions are distributed along the course of the $\delta$ network. Note the $a$ veining associated with these inclusions.

(d) Electrolytic iron containing aluminum (ingot 972 ), $\times 500$. The inclusions along the $\delta$ network are too small to be seen at this magnification. 


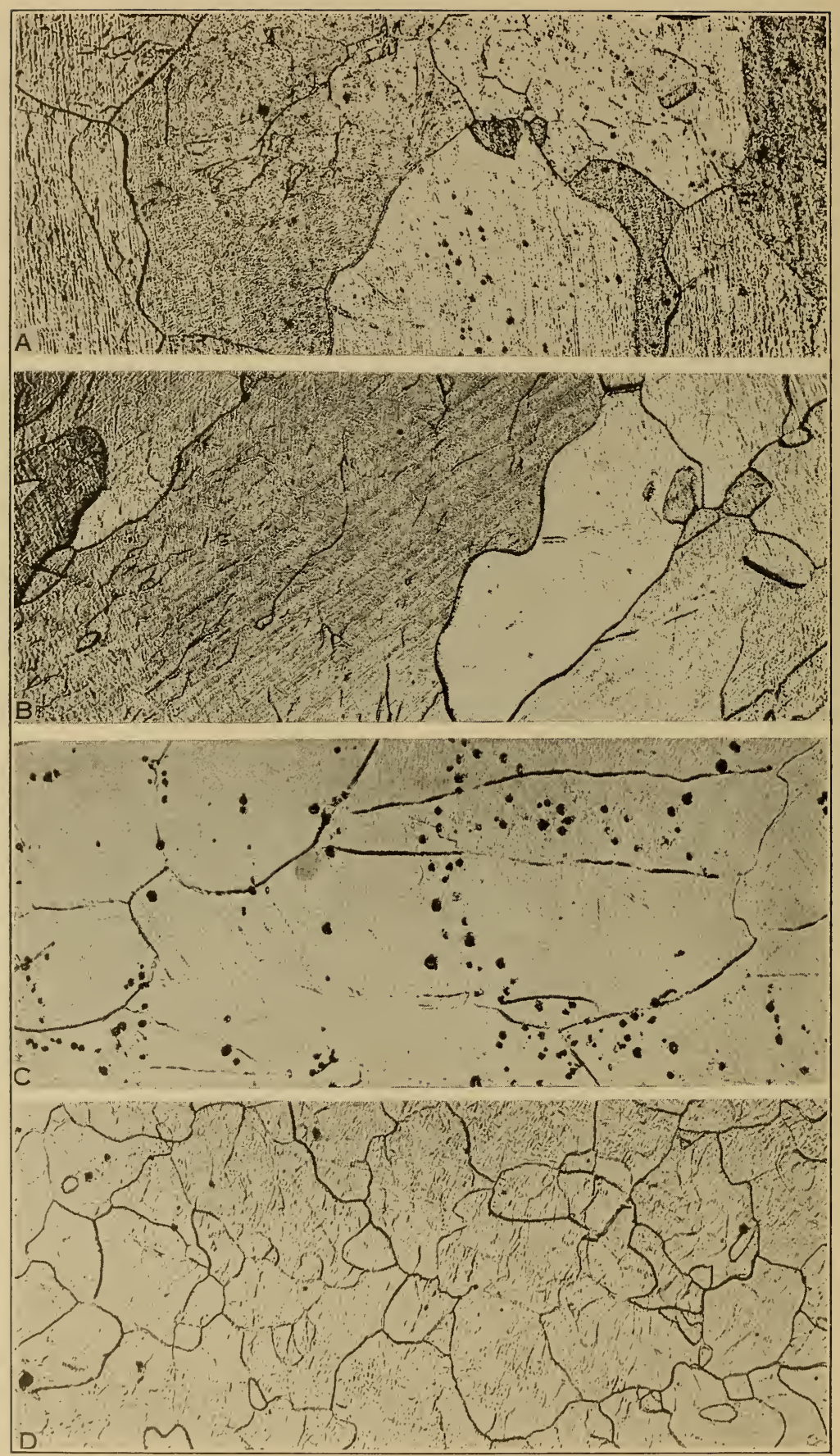

FIG. 26.-Structure of ferrite forged at a temperature considerably above the

$a-\gamma$ transformation

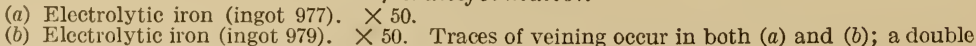
etching method was used, picric acid followed by ammonium persulphate.

(c) Electrolytic iron with a relatively high oxide content (ingot 980). $\times 100$. No unusual sructural features are present.

(d) Open-hearth iron. $\times 100$. Many of the grains show some veining. 


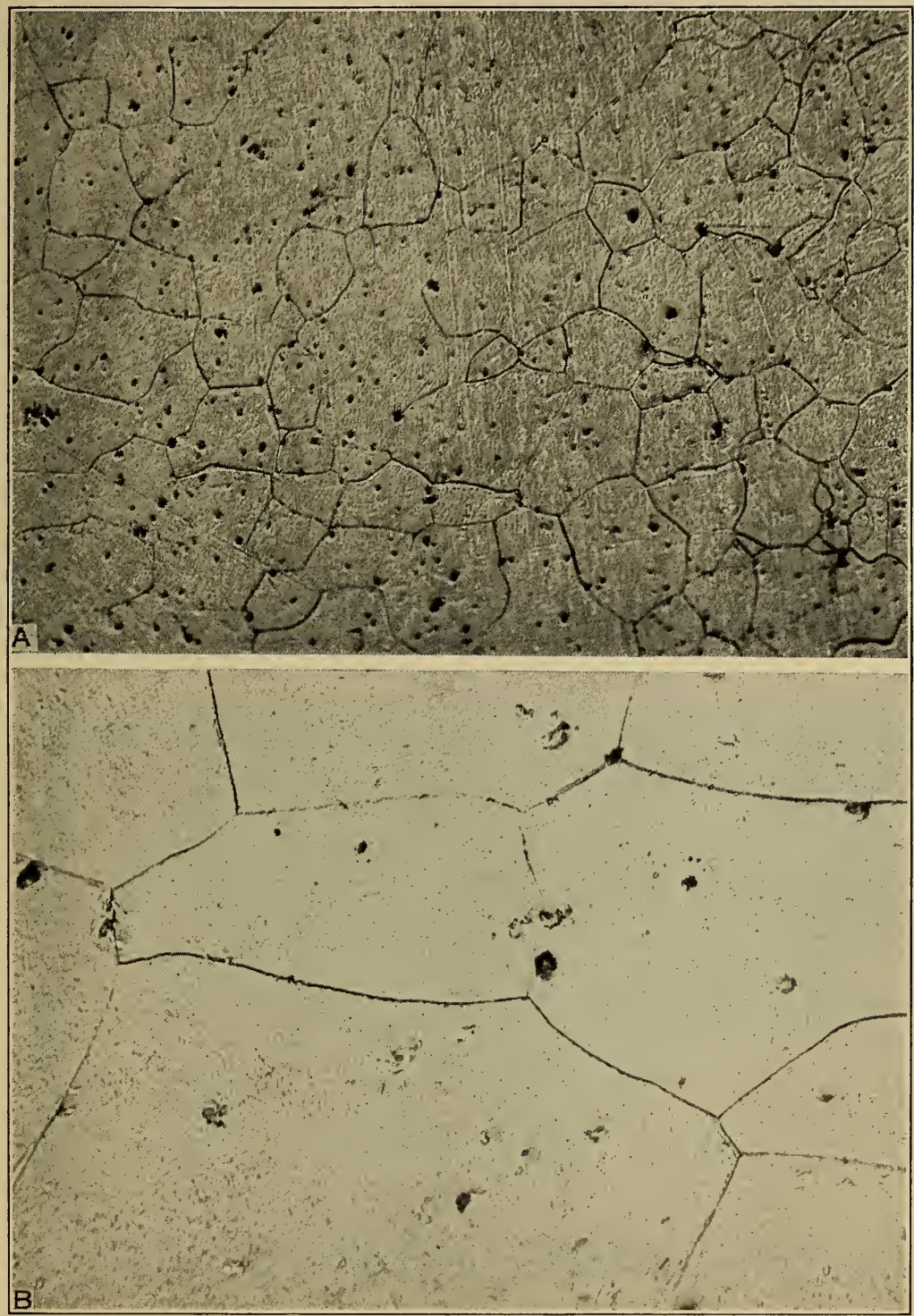

FIG. 27.-Structure of ferrite containing aluminum after being forged at a high temperature

(a) Electrolytic iron containing aluminum forged at a temperature considerably above the $a-\gamma$ transformation (ingot 972 ). $\times 100$.

(b) Same as $(a) . \times 100$.

The addition of aluminum to ferrite does not cause the formation of veining when the material is forged at a high temperature. 

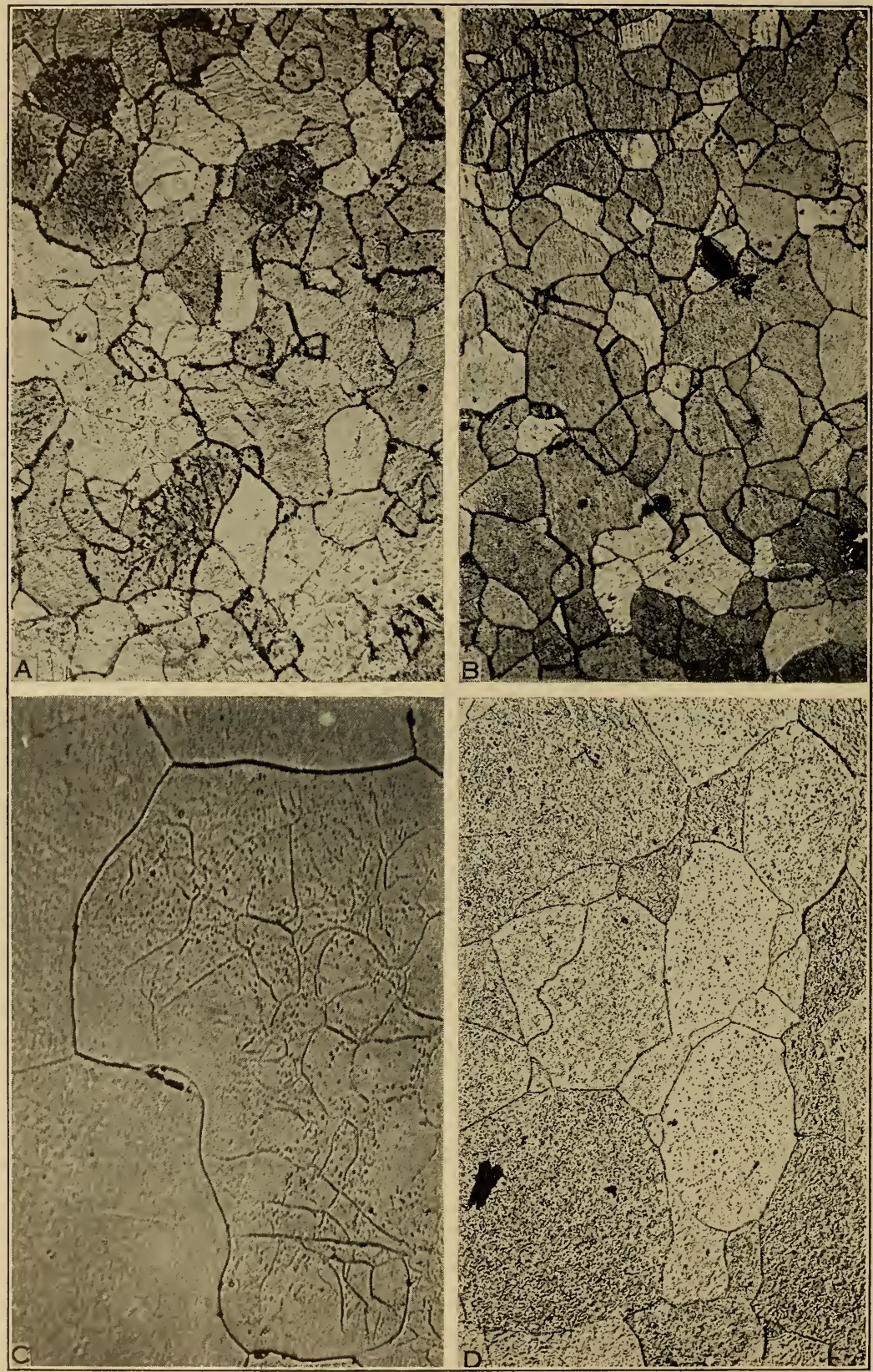

FIG. 28.-The structure of ferrite containing manganese and silicon after being forged at a high temperature

(a) Electrolytic iron containing manganese (ingot 983), $\times 100$.

(b) Open-hearth iron containing manganese (ingot 984). $\times 100$.

(c) Same as $(a), \times 500$. A few grains showed veining of the character shown.

(d) Electrolytic iron containing silicon (ingot 981) after being forged. $\times 20$.

The manganese ferrite after forging showed some slight traces of veining, but no other unusual features. The silicon showed no unusual features whatever. 
of "slip" and in each individual grain consisted essentially of more or less parallel markings rather widely separated from one another.

As stated above, open-hearth iron could be successfully forged only with great care in this temperature range although at the higher temperature no difficulty whatever was experienced. The examination of the structure of fragments of the "hot-short" material failed to show any definite relationship between the "shattering" cracks and the $\alpha$ grain boundaries or the veining within the $\alpha$ grains. Such evidence as was obtained indicated that the cracks followed the $\gamma-\delta$ network, which was rendered visible by the localized inclusions, although it can not be concluded from the results available that the inclusions are wholly responsible for the characteristic behavior of the iron in the "red-short" range. As shown in Figure 33, the cracks often break sharply across the $\alpha$ grains instead of following along their boundaries. Sauveur ${ }^{14}$ has shown by means of twisting tests of differentially heated bars, that iron is relatively weak and "tender" during the $\alpha-\gamma$ transformation as compared with the same metal when either above or below the transformation temperature. To this characteristic property of the metal he ascribes the red-shortness of iron.

Some specimens of iron were forged at a temperature considerably below the $\mathrm{A} 3$ transformation, the finishing temperature being approximately $600^{\circ} \mathrm{C}$. In addition to the relatively coarse parallel veining in the grains which were found in iron forged at a temperature close to the transformation, this material showed definite evidence of cold working in the elongated shape of the grain and the occurrence of the fine deformation or "slip" lines usually associated with cold-worked metals (fig. 34).

\section{TENSION TESTS OF OPEN-HEARTH IRON AT ELEVATED TEMPERATURES}

The results of the forging experiments showed definitely that at least one form of veining of the $\alpha$ grains is related to the deformation of the metal, particularly when carried out within a certain temperature interval. It is impossible, of course, to carry out forging at any fixed temperature since the temperature of the small bar drops rapidly as it is being forged and also it may vary somewhat in different parts of the bar during the forging operation. In order to get the deformation of the material to take place within as small a temperature interval as possible, tension tests of one-fourth-inch rods of open-hearth iron heated in an electrical resistance tubular furnace to different constant temperatures were carried out. Chappell in his study of the recrystallization of deformed iron ${ }^{15}$ obtained some

14 A. Sauveur, What is steel? Henry M. Howe memorial lecture, Trans. Am. Inst. Min. Met. Engrs., 70, p. $3 ; 1925$.

1s C. Chappell, The recrystallization of deformed iron, J. Iron and Steel Inst., 89, p. $460 ; 1914$. 
evidence in the examination of the microstructure of iron tested in tension at 750 to $870^{\circ} \mathrm{C}$., that the internal structure of the ferrite grains contained a permanent record of the deformation to which it had been subjected, the appearance of the structure being similar in many respects to that of veining.

Before testing, the rods were marked at 1 -inch intervals along the whole length and the hot junction of a chromel-alumel thermocouple was bound tightly to the rod at a point which would be at the center of the heated zone of the furnace during testing. The temperature was maintained constant at approximately the desired point for about one-half hour before testing in most cases in order to establish equilibrium, except that at the higher temperatures this period was reduced to 10 minutes in order to prevent too much oxidation.

In their initial condition, the one-fourth inch rods had a relatively fine-grain structure and showed no unusual features. The rods were annealed at a temperature of approximately $1,200^{\circ} \mathrm{C}$. after first being packed in sand containing a small amount of powdered charcoal in a container made of iron pipe capped at each end. The container with the rods inside was maintained at the temperature desired for one hour and then allowed to cool in the furnace. The surface of the rods became slightly carburized during this treatment and the ferrite grains showed pronounced veining (fig. 35).

The principal object of the tests was to obtain iron specimens which had been deformed by tension at a known temperature for the determination of the effect upon the structure and not the precise measurement of the tensile properties at any given temperature, although these properties were determined with a degree of accuracy sufficient to show clearly the relative properties at different temperatures, and are shown graphically in Figure 36. In all cases where the temperature was $400^{\circ} \mathrm{C}$. or higher, the fracture occurred very close to the center of the rod. At room temperature, however, the fracture occurred near the grips, as is usual when a sample of uniform cross section along its entire length is tested. In a test made at $300^{\circ} \mathrm{C}$. the fracture occurred outside of the heated zone, thus indicating that at this temperature iron is at least as strong as it is at room temperature. The dotted portions of the curves have been drawn in agreement with data available in the literature and with values obtained at the bureau in other investigations. ${ }^{16}$ The change in elongation is of particular interest and the curves, together with the appearance of the fractured specimens (fig. 37), indicate clearly the temperature interval in which red-shortness of open-hearth iron is likely to occur.

The structure of the bars tested at different temperatures, as shown by specimens taken close to the fractured end, and, hence,

${ }^{16} \mathrm{H}$. J. French, Effect of temperature, deformation, and rate of loading on the tensile properties of lowcarbon steel below the thermal critical range, B. S. Tech. Paper No. 219; 1922. 


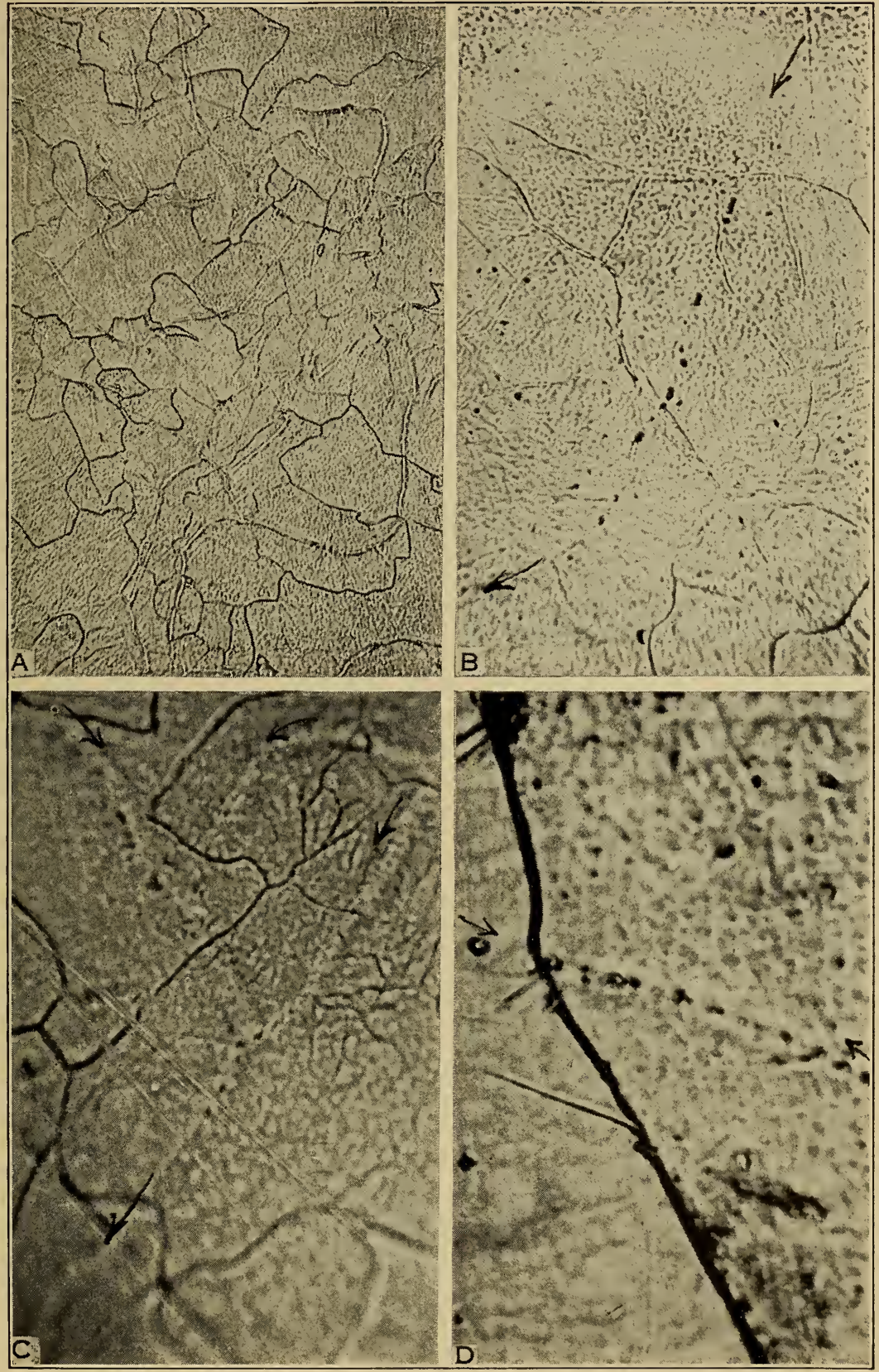

FIG. 29.- Nature of the $\gamma$ network occurring in open-hearth iron after being forged at a high temperature

(a) $\gamma$ network in ferrite after being forged at a high temperature (ingot 978). $\times 100$.

(b) Same. $\times 1,000$

(c) Same. $\times 1,000$. Another spot.

(d) Same. $\times 2,500$.

The $\gamma$ network in this material is associated with small inclusions which outline the course of the network to a considerable extent. 


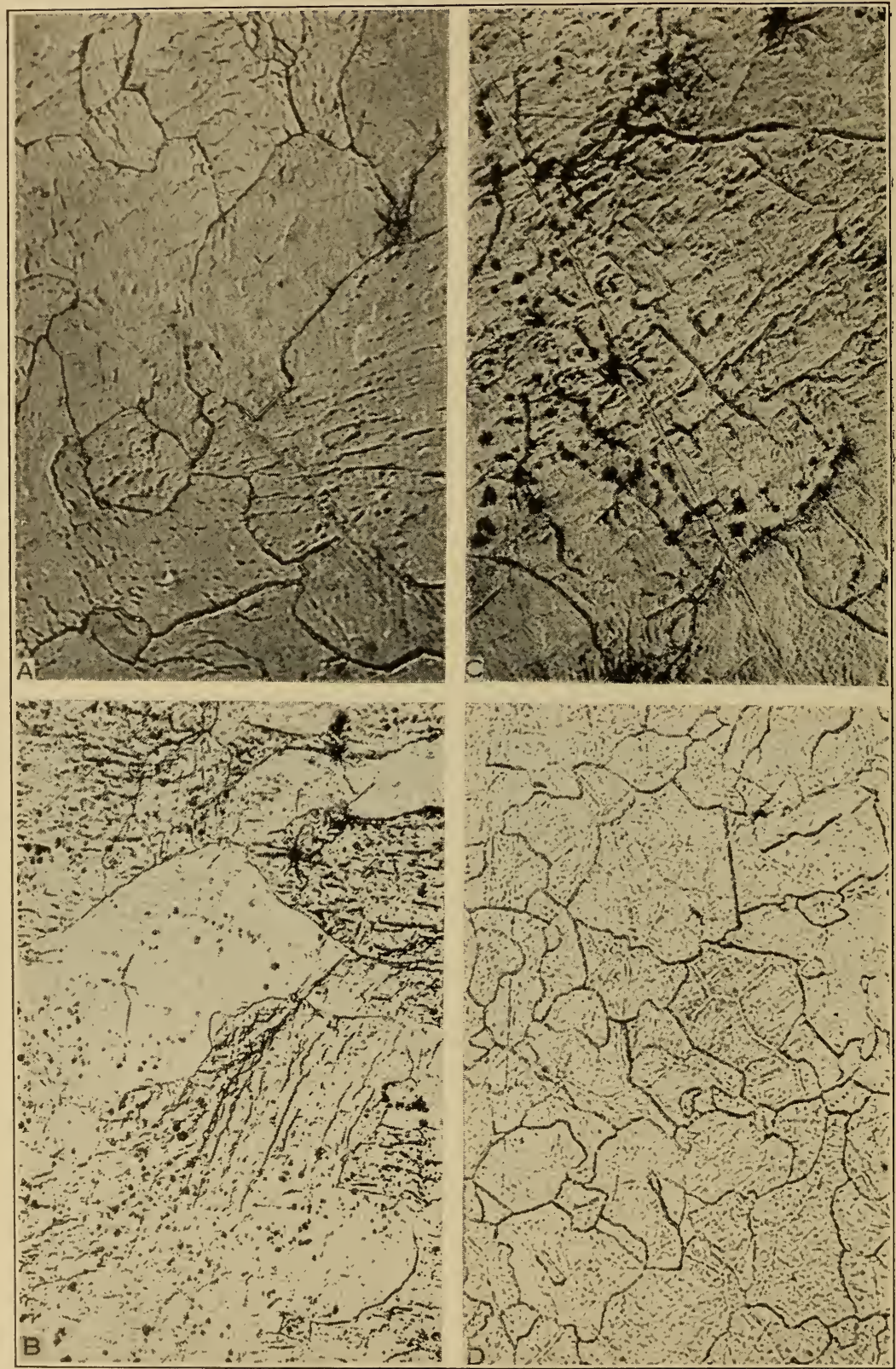

FIG. 30.-Structure of ferrite after being forged at a temperature close to that of the $\alpha-\gamma$ transformation

(a) Electrolytic iron (ingot 979), $\times 250$

(b) Electrolytic iron of high oxygen content (ingot 980$), \times 250$

(c) Same as (b), another spot. $\times 250$.

(d) Open-hearth iron (ingot 978$). \times 100$

Veining is very pronounced in the specimens of electrolytic iron; in the open-hearth iron this feature is not so plain, presumably because of the much lighter pressure which was necessary in forging this material. 


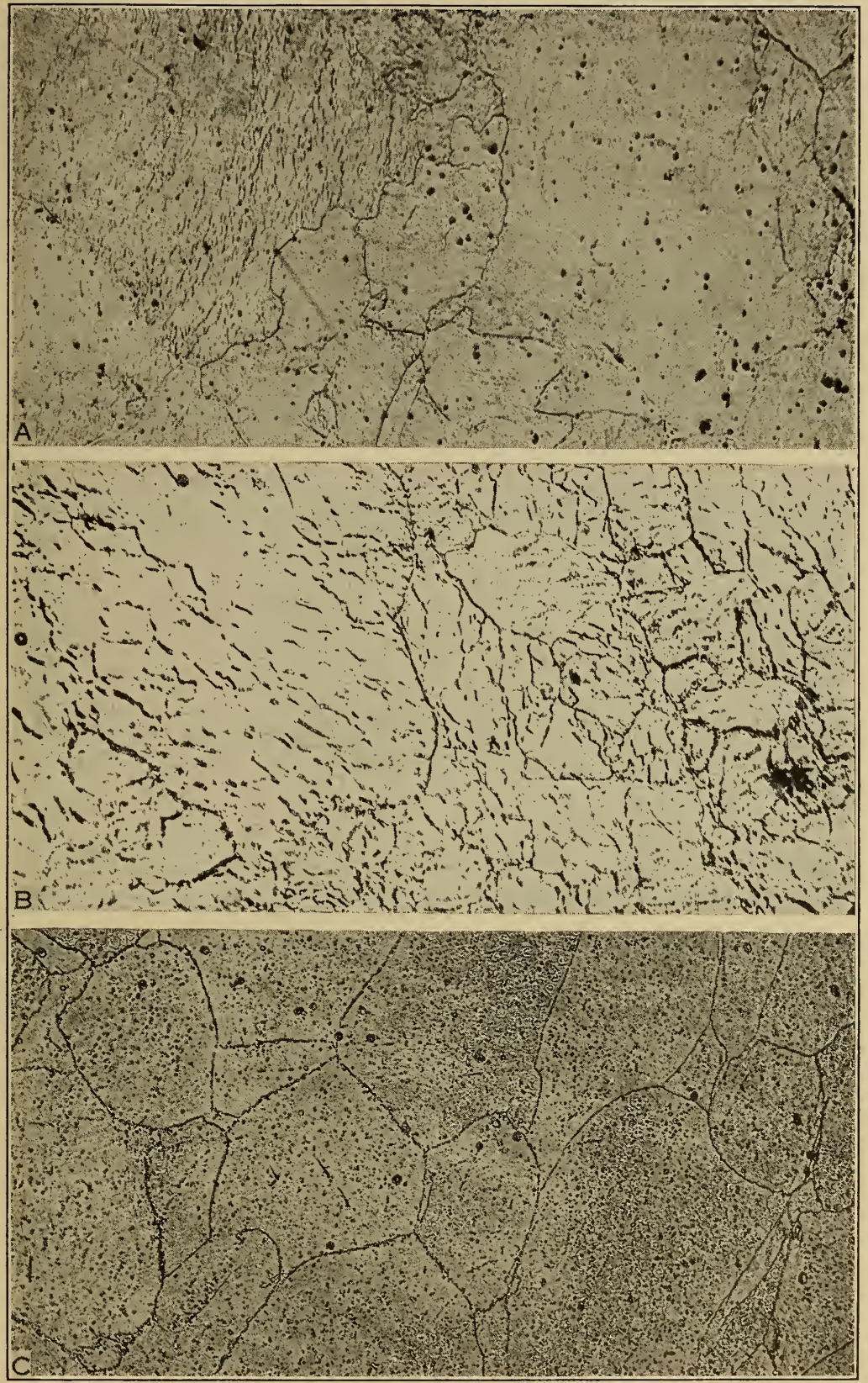

FIG. 31.-Structure of ferrite containing aluminum and silicon after being forged as in Figure 30

(a) Electrolytic iron containing aluminum (ingot 972), $\times 100$.

(b) Same. $\times 250$.

(c) Electrolytic iron containing silicon (ingot 981) forged as in Figure $30 . \times 20$.

No unusual structural features occur. 


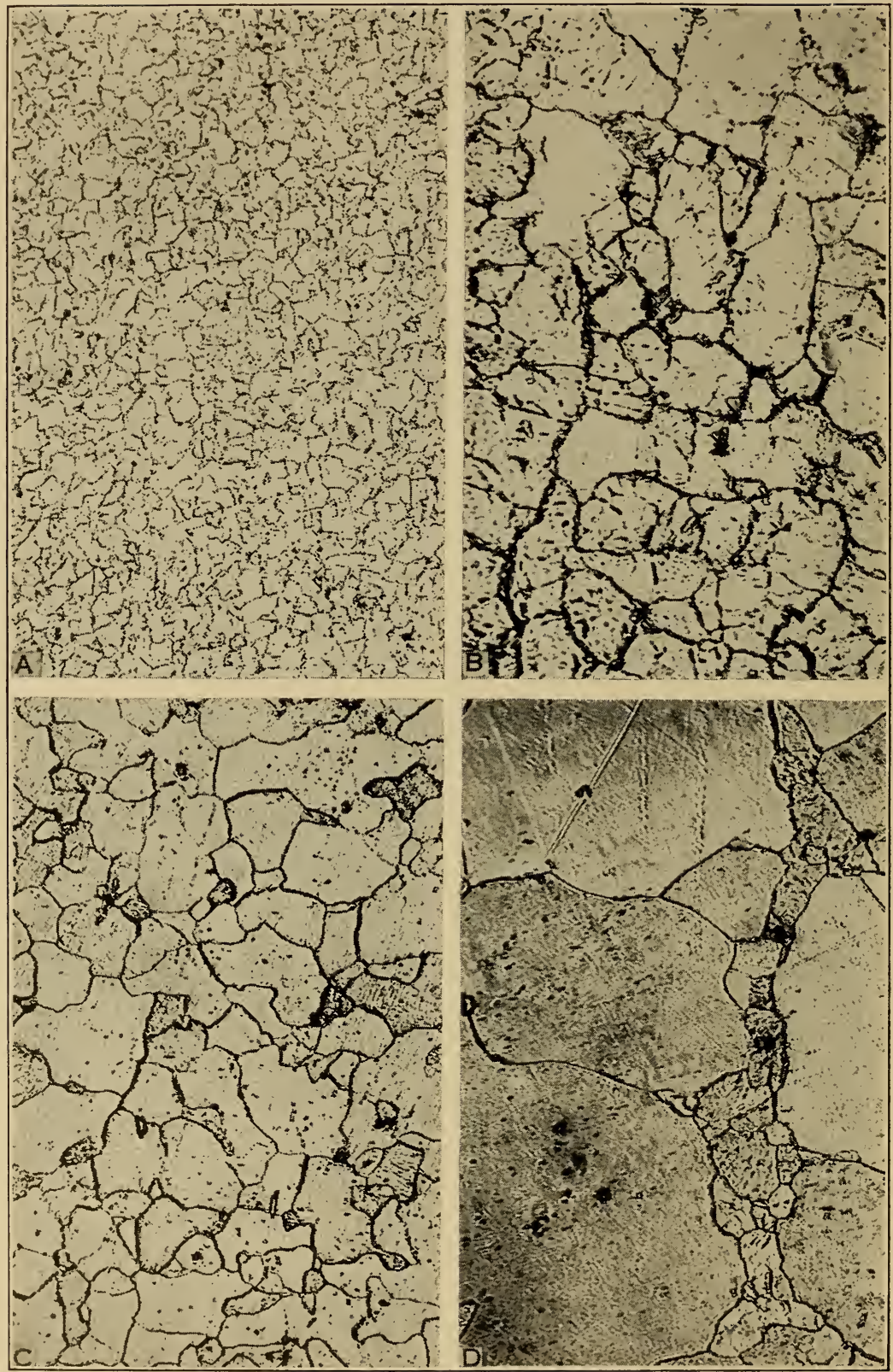

FIG. 32.-Structure of ferrite containing manganese after being forged as in Figure 29

(a) Electrolytic iron containing manganese (ingot 983). $\times 100$

(b) Same as $(a) . \times 500$.

(c) Open-hearth iron containing manganese (ingot 984). $\times 100$.

(d) Same as $(c) . \times 500$.

Only slight traces of veining were found in these materials after forging. 


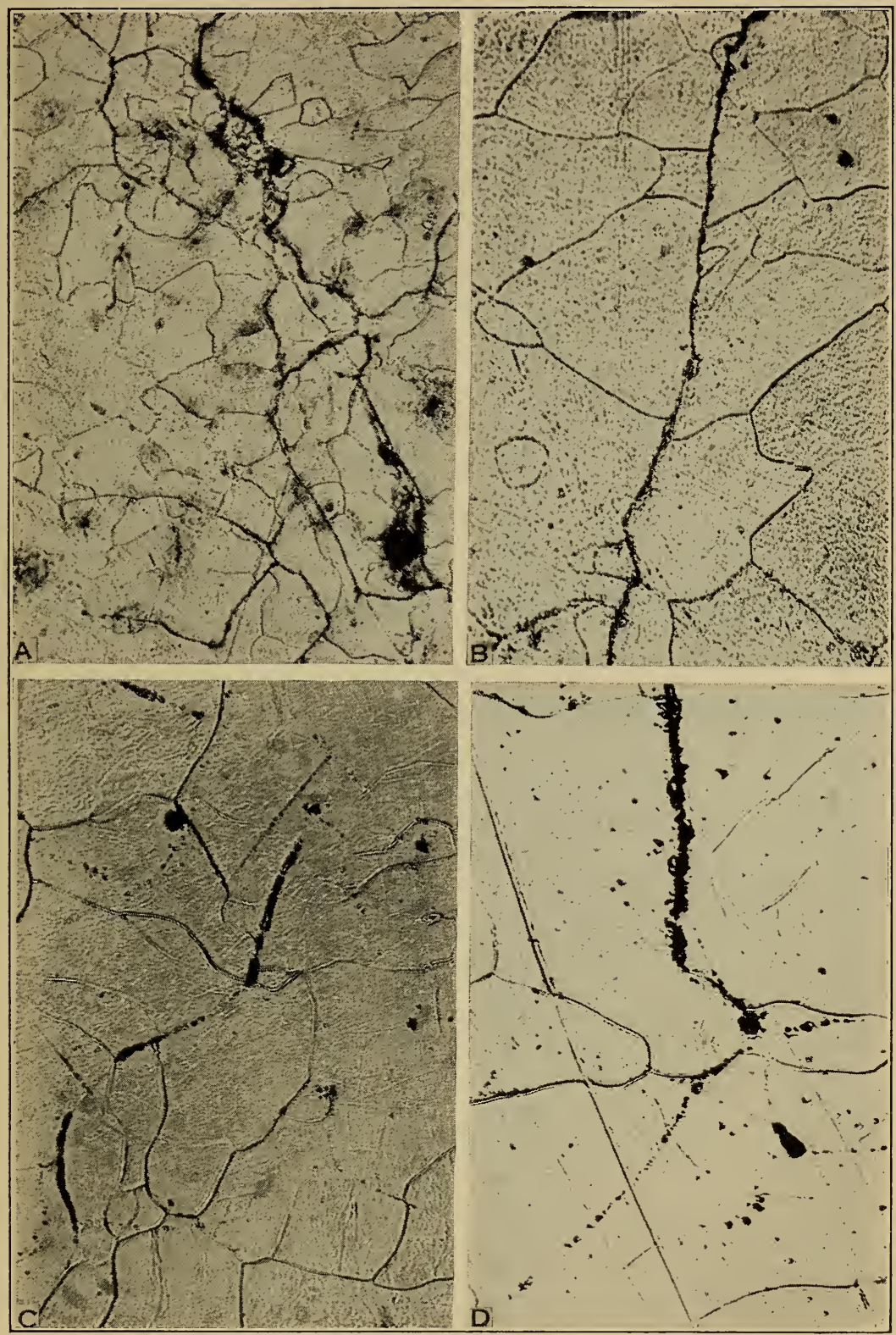

FIG. 33.-Structure of open-hearth iron which was "red-short" when forged (ingot 973)

(a) Open-hearth iron showing the cracks which formed when the iron was forged in the ordinary manner. $\times 100$

(b) Same. $\times 250$.

$(c)$ and $(d)$. Same. $\times 500$.

The latter micrographs show cracks which are just developing. The cracks, as a rule, do not coincide with the $\alpha$-grain boundaries. Their course appears to be determined more by the $\gamma$ network. 


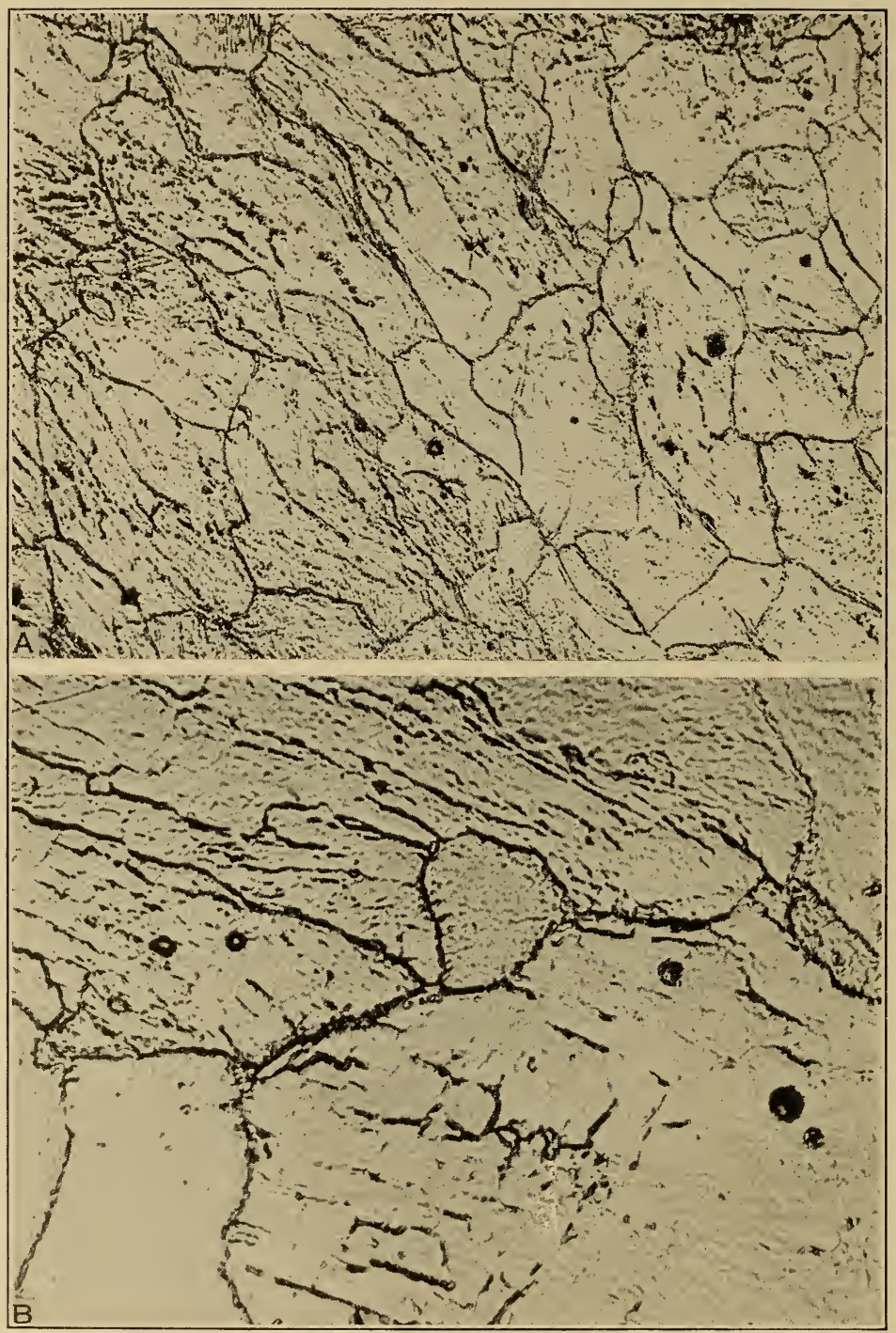

FIG. 34.-Structure of electrolytic iron forged at a temperature below that of the $a-\gamma$ transformation (ingot 966)

(a) $\times 100$.

(b) $\times 500$.

The veining is very pronounced in most of the grains and as a result of the "cold working" a parallelism in the veining has been produced. 


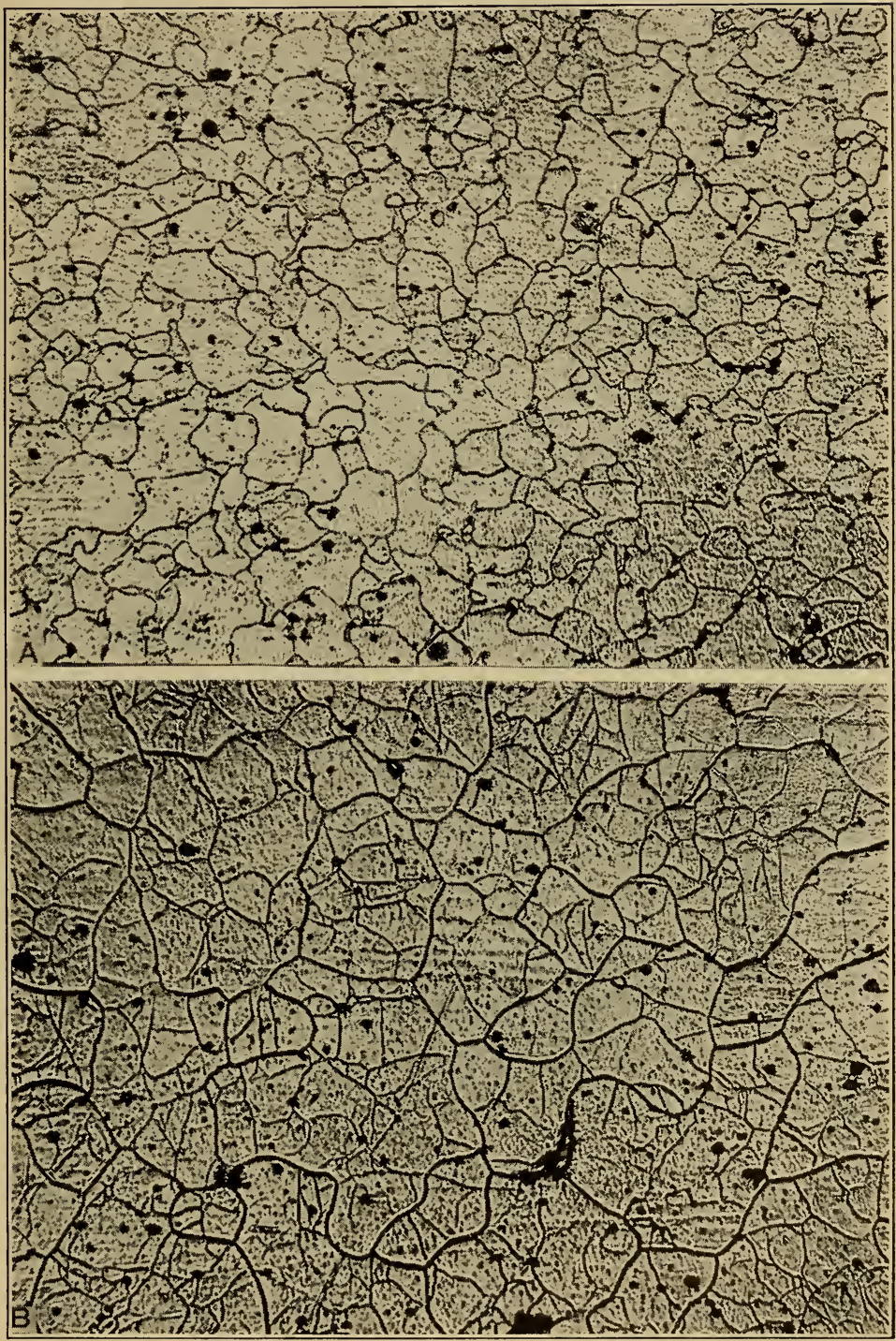

FIG. 35.-Structure of the open-hearth iron used in high-temperature tension tests. $\times 100$

(a) Hot-rolled rod one-fourth inch diameter. Note the absence of any unusual features.

(b) Same as (a) after being heated at $1,200^{\circ} \mathrm{C}$. for one hour and allowed to cool with the furnace. Veining formed a prominent feature of the structure after this treatment. The high-temperature tension tests were made on material $(b)$. 
representing the most severely deformed part of the rod, is shown in Figure 38. It will be seen from these micrographs that the veining initially present in the ferrite grains (fig. 35 ) persisted in the grains after being elongated by tension up to approximately $600^{\circ} \mathrm{C}$. When a temperature of $700^{\circ} \mathrm{C}$. was reached, however, the iron had recrystallized and in the new grains thus formed veining did not appear, at

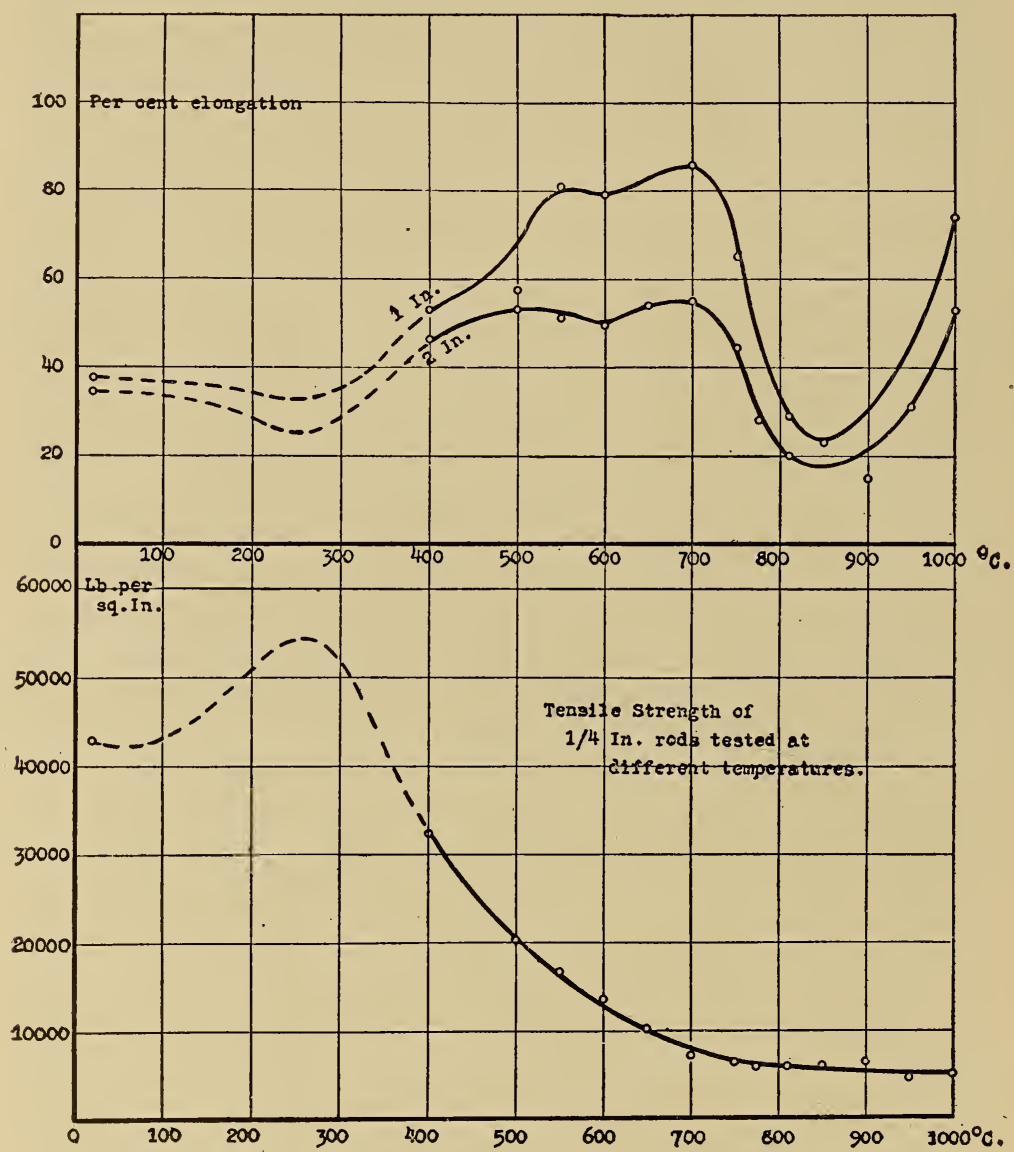

FIG. 36.-Results of tension tests of open-hearth iron, one-fourth inch rod, at elevated temperatures

The dashed portion of the curves represent values obtained from other sources.

least when the specimen was etched in the same manner as served to reveal the veining very readily in the material in its initial condition. In the material which was stressed and broken at $850^{\circ} \mathrm{C}$. veining was again apparent in most of the grains in the form of a fine interlacing network, although in the bars broken at $900^{\circ}$ this feature was not evident in the structure. 
These observations, therefore, support the conclusion that the condition resulting from the stressing in tension of ferrite which is at a temperature close to that of the $\alpha-\gamma$ transformation is favorable to the formation of veining within the grains of the metal.

\section{MISCELLANEOUS FACTORS AFFECTING VEINING}

\section{LONG-CONTINUED HEATING IN HYDROGEN}

Specimens of both electrolytic and open-hearth iron which had been annealed at $1,300^{\circ} \mathrm{C}$. after being cast (fig. 39) were heated in

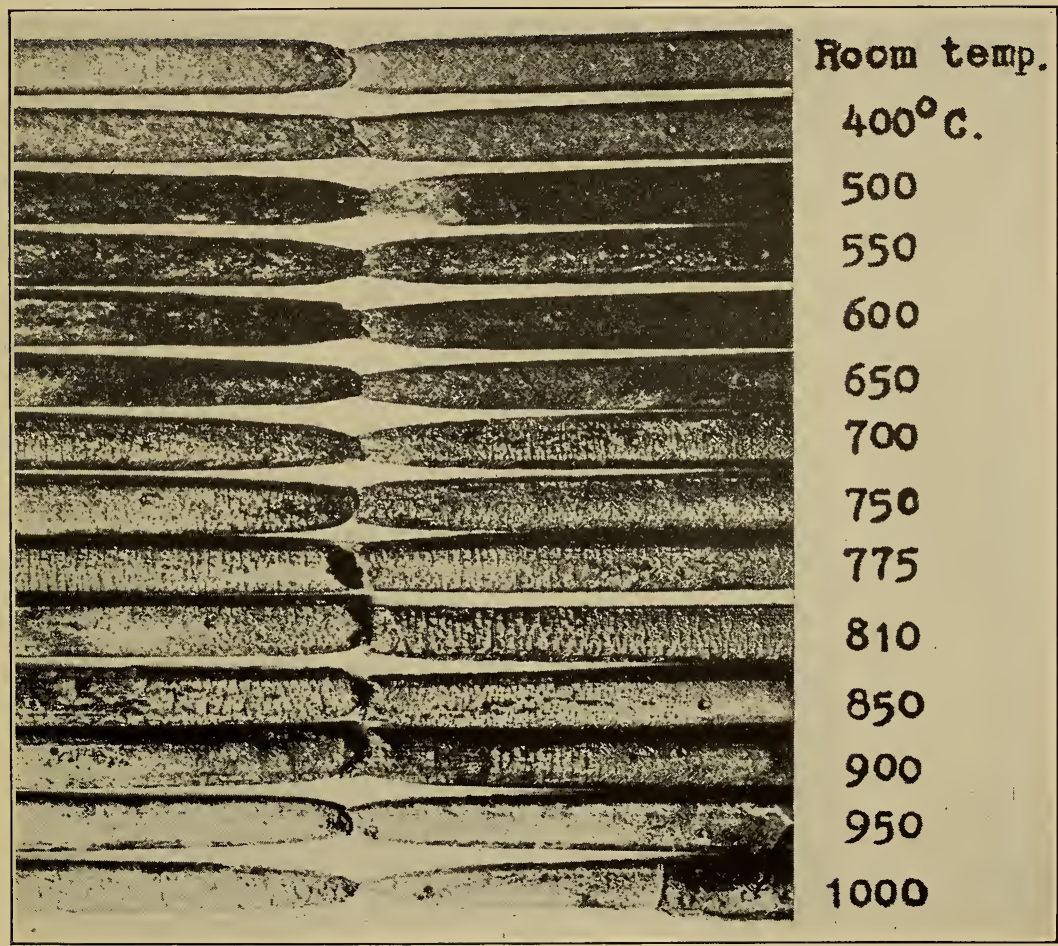

Fig. 37.-Appearance of open-hearth specimens broken in tension at different temperatures

Note the appearance of the specimens corresponding to the temperature range (fig. 36) in which the elongation was low.

hydrogen for approximately 100 hours, the temperature being maintained between 750 and $800^{\circ} \mathrm{C}$. This is considerably below the temperature of the $\alpha-\gamma$ transformation $909^{\circ} \mathrm{C}$. (Ac3) or $898^{\circ} \mathrm{C}$. (Ar3) according to Burgess and Crowe, ${ }^{17}$ but close to that of the A2 change, $768^{\circ} \mathrm{C}$. A slow stream of dry commercial hydrogen was passed through the furnace throughout the entire time the specimens were in it. A pronounced "heat-etching" effect, which is possibly the result of slight volatilization, was produced on the polished surface which very 


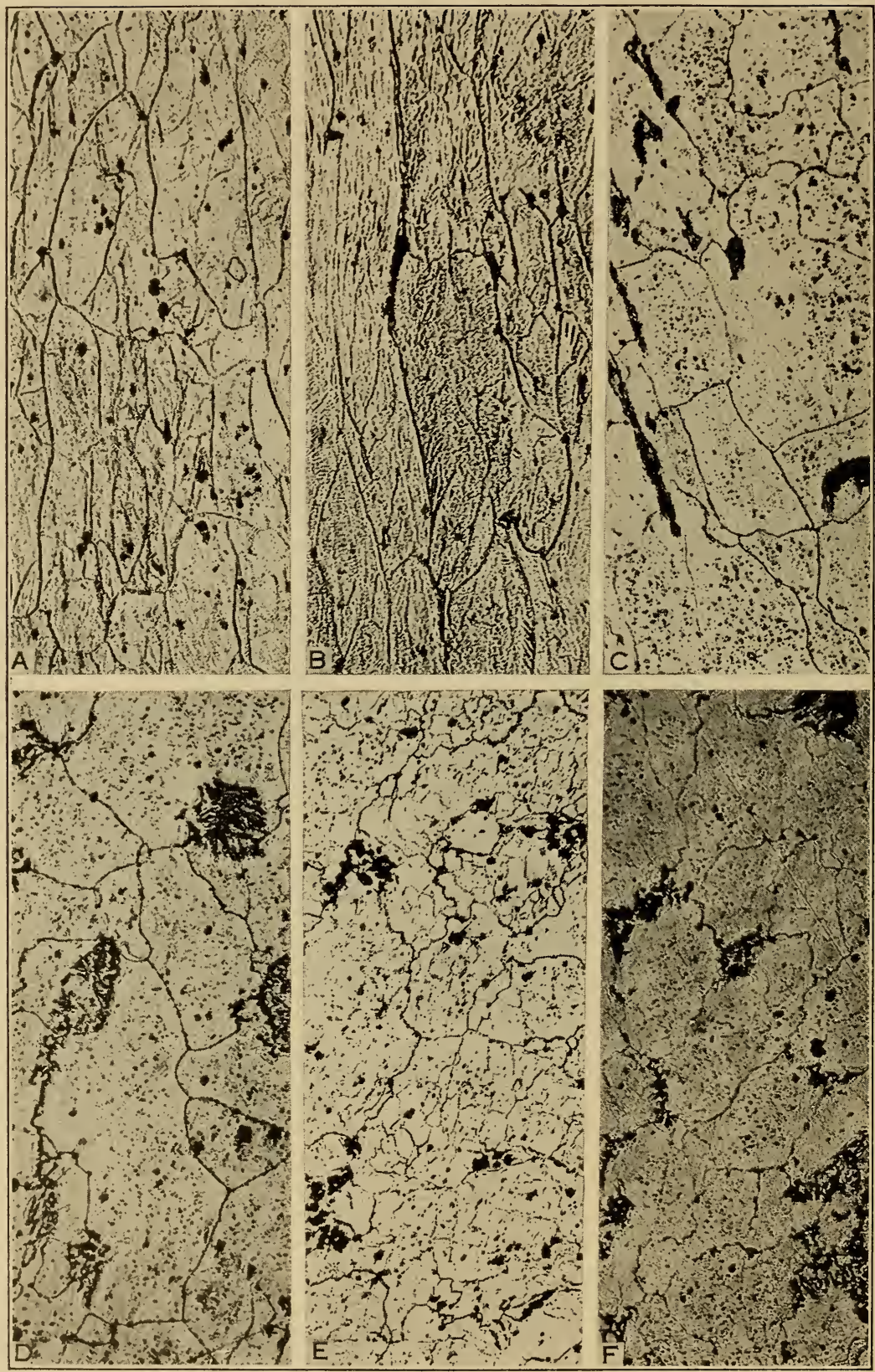

FIG. 38.-Structure of open-hearth iron specimens broken by stressing in tension at elevated temperatures. $\times 100$

All the specimens were etched for the same length of time.

(a) Room temperature.

(b) $500^{\circ} \mathrm{C}$

(c) $700^{\circ} \mathrm{C}$

(d) $810^{\circ} \mathrm{C}$

(e) $850^{\circ} \mathrm{C}$

Note the disappearance of the veining initially present and its reappearance in the material stressed at $850^{\circ} \mathrm{C}$. 
clearly revealed the grain boundaries and relative crystalline orientation of the ferrite grains. In some cases evidence of twinned crystals, such as are usually associated with the $\gamma$ form of ferrite, were revealed, although the temperature used was considerably below that of the $\alpha-\gamma$ change.

The appearance of the heat-etched surface is shown in Figures 40 and 41 . On the whole, the results appear to have only little bearing on the subject of the unusual structural features of ferrite. There will be noticed, however, in some of the crystals in which the parallel markings are strongly developed, other markings apparently corresponding to veining (fig. 40, c and d), along which the heat-etching effect was somewhat more pronounced than elsewhere. In those cases in which these markings cross the fine parallel strias at a large angle, for example, 90 degrees or somewhat less, only a slight change can be detected in the general direction of the parallel strias, whereas when the veining(?) roughly parallels the strias (fig. 40, d) a much more marked disturbance in the general arrangement of the strias exists.

An examination of the structure of the metal directly beneath the heat-etched surface (fig. 42) showed that during the long period of heating in hydrogen, veining was eliminated to a considerable extent from surface crystals. Throughout the body of the specimen, however, veining still persisted as a prominent feature of the structure.

\section{INCLUSIONS}

The conclusion expressed by some writers ${ }^{18}$ concerning the close relation between the occurrence of inclusions and the formation and distribution of veining in the $\alpha$ ferrite grains has not been confirmed, in general, by the observations made in the course of this investigation. In a few cases, such as in low temperature forging of specimens in which an internal crack developed or when relatively large oxide inclusions existed in the metal forged at a higher temperature, some evidence was obtained indicating that the amount and distribution of the veining had been influenced. This is shown in Figure 43. The higher stress existing around the end of the crack and the large oxide inclusion evidently resulted in the more pronounced veining in these portions of the specimen.

In a few cases in which open-hearth iron of rather high oxide content was used, the oxide globules appeared to act as centers from which veins radiated as is shown in Figure 43. As a general rule, however, no close relationship between veining and the inclusions present in the iron was found in the course of the investigation. 


\section{EFFECT OF $\alpha$ VEINING ON MECHANICAL PROPERTIES}

When a specimen of open-hearth iron showing $\alpha$ veining in its microstructure was compressed at room temperature by means of the trip hammer, slip bands were produced on a previously polished and etched surface which was at right angles to the direction at which the load was applied. The result obtained suggested that "slip" occurs first in those grains which are free from veining (fig. 44). It might be concluded, therefore, that the presence of veining in ferrite should have a slight strengthening effect upon the metal. Since there may be several other factors, however, which affect the relative tendency of the different constitutent grains of any metal toward "slip," a definite conclusion in this respect is hardly warranted.

When "slip" does occur within the grains in which veining is present, its character appears not to be affected to any very appreciable extent.

In some grains the slip bands roughly parallel the prominent veining lines, but, in general, as judged by the examination of plane sections only, there appears to be no evident relationship between the veining pattern and the resulting slip bands (fig. 44). The fast that the general course of the individual slip bands is apparently not changed in the least in any of the smaller subdivisions into which a grain appears to be divided by the veining network clearly shows that the crystalline orientation of the various parts of the grain has not been changed to any appreciable extent by the veining. In most cases the slip-band pattern shows the same regularity in grains containing veining as in those which are free from it.

The examination of the microstructure of specimens of open-hearth iron which have been broken in a notched-bar impact test indicates that the presence of veining in the grain structure of such material does not affect the characteristic behavior of iron under impact. Figure 45 shows the structure of iron which has been subjected to impact. It will be seen that the "shock lines" (Neumann bands) bear no apparent relationship to the $\alpha$ veining pattern of the material.

Eldridge ${ }^{19}$ has published micrographs of wrought iron before and after the metal had been used in fatigue tests by repeated bending. In its initial state the iron showed marked veining in most of the grains and in the micrographs showing the slip lines which developed as the test progressed there is no indication of any tendency for the slip to be directed by the preexisting veining network. In order to show the possible effect of $\alpha$ veining upon the mechanical properties of iron, a few tests were made upon open-hearth iron showing prominent veining in its grain structure. These tests were made on the

${ }^{10}$ A. G. Eldridge, Photography in research, Chem. and Met. Eng., 20, p. 506; 1919. 


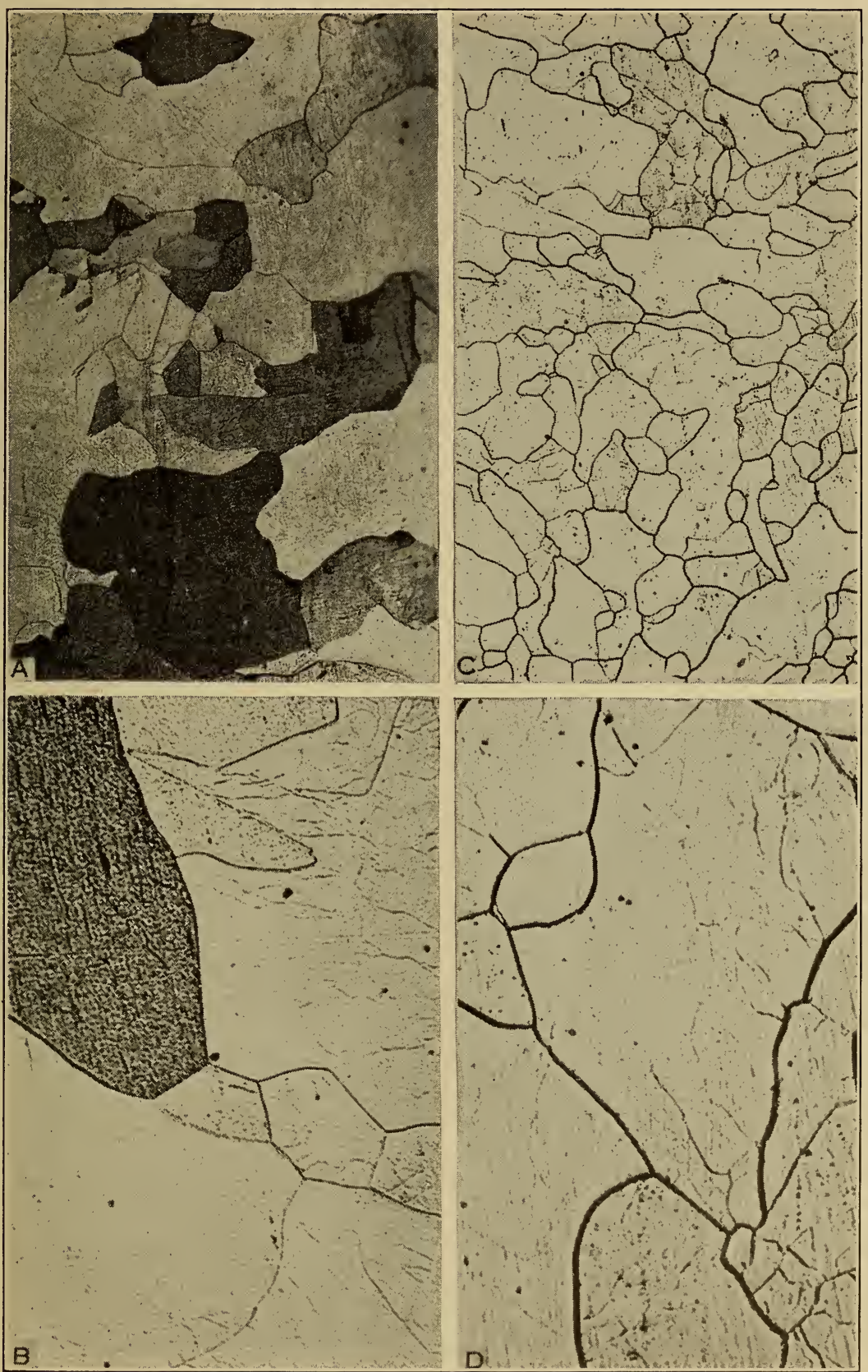

Fig. 39.-Effect of annealing at a very high temperature upon the structure of ferrite in the cast condition

(a) Electrolytic iron (ingot 973 ) heated for one hour at $1,300^{\circ} \mathrm{C} . \times 100$.

(b) Same. $\times 500$.

(c) Open-hearth iron (ingot 973) heated for one hour at $1,300^{\circ} \mathrm{C}, \quad \times 100$.

(d) Same. $\times 500$.

In both materials veining was a prominent feature of the structure of the annealed iron. This material was used for the long-continued heating in hydrogen (fig. 40). 


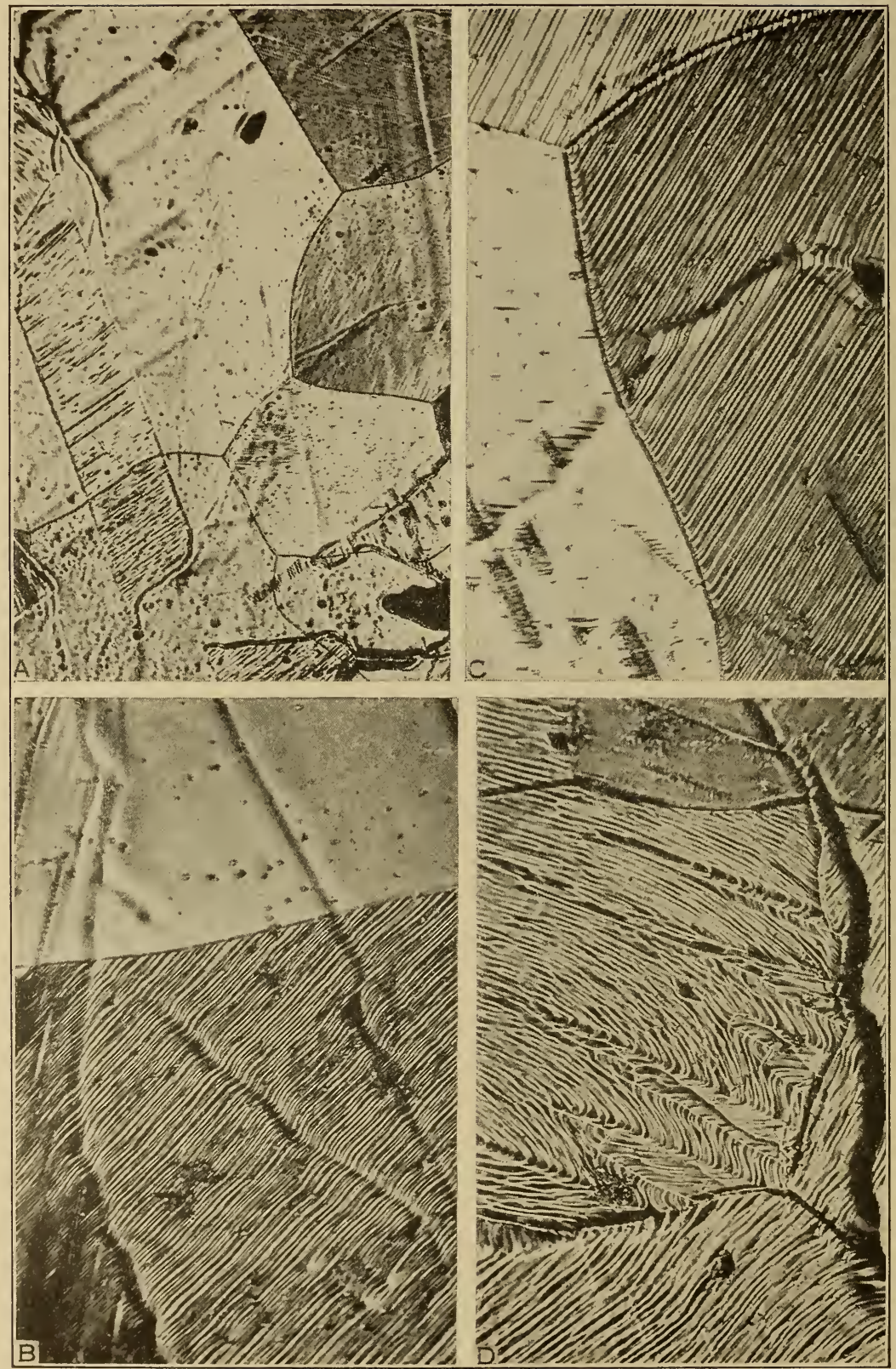

FIG. 40.-Surface appearance of polished specimens of electrolytic iron after being heated in hydrogen for about 100 hours, 750 to $800^{\circ} \mathrm{C}$.

(a) $\times 100$

(b) and $(c) \times 500$.

(d) $\times 250$

Note in $(b)$ and $(d)$ the relation of the veins to the crystalline lamellae. 

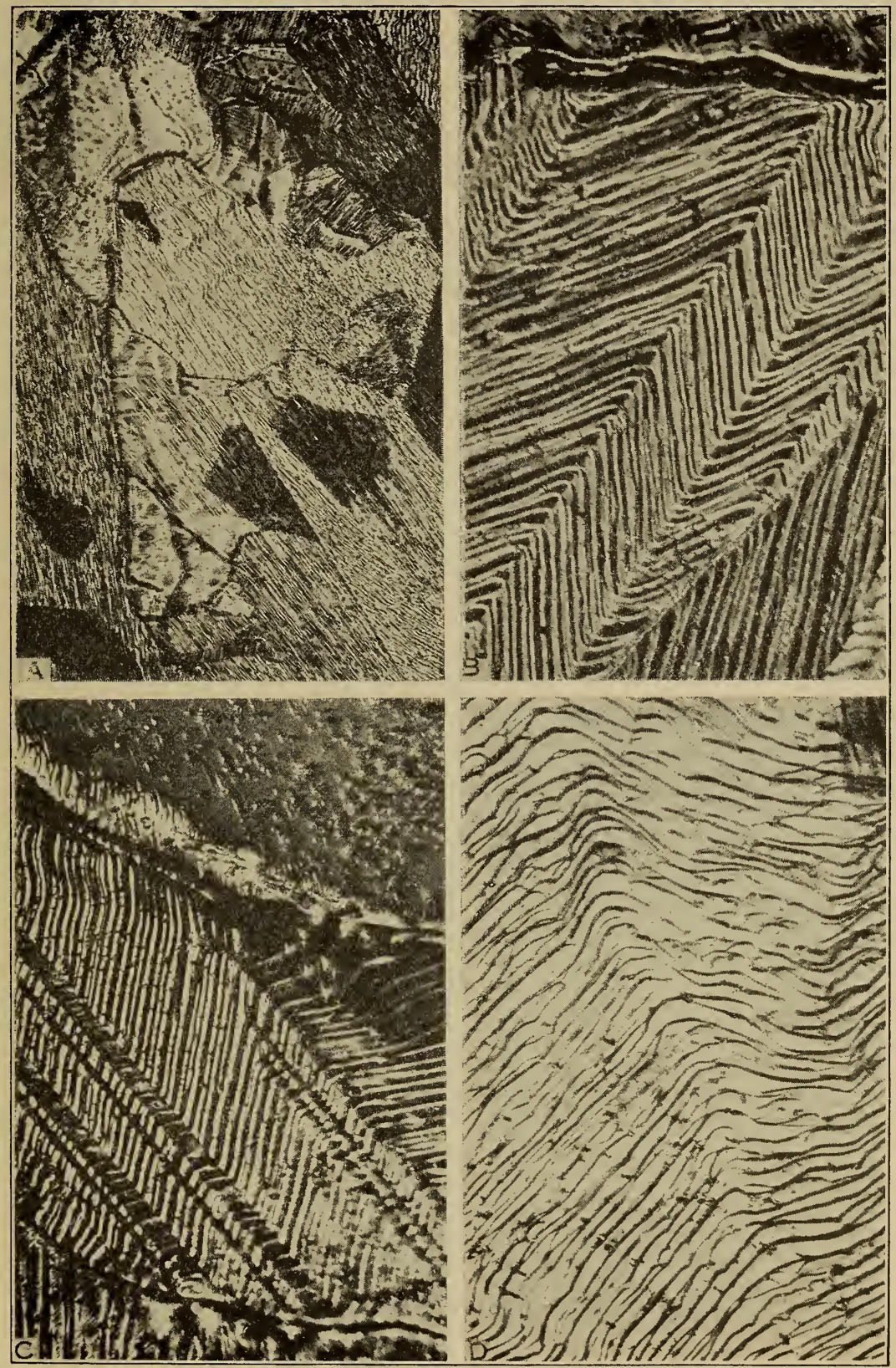

FIG. 41.-Surface appearance of polished specimens of open-hearth iron after being heated in hydrogen for about 100 hours, 750 to $800^{\circ} \mathrm{C}$.

(a) $\times 100$.

$(b),(c)$, and $(d) \times 5 c 0$.

Note the evidence of twinning, although the iron was not heated above the $\alpha-\gamma$ transformation. 


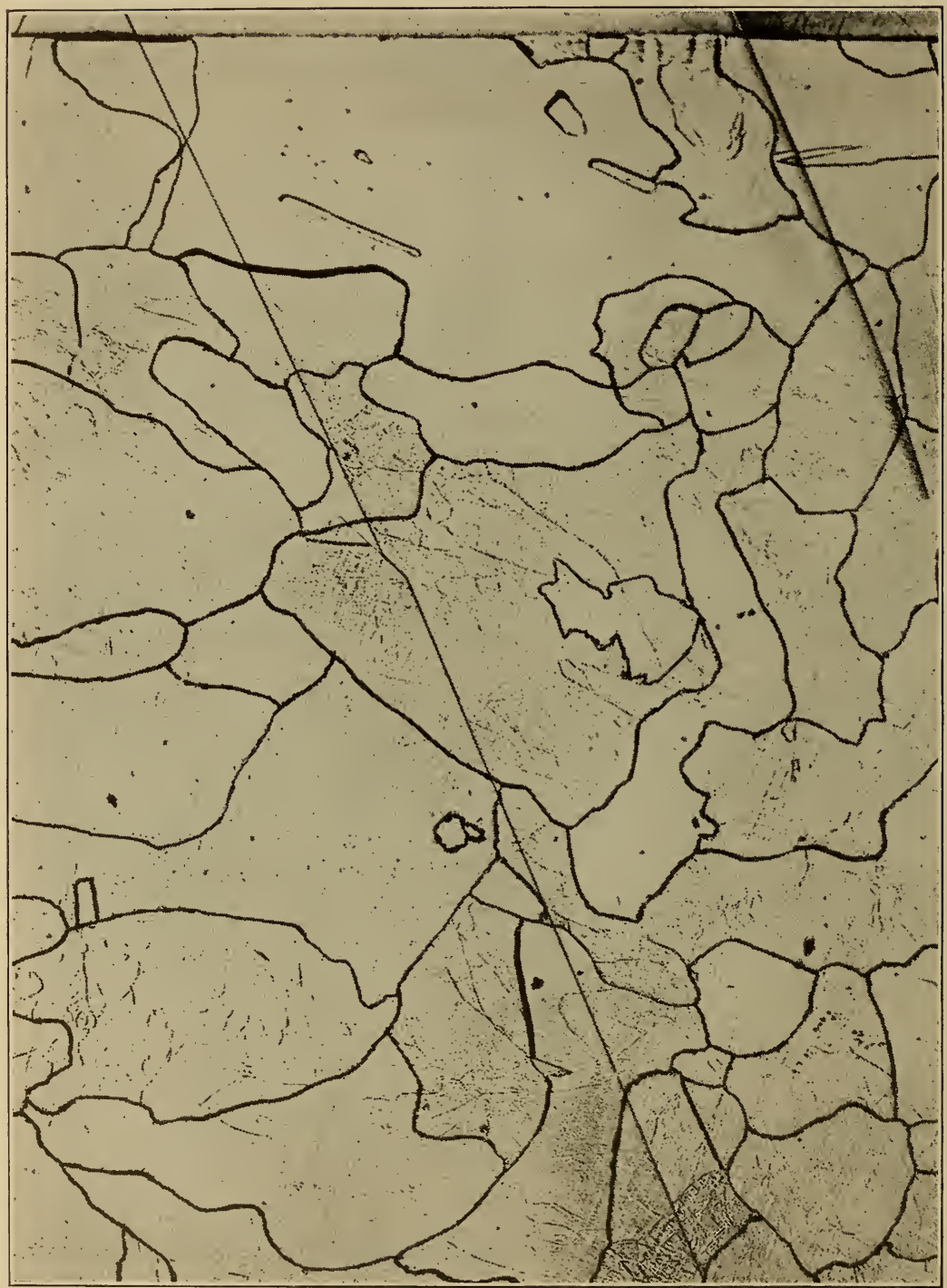

FIG. 42.-Structure of open-hearth iron after long-continued heating in hydrogen (fig. 41)

The grain boundaries in the assembled micrographs were outlined with black ink before rephotographing.

The upper edge of the figure corresponds to the heat etched polished surface shown in Figure 41 . Except in the crystals comprising the surface layer, the veining which existed initially in the iron was not affected to any extent by the heating in hydrogen. 

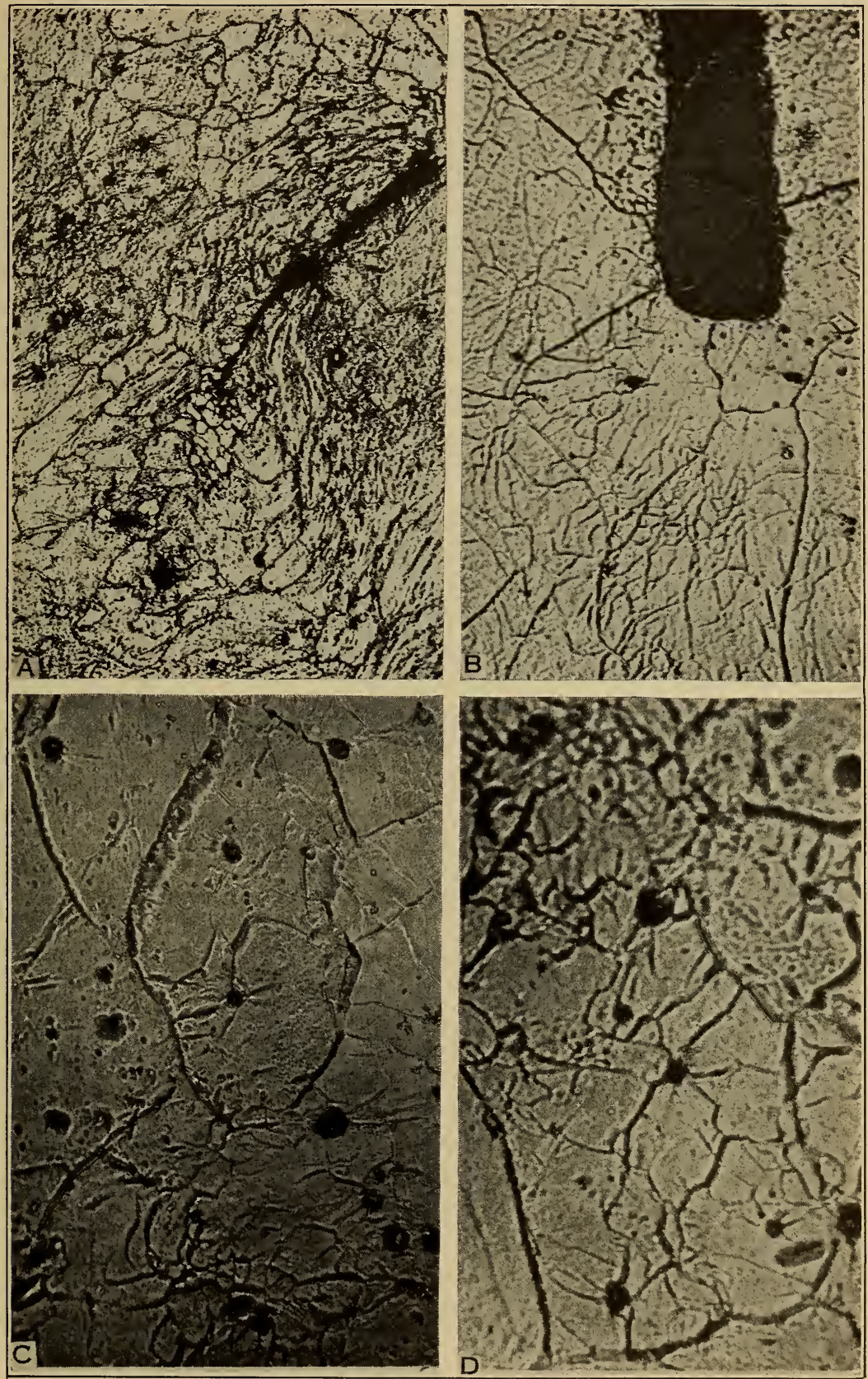

FIG. 43.-Relation of inclusions in ferrite to veining

(a) Electrolytic iron forged at a temperature below the $\alpha-\gamma$ transformation. Note the abundant veining around the oxidized forging crack which formed (compare fig. 34). $\times 100$.

(b) Open-hearth iron (ingot 978 ) forged at $950^{\circ} \mathrm{C}$. (approximately) showing abundant veining in the proximity of inclusions. Elsewhere, very little veining occurred (compare fig. $30(d)$ ). $\times 500$.

(c) Open-hearth iron showing how oxide inclusions may act as centers for veining. $\times 500$.

$(d)$ Same spot at a different focus. $\times 500$.

Compare also Figure 25. 


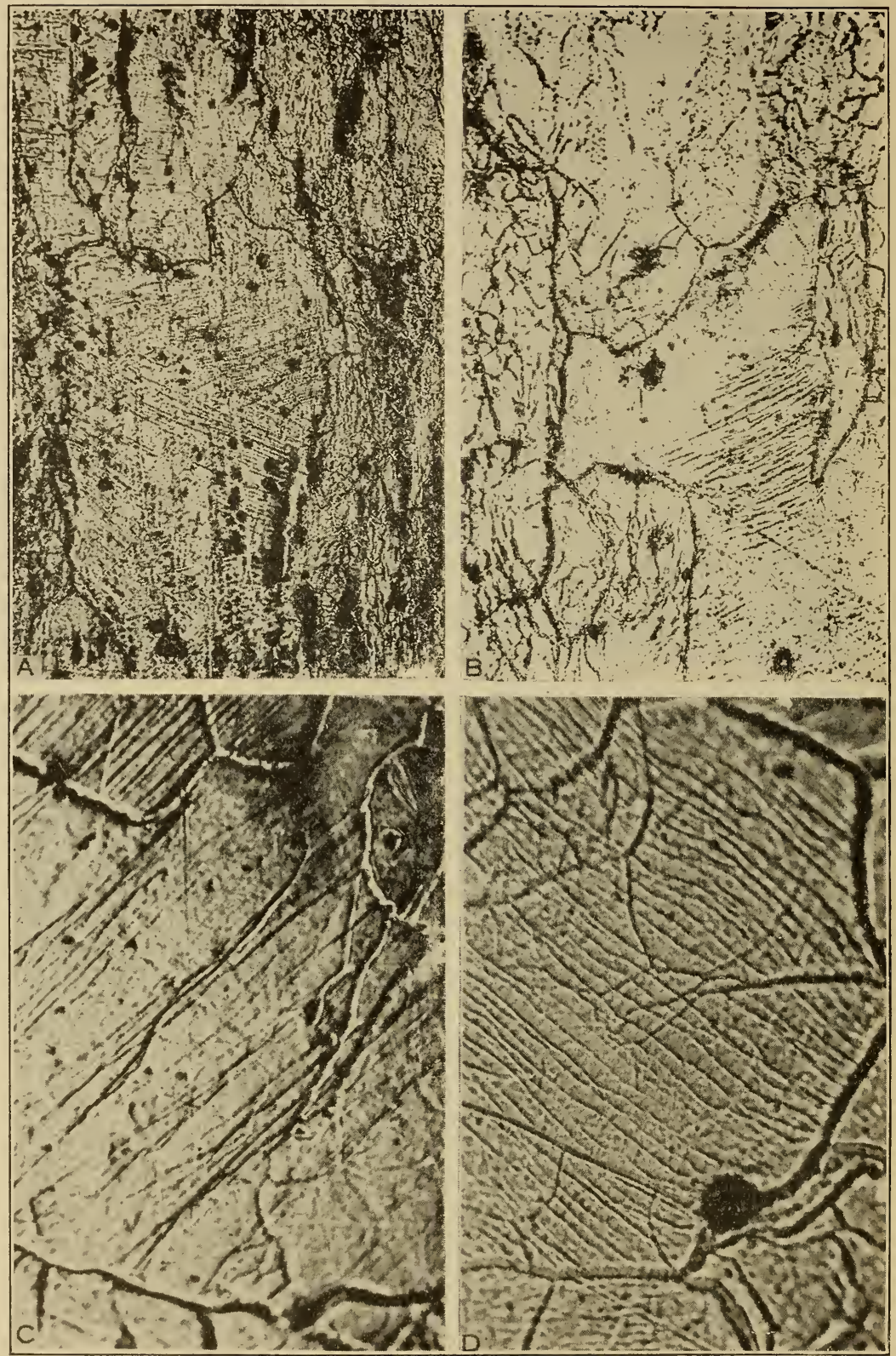

FIG. 44.-Structure of open-hearth iron deformed at room temperature by compression; relation of the slip bands formed to preexisting veining

(a) $\times 100$.

(b) $\times 250$. Note that the grains relatively free from veining show the slip bands best.

(c) $\times 800$. The slip bands here parallel the veining.

(d) $\times 800$. The veining and the slip bands do not show any relationship. 


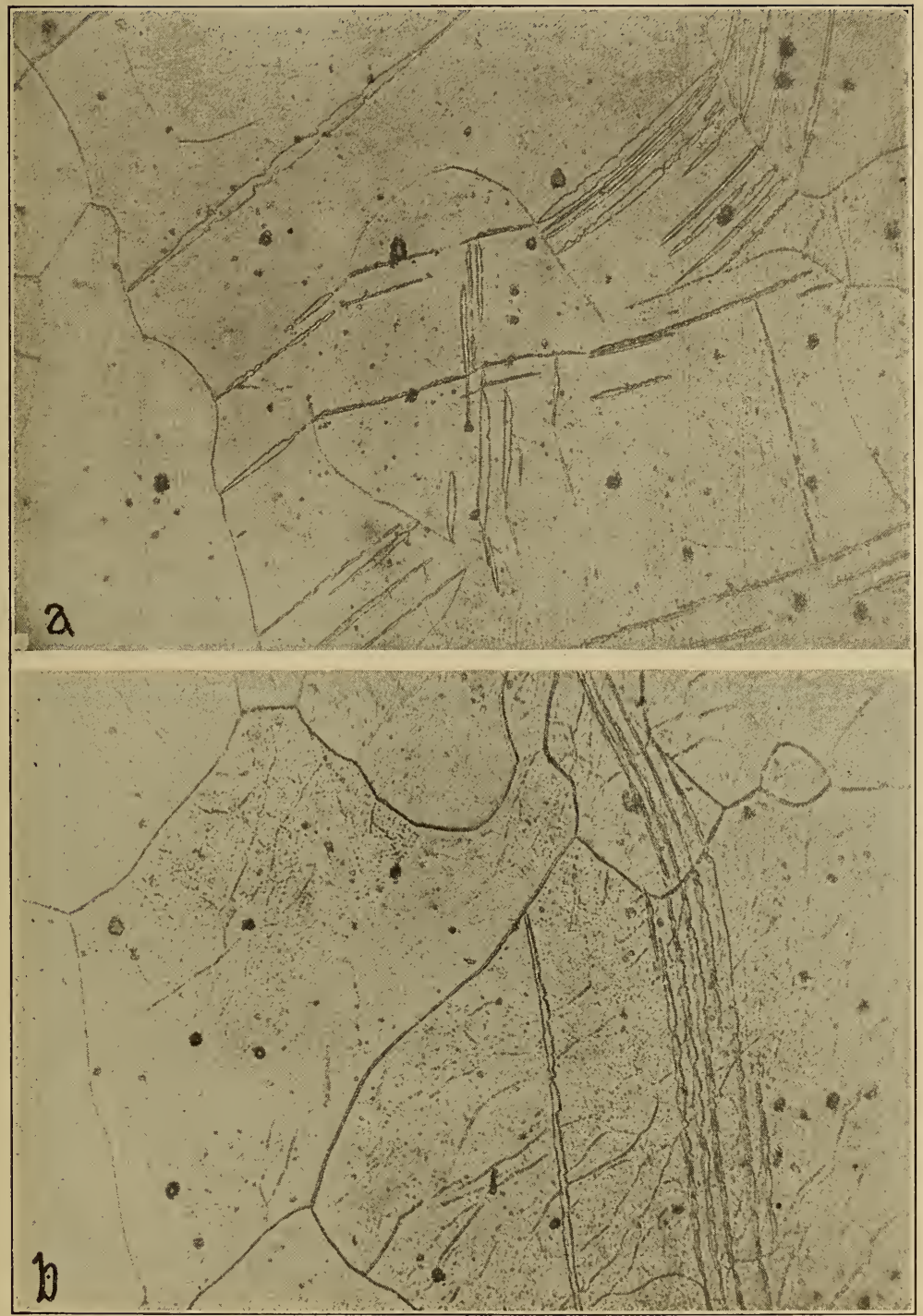

FIG. 45.-Structure of open-hearth iron broken by impact; relation of the shocklines (Neumann bands) to the preexisting veining. $\times 250$

(a) Air-cooled after being heated to $1,100^{\circ} \mathrm{C}$, reheated to $700^{\circ} \mathrm{C}$., and quenched in water.

(b) Treatment similar to (a) except that the specimen was air-cooled instead of being quenched from $700^{\circ} \mathrm{C}$.

There is no obvious relationship between the course of the shock lines and the course of the preexisting veining. 
material in two conditions, after being air cooled from $700^{\circ} \mathrm{C}$. and after being quenched in ice water from this temperature. As has been shown in the early part of this report, veining, if present in the structure of ferrite, will not be eliminated by this heat treatment although such a treatment may necessitate a longer etching period in order to reveal the veining. The mechanical properties determined for open-hearth iron, as affected by heat treatment are summarized in Table 3. Quenching the iron from $700^{\circ} \mathrm{C}$. resulted in a material strengthening of the iron. The somewhat "erratic" results obtained in the impact tests are to be attributed to the high-oxide content of some of the samples. Iron of high oxide content usually shows a lower impact resistance than iron of lower oxide content but of otherwise similar character.

TABLE 3.-Effect of quenching upon the mechanical properties of ferrite (openhearth iron) showing veining in its grain structure

\begin{tabular}{|c|c|c|c|c|c|c|}
\hline \multirow{2}{*}{ Treatment } & \multirow{2}{*}{ Brinell hardness } & \multicolumn{4}{|c|}{ Tensile properties } & \multirow{2}{*}{$\begin{array}{l}\text { Impact resist- } \\
\text { ance, energy } \\
\text { absorbed } \\
\text { (Charpy test) }\end{array}$} \\
\hline & & $\begin{array}{l}\text { Yield } \\
\text { point } 1\end{array}$ & $\begin{array}{l}\text { Ultimate } \\
\text { tensile } \\
\text { strength }\end{array}$ & $\begin{array}{l}\text { Elonga- } \\
\text { tion (2 } \\
\text { inches) }\end{array}$ & $\begin{array}{l}\text { Reduc- } \\
\text { tion of } \\
\text { area }\end{array}$ & \\
\hline $\begin{array}{l}700^{\circ} \text { C., } 1 / 2 \text { hour, air } \\
\text { cooled. } \\
700^{\circ} \text { C., } 1 \text { 1/2 hours, } \\
\text { quenched in ice water. } \\
1,100^{\circ} \text { C., } 1 / 2 \text { hour, air } \\
\text { cooled. } \\
\text { Above treatment }+700^{\circ} \\
\text { C., } 1 \text { hour, air cooled. } \\
\text { As above but quenched } \\
\text { in ice water. }\end{array}$ & $86,87,83$, average & $\left\{\begin{array}{r}\text { Lbs./in. }{ }^{2} \\
20,000 \\
20,000 \\
29,800 \\
29,100\end{array}\right.$ & $\begin{array}{r}\text { Lbs./in. }{ }^{2} \\
46,100 \\
46,100 \\
50,500 \\
49,400 \\
\end{array}$ & $\begin{array}{r}\text { Per cent } \\
40 \\
40 \\
25 \\
38\end{array}$ & $\begin{array}{r}\text { Per cent } \\
61 \\
62 \\
60 \\
65 \\
\end{array}$ & $\begin{array}{c}55,49,19,{ }^{3} 76 . \\
98,{ }^{3} \quad 131,4 \quad 177, \\
130,105,4166 \\
169, \quad 136, \quad 81,3 \\
85,{ }^{3} 159,78 .^{3}\end{array}$ \\
\hline
\end{tabular}

Although the results in Table 3 can not be used as supporting the conclusion that $\alpha$ veining has no effect whatever upon the mechanical properties of ferrite, it would appear that, since the properties of the metal can be materially changed by quenching without producing a correspondingly marked change in the structural aspects of the metal as regards veining, the effect of veining upon the mechanical properties must be of relatively minor importance. It is probably true, however, that the underlying condition, whatever it may be, that is responsible for the strengthening of the material may also result in the longer etching period required for revealing veining in ferrite after it has been quenched. Carbon is soluble to an appreciable extent in $\alpha$ ferrite ${ }^{20}$ and can be retained in solid solution by quenching from above $630^{\circ} \mathrm{C}$. The improvement in properties of ferrite by quenching are undoubtedly related to this, and it is not

${ }^{20} \mathrm{~J} . \mathrm{H}$. Whiteley, The solubility of cementite in $a$ iron and its precipitation, J. Iron and Steel Inst. sdvance copy, September meeting; 1927. 
improbable that veining may be also to some extent. Some of the characteristic features of veining-for example, the change produced by quenching from a temperature somewhat below the A1 pointcan be explained on the basis of a change in the solubility of the small amount of carbon present. All of the features of veining can not be satisfactorily accounted for, however, by such a simple explanation.

In general, the results of the tests serve to illustrate the already established fact that the properties of ferrite can be noticeably improved by a simpie heat treatment. The early work of Arnold ${ }^{21}$ confirmed by that of Brooke and Hunting ${ }^{22}$ on open-hearth iron of essentially the same composition as that used in the tests reported here showed that an appreciable "strengthening" of iron results upon quenching from $500^{\circ} \mathrm{C}$. and above, the degree of "strengthening" produced being approximately proportional to the temperature above the $500^{\circ}$ point. Smith ${ }^{23}$ has recently carried this method of treatment further and made practical application of it. $\mathrm{He}$ has shown that the tensile properties of such materials can be very materially improved if the quenching speed is fast enough. On the other hand, Bauer and Schneider ${ }^{24}$ have reported that electrolytic iron, which undoubtedly was a much purer material than openhearth iron, showed no hardening when quenched from temperatures varying from 650 to $1,260^{\circ} \mathrm{C}$., the average Brinell hardness being 57 . Since veining is often as prominent a feature in the structure of remelted electrolytic iron as in open-hearth iron, this difference, which has been reported in the properties of the two when heat treated, may be considered as another line of evidence that the properties of ferrite are not materially affected by veining in the structure.

\section{DISCUSSION}

It may be repeated here that the various structural features described in the foregoing sections differ from most of the structural effects which may be produced on a polished iron surface by "heat etching" such as by heating it in vacuo. In the latter case the surface only is affected, as a rule, whereas the features discussed here exist throughout the body of the metal specimen and constitute a permanent feature of the structure.

The two features which have been designated as the $\delta$ and $\gamma$ networks appear to be similar in many respects in appearance and mode of formation. Both may be attributed largely to the dissemination

21 J. O. Arnold, The influence of sudden cooling on nearly pure iron, Engineering, 64, p. 48; 1897.

${ }^{22}$ W. J. Brooke and F. F. Hunting, A note on the microstructure of commercially pure iron between Ar3 and Ar2. Iron and Steel Inst., 96, p. 233; 1917.

${ }^{23}$ R. H. Smith, Some physical properties of low-carbon steels, Trans. Am. Soc. Steel Treat., 7, p. 569; 1925.

34. Bauer and W. Schneider, A contribution to the knowledge of electrolytic iron, Stahl und Eisen, 41, p. $647 ; 1921$. 
of inclusions present in the ferrite in such a way as to form a record of the crystalline condition of the metal which obtains at high temperatures. In one case inclusions are distributed so as to record the position of the boundaries of the grains as they were formed from the melt upon cooling. These are the $\delta$ grain boundaries and the $\delta$ network has been observed only in cast ferrite and, in a limited number of cases, in ferrite which after being worked has been heated to an exceedingly high temperature. The $\gamma$ network has been found only in ferrite mechanically worked while the iron was in the $\gamma$ condition or in iron heated for a considerable time at a temperature corresponding to the $\gamma$ state. This explanation of the formation of the $\gamma$ network implies at least some solubility of the inclusions in the ferrite matrix and a decrease in solubility as the iron cools, or to some movement of the inclusions within the structure of the heated iron. It is very probable, therefore, that the inclusions which can contribute to the formation of the $\gamma$ network are more limited in number than those which form the $\delta$ network; the formation of which is assumed to be largely mechanical in origin as the crystals increase in size as they form in the molten metal. This conclusion is in agreement with the observations made on different samples of ferrite in the cast state and the same after various forging treatments. The occurrence of the $\delta$ network in the cast metal was observed much more frequently than was the $\gamma$ network in the same metals after forging.

The results of the investigations have not indicated that occurrence of either the $\gamma$ or the $\delta$ network in ferrite affects the mechanical properties of the material, at least as they are ordinarily determined at room temperature. On the other hand, some of the observations indicate that the properties of iron at elevated temperatures are quite closely related to these features of the structure; particularly is this true of the hot-shortness of iron in certain temperature intervals.

Of the various structural features described, veining of the $\alpha$ ferrite grains is the most obscure as to its real nature and origin. Although this has been designated as an unusual feature in the structure of ferrite, it was of common occurrence in the materials used in this investigation. Prolonged etching is often required in order to reveal veining, and this may account for the fact that this feature has not been more frequently shown in published micrographs in the literature, although it is not to be inferred from this report that open-hearth and electrolytic iron invariably show veining in their structure. The investigation has not furnished answers to all the questions which may be asked concerning veining, but the results have shown definitely some of the principal underlying conditions which favor its formation. 
Although, in this investigation, veining was practically always found in the specimens of iron which had been melted at one stage in their production, melting is not to be considered as absolutely necessary for the formation of veining. This is shown by some results obtained by this bureau several years ago. ${ }^{25}$ Electrolytic iron which had never been melted but which, in the "cathode" form, had been heated several times to a temperature considerably above that of the A3 change, showed marked evidence of veining in the crystals, although this feature was not detected in the structure of the iron as deposited. Veining differs decidedly from recrystallization in that the smaller subdivisions into which a grain appears to be divided by the veining network do not differ from one another in their crystalline orientation. The grain still retains its individuality, as is clearly shown by its response to etching, both by ordinary chemical reagents and by "heat etching," and by the slip bands produced when a grain showing veining is severely deformed. As a consequence, the mechanical properties of iron are not influenced to any appreciable extent by the existence of veining.

The allotropic change in ferrite whereby, upon cooling, the crystal structure or atomic arrangement changes from the face-centered cubic type of packing of the $\gamma$ ferrite to the body-centered type of packing of the $\alpha$ ferrite appears to be closely associated with the formation of veining. A transformationless silicon ferrite showed no veining in its grain structure either in the cast state or after the metal had been treated in a manner identical with that which induced pronounced veining in ordinary ferrite. Forging of electrolytic and of open-hearth iron at a temperature considerably above the transformation temperature did not induce the formation of veining in the grains. The same materials, however, when forged close to and slightly below the temperature of the $\alpha-\gamma$ change showed profuse veining in the $\alpha$ grain structure. Rods broken by stressing them in tension at a temperature only slightly below the transformation temperature showed evidence indicating that veining had been produced, whereas at higher temperatures this evidence was lacking in specimens treated in a similar manner.

Deformation, either by compression or shear, as in forging or by tension, is evidently very favorable to the formation of veining, provided, of course, that the metal is at a suitable temperature when deformed. This suggests that veining as produced in this manner partakes somewhat of the nature of the phenomenon of "slip" although on a much grosser scale than that which results in the familiar slip bands of metal deformed at room temperature. The appearance of the "veins" produced in this manner also helped to confirm this suggestion. 
Changes in composition of ferrite by the addition of materials such as ordinarily employed in iron and steel manufacture do not have any very pronounced result upon the tendency toward veining unless, as in the case of silicon, a transformationless ferrite is produced. Other additions, such as manganese, may improve the forging properties so that veining may be much reduced in amount but is not entirely eliminated.

Any attempt to explain the formation of veining in ferrite which has been allowed to cool from the melt without any mechanical deformation or other disturbance involves considerable assumption. Without doubt veining forms in such cast metal as it is passing through the temperature interval close to the allotropic change. Story's suggestion, ${ }^{26}$ that as the metal slowly cools the $\alpha-\gamma$ transformation may begin at several different nuclei within the same grain and progress outwardly, although without any change of crystalline orientation, until the different transformed portions meet and form the veining network at their junctions is only partially satisfactory. The character of the slip bands within a grain showing veining shows that the subdivisions of the grain are of the same crystalline orientation, and hence the veins are not the same as grain boundaries although they resemble them in many respects. The slip bands show no deviation in their course as they cross the veins, whereas they do upon approaching a grain boundary.

The fact that veining is revealed only by etching suggests that it is dependent in some measure, at least, upon the composition of the ferrite. Some of the characteristic features of veining may be satisfactorily correlated with the presence of a small amount of carbon in solid solution in the ferrite. The quenching of ferrite from a temperature of approximately $700^{\circ} \mathrm{C}$. renders it necessary to etch the material much longer in order to reveal the veining-a result which would be predicted if veining were directly related to the existence of cementite in submicroscopic particles along the course of the "veins." The stressing of ferrite, either in tension or in compression and shear as forging, when at a temperature near the $\alpha-\gamma$ transformation results in a pronounced development of veining. It is not inconceivable that this effect may be the result of the influence of the stress upon the distribution of the carbon in solid solution throughout the ferrite. Some slight evidence suggesting this hypothesis was noted in the high-temperature tension tests which were made. On the other hand, it would be expected that if veining were caused by carbon in solid solution it should be possible to demonstrate this by prolonged annealing of the material at a temperature of $700^{\circ} \mathrm{C}$. The results of such tests have not definitely confirmed the presence of cementite along the veining network in 
particles of sufficient size as to render them visible under the microscope, although such an annealing treatment does render the veining much more conspicuous as a general rule. A full and satisfactory explanation of all aspects of veining, however, on the evidence available is not yet forthcoming.

\section{SUMMARY}

1. Ferrite, in the form of electrolytic iron, open-hearth iron, and wrought iron, which is usually considered to have a very simple microstructure, sometimes shows rather unusual structural features. These are of three general types which, in this report, have been referred to as $\alpha$ veining, $\gamma$ network, and $\delta$ network, since they appear to be associated in their origin with the three allotropic forms of iron. The $\gamma$ and $\delta$ networks do not occur simultaneously in the same specimen although the $\alpha$ veining often accompanies either one of the other two features. Although all of these features are revealed only by etching, they exist throughout the body of the metal and are not merely surface appearances.

2. The $\delta$ network, which is found only in ferrite in the cast or slightly worked condition, appears as a relatively coarse network superimposed upon, and apparently unrelated to, the familiar $\alpha$ grain boundary pattern. It can usually be shown that this network consists of minute inclusions in the ferrite and apparently it records the grain structure of the iron when in the $\delta$ state-that is, immediately following solidification-and is often very well developed in ferrite to which aluminum has been added. Apparently it has practically no effect upon the mechanical properties of the iron as ordinarily determined but is related to the "hot-shortness" often shown by ferrite in a certain temperature range.

3 . The $\gamma$ network, like the $\delta$ network, appears as a network superimposed upon the $\alpha$ grain boundary pattern and usually occurs in iron which either has been mechanically worked while the metal was in $\gamma$ condition or has been heated for a considerable length of time above the $\alpha-\gamma$ transformation temperature. The $\gamma$ network, like the $\delta$ network, seems to depend upon the presence of minute inclusions in the metal, and perhaps upon a slight solid solubility of certain substances. The ordinary mechanical properties of ferrite seem to be affected little, if any, by the presence of the $\gamma$ network.

4. $\alpha$ veining, which is the most common of the "unusual" features, is definitely associated with the $\alpha$ grain structure of ferrite. It appears as a branching network within the individual $\alpha$ grains and often gives to the metal the appearance of having a very fine grain size. The grain size is not changed, however, by the formation of veining; each grain, though it may have the appearance of having 
been broken up into smaller ones, in reality retains its initial size. Ferrite, in which $\alpha$ veining occurs, when quenched from a temperature of 700 to $750^{\circ} \mathrm{C}$. and then etched according to the usual metallographic procedure, has the appearance of being free from veining. By prolonging the etching period, however, the $\alpha$ veining can be revealed. No direct relationship between $\alpha$ veining and the mechanical properties of ferrite in which it occurs has been established. The slip bands in ferrite which has been deformed by compression are apparently not influenced to any extent by the presence of veining within the grains.

5. The form of the ingot has no appreciable effect upon the prevalence of $\alpha$ veining in cast ferrite. Iron heated close to the melting point may show more pronounced veining than similar material after being melted and allowed to cool. Electrolytic iron, which shows no veining as deposited, may show it to a rather pronounced exten $t$ after being heated above the $\alpha-\gamma$ transformation temperature but still very far below the melting point.

6. Ferrite mechanically worked by forging at or somewhat below the temperature of the $\alpha-\gamma$ transformation shows $\alpha$ veining in abundance. The same material forged at a very high temperature usually shows very little veining.

7. Ferrite, which has been alloyed with sufficient silicon, approximately 5 per cent, so that a "transformationless" ferrite was produced, shows almost complete freedom from veining both in the cast and forged condition. The addition of aluminum, approximately 0.9 per cent, to electrolytic iron accentuated the $\delta$ network of the cast metal but had little influence on the $\alpha$ veining either in the cast metal or after forging. Likewise, the addition of manganese to openhearth and to electrolytic iron did not render the metal free from veining, although after forging the ferrite alloyed with manganese did not show veining to such an extent as did the ferrite treated with aluminum.

8. The annealing of ferrite, even for prolonged periods and at high temperatures, does not result in the removal of the $\alpha$ veining from the structure although it was shown, by successive observations on the same spot on polished material annealed in hydrogen, that in some grains the veining may become somewhat less prominent whereas in neighboring grains it may become more prominent than it was before annealing.

9. Ferrite stressed in tension to the breaking point at various elevated temperatures showed evidence in the microstructure that $\alpha$ veining became prominent in the material broken at a temperature slightly below that of the $\alpha-\gamma$ transformation.

10. Inclusions in ferrite often serve as "centers" at which $\alpha$ veining: starts, but the presence of visible inclusions in the microstructure 
does not appear to be a necessary condition for the formation of veining.

11. Some very interesting observations on the surface changes which occur upon the prolonged heating of ferrite in hydrogen at a temperature considerably below that of the $\alpha-\gamma$ transformation have been made. These do not appear, however, to have any very direct bearing on the subject of $\alpha$ veining in ferrite.

12. A full explanation of the nature of $\alpha$ veining in ferrite can not be given on the basis of the evidence from this investigation. The formation of veining is definitely to be associated with the allotropic, or $\alpha-\gamma$, change in ferrite, and this structural feature may perhaps also bear some relationship to the presence of a small amount of carbon in solid solution in the metal.

Washington, October 26, 1927. 